Erster Beratungsgegenstand:

\title{
Der Bildungsföderalismus auf dem Prüfstand
}

1. Referat von Professor Dr. Bernhard Ehrenzeller, St. Gallen*

Inhalt

Seite

I. (In-)Fragestellung . . . . . . . . . . . . . . 7

II. Veränderungsprozesse im Bereich von Bildung und

Föderalismus. . . . . . . . . . . . . . . . 9

1. Veränderungsdynamik im Bildungsraum . . . . . . . . . 9

2. Gewandelter Föderalismus . . . . . . . . . . . . . . . . 12

III. Der Bildungsföderalismus in Deutschland und in der Schweiz 15

1. Allgemeine Entwicklung . . . . . . . . . . . . . 15

2. Der deutsche Bildungsföderalismus . . . . . . . . . . . . 19

3. Der schweizerische Bildungsföderalismus . . . . . . . . 21

4. Zusammenfassender Vergleich . . . . . . . . . . . . . 28

IV. Gesamtwürdigung: Die Zukunftsfähigkeit des Bildungs-

föderalismus . . . . . . . . . . . . . 30

\section{I. (In-)Fragestellung}

Der „Bildungsföderalismus“ hat für manche Zeitgenossen einen negativen Beigeschmack. Sie betrachten ihn als föderalistischen Holzweg oder gar als „staatsrechtliche Form des Sadismus“" Mildere Kritiker sehen im „Bildungsföderalismus“ das Paradebeispiel für Verwicklung in „Kleinstaaterei“, „Kantönligeist“ und provinzielles Denken. ${ }^{2}$

* Meinem Assistenten, Kaspar Ehrenzeller, BLaw \& Economics HSG, danke ich bestens für die wertvolle Unterstützung bei der Vorbereitung und Ausfertigung dieses Beitrages. Ein herzlicher Dank gilt auch meiner Frau, PD Dr. iur. Sabine Kofmel Ehrenzeller, für die kritische Durchsicht und Beurteilung des Vortrages.

1 H. Prantl Ein deutscher Sadismus, in: Süddeutsche Zeitung vom 18. Mai 2013.

2 Siehe beispielweise die Streitschrift: T. Schultz/K. Hurrelmann (Hrsg.) Bildung und Kleinstaaterei: Brauchen wir mehr Zentralismus?, 2012; oder bei H. Lübbe Raumordnung in der zivilisatorischen Evolution. Über die Reichweite des Föderalismusbegriffs, 
In der Tat ist der Begriff des „Bildungsföderalismus“ verfassungsrechtlich schwer fassbar und zwar als Ganzes wie in seinen beiden Komponenten: Bildung entzieht sich rechtlicher Determination. Auch den Ausdruck „Föderalismus" finden wir eher in der Staatslehre oder in den Politikwissenschaften als im verfassungsrechtlichen Vokabular. ${ }^{3}$ „Bildungsföderalismus" ist somit kein Rechtsbegriff. ${ }^{4}$ Verfassungsrechtlich fassbarer ist dagegen die Zuständigkeit der bundesstaatlichen Organe zur Gestaltung der Bildungspolitik. In diesem engeren, bundesstaatsrechtlichen Sinne soll der Begriff nachfolgend verstanden werden. Dennoch verbleibt der Themenstellung eine erhebliche staats- und verfassungspolitische Dimension.

Ziel und Aufgabe meines Vortrages ist es, den so verstandenen Bildungsföderalismus Deutschlands und der Schweiz auf den Prüfstand zu stellen. Die (In-)Fragestellung kann in zwei Richtungen gehen:

Entweder man fragt: Ist die Bildungshoheit noch eine Kernkompetenz, ein „,Hausgut' eigener Aufgaben“ der Länder ${ }^{5}$ und der Kantone? Und falls dies nicht mehr der Fall ist: wie könnten diese gliedstaatlichen Kompetenzen im Bildungsbereich revitalisiert werden?

Oder es wird gerade umgekehrt gefragt: Ist die föderalistische Aufgabenerfüllung noch eine adäquate Antwort auf die grossen Herausforderungen in der Bildungspolitik, sind die bestehenden bundesstaatlichen Strukturen $\mathrm{zu}$ deren Bewältigung überhaupt noch geeignet? Und falls nicht: in welche neue Richtung müsste die Reform gehen?

Ausgehen möchte ich nachfolgend von der Feststellung, dass sich im Bereich der Bildung wie auch im Bereich des Föderalismus grundlegende Veränderungsprozesse abgespielt haben und weiter abspielen. Erst das Bewusstsein für diesen tiefgreifenden Wandel ermöglicht eine staatsrecht-

in: I. Härtel (Hrsg.) Handbuch Föderalismus: Föderalismus als demokratische Rechtsordnung und Rechtskultur in Deutschland, Europa und der Welt, Bd. 1, 2012, $23 \mathrm{ff}$. Dazu auch U. Volkmann in: v. Mangoldt/Klein/Starck (Hrsg.) GG Bonner Grundgesetz: Kommentar, 6. Aufl., 2010, Bd. 3, Art. 91a Rn. 4, wonach der kooperative Föderalismus eher als „Auslauf- denn als Zukunftsmodell“ erscheine. Dieser befinde sich in einer ,umfassenden Sinn- und Legitimationskrise“.

3 I. Härtel Alte und neue Föderalismuswelten, in: Härtel (Fn. 2), Bd. 1, Rn. 32 ff. Kommt dazu, dass in den verschiedenen Fachdisziplinen ganz unterschiedliche Föderalismusverständnisse existieren. Ein idealtypisches Leitbild des Föderalismus gibt es nicht. Vgl. A. Koller Der schweizerische Föderalismus aus internationaler Sicht, Festgabe Walter Straumann, 2013, 25 und G. Anderson Föderalismus, 2008.

${ }^{4}$ So auch M. Winkler Der Bildungsföderalismus auf dem Prüfstand, DVBl. 2013, $1069 \mathrm{ff}$.

${ }^{5}$ So in BVerfGE 6, 309 (310, 312, 315, 346 f.), 34, 169 f. Nach BVerfGE 123, 267 (363) bilden die Länder einen „eigenen Kulturraum“, der das Schul- und Bildungswesen erfasst und von Verfassungswegen als besonders sensibel für die demokratische Selbstgestaltungsfähigkeit eines Verfassungsstaates betrachtet wird. 
liche Lagebeurteilung des Bildungsföderalismus. Ich gehe deshalb in einem ersten Schritt (II.) auf den Veränderungsprozess im Bereich der Bildung sowie auf den Wandel im Föderalismus ein. Anschliessend (III.) vergleiche ich die unterschiedlichen Wege, die der schweizerische und der deutsche Bundesstaat im Bildungsbereich gegangen sind. Und schliesslich soll in einem letzten Teil (IV.) im Sinne einer Gesamtwürdigung geprüft werden, wie zukunftstauglich der Bildungsföderalismus aus der Sicht des öffentlichen Rechts ist.

\section{Veränderungsprozesse im Bereich von Bildung und Föderalismus}

\section{Veränderungsdynamik im Bildungsraum}

Im Mittelpunkt des Bildungsföderalismus steht die Bildungshoheit. Herkömmlicherweise verbinden wir damit das Recht staatlicher Organe von Bund und Kantonen oder Ländern, im Rahmen ihrer Zuständigkeit die wesentlichen bildungspolitischen Entscheidungen zu treffen. Angesichts der enorm gestiegenen Bedeutung der Bildung für das Wohl und das Fortkommen des Einzelnen wie der Gesellschaft als Ganzes müsste man eigentlich annehmen, dass es zu einer Verstärkung der Rolle des Staates im öffentlichen Bildungswesen gekommen ist. Doch diese Annahme entspricht nicht der Wirklichkeit. Die Sozial- und vor allem die Bildungswissenschaften weisen uns darauf hin, dass - bei formal fortbestehender nationaler Bildungssouveränität - eine Entgrenzung der Bildungspolitik $^{6}$ stattgefunden hat und dies sowohl in vertikaler wie in horizontaler Richtung: vertikal im Sinne der Europäisierung und Globalisierung ${ }^{7}$ bei gleichzeitiger Verstärkung der Autonomie der Schulen, von der Volksschule bis zur Hochschule, ${ }^{8}$ horizontal im Sinne der Verschmelzung der Bildungspolitik mit andern Gesellschaftspolitiken, insbesondere

${ }^{6}$ Dazu: K. Amos Herausforderungen der Bildungspolitik im 21. Jahrhundert, in: R. Hrbek/M. Hüttman/J. Schmid (Hrsg.) Bildungspolitik in Föderalstaaten und der Europäischen Union: Does Federalism Matter?, Bd. 38, 2012, 22 ff.

${ }^{7} \mathrm{Zu}$ den Begriffen: Globalisierung, Internationalisierung und Europäisierung im Bildungskontext siehe: B. Müller Die Anfänge der Bologna-Reform in der Schweiz: Rekonstruktion, Kontextualisierung und Rezeption des hochschulpolitischen Prozesses aus akteurtheoretischer Perspektive, 2012.

${ }^{8}$ L. Criblez Die neue Bildungsverfassung und die Harmonisierung des Bildungswesens, in: L. Criblez (Hrsg.) Bildungsraum Schweiz: Historische Entwicklungen und aktuelle Herausforderungen, 2008, 278 (296); R. Dubs Die Führung der Schule, 2. Aufl., 2005. Zur Hochschulautonomie siehe B. Ehrenzeller Hochschulautonomie, Steuerungsbedarf im Autonomiebereich, Schweizer Hochschulverfassung, in: S. Breitenmoser/ B. Ehrenzeller et al. (Hrsg.) librum amoricum für Luzius Wildhaber, 2007, 203 ff. 
der Sozialpolitik: das Ganze eingebettet in einen Prozess der Expertisierung und Ökonomisierung des ganzen Bildungsbereichs. Dadurch ist ein neues Verhältnis von Staat, Schule und Lebenswelt entstanden. ${ }^{9}$ Im Ergebnis hat dies zu neuen bildungspolitischen Strukturbildungen geführt, die in Begriffen wie „Educational Governance“ und gar „Edukativen“ zusammengefasst werden. Eine entscheidende Rolle spielen dabei die Internationalen Organisationen wie die OECD, die WTO und die UNESCO wie auch die EU, aber auch NGOs und verschiedenste internationale Fachexpertengruppen. Ohne ausdrückliche Zuständigkeit und auch ohne klares bildungspolitisches Mandat dienen sie als wichtige „Transmissionsriemen" bei der Verbreitung kognitiver Orientierungsmuster und dem Agendasetting. ${ }^{10}$ Unabhängig von und neben den verfassungsrechtlichen Zuständigkeitsordnungen sind lokale, regionale, nationale und internationale Bildungsräume entstanden, die - als Metapher - zu verstehen sind als ,politische Räume, in denen verschiedene Akteure, institutionelle Strukturen, normative Vorgaben und Funktionen in ihren jeweiligen Eigenlogiken aufeinandertreffen". ${ }^{11}$ Vorab im europäischen Bildungsraum wird durch Kooperation und Vernetzung, wie es Fritz Scharpf ausgedrückt hat, „das Feld aufbereitet, kognitiv verändert und der Diskurs bestimmt, was faktisch einer Kompetenzerweiterung gleichkommt". ${ }^{12}$ Es ist die Rede von der sogenannten ,empirischen Wende“: 13 durch bekannte large scale assessments wie die TIMS oder PISA-Studien sind enorme Datenvergleichsmengen entstanden, die nicht nur Transparenz erzeugen, sondern anhand von Indikatoren-, Bildungsstandards und Benchmark-

\footnotetext{
${ }^{9}$ Diese Entwicklung gut nachzeichnend: P. Becker Die Europäische Bildungspolitik - Europäisierung und Ökonomisierung eines jungen Politikbereichs, in: Hrbek/Hüttman/Schmid (Fn. 6), 183 ff. und ebenfalls R. Hrbeck Die Rolle Europäischer Agenturen in der EU-Bildungspolitik, in: Hrbek/Hüttman/Schmid (Fn. 6), 212 ff.

${ }_{10}$ M. Große Hüttmann Bildungspolitik in Föderal- und Mehrebenensystemen - die Beiträge des Bandes im Überblick, in: Hrbek/Hüttman/Schmid (Fn. 6), 9 ff., wie auch: Derselbe Das Thema Bildungspolitik und die Perspektiven der Föderalismusforschung, in: Hrbek/Hüttman/Schmid (Fn. 6), 229 ff., wo der Autor darauf hinweist, dass die Internationalisierung nicht allein zu Veränderungen führt, sondern oft auf subtile, indirekte Weise wirkt. Siehe auch: Müller (Fn. 7), Abschnitt 4.1.

${ }^{11}$ So H. Tenorth Perspektiven einer Steuerung von Bildungssystemen im föderalen Staat - verfassungsrechtliche Tagungsprotokolle und bildungswissenschaftliche Würdigung der unterschiedlichen Konzepte, in: Deutsch-schweizerischer Expertenworkshop am 2./3. März 2010, Max-Planck-Institut für Bildungsforschung zum Thema: Ein nationaler Bildungsraum: ein tragfähiges Verfassungsmodell und zugleich ein angemessenes Steuerungskonzept?, 47.

12 So F. Scharpf Tagungsprotokolle (Fn. 11), 25.

13 W. Meyer-Hesemann in: Friedrich-Ebert-Stiftung (Hrsg.) Stabsabteilung Bildungsföderalismus auf dem Prüfstand: Status quo und Perspektiven, 2009, 12.
} 
modellen zu einer höheren Rationalität des Bildungssystems führen. Diese Leistungsvergleiche bewirken zwischen und in den Staaten eine eigene Dynamik und Handlungszwänge. ${ }^{14}$ Die durch diese Vergleiche sichtbar gewordenen Leistungsunterschiede in den öffentlichen Schulen erzeugen bei den Schul- und politischen Behörden aller Stufen einen Rechtfertigungsdruck und einen faktischen Zwang, sich an demokratisch teilweise schwach legitimierte und rechtlich wenig verbindliche internationale Orientierungsvorgaben anzupassen. Die Rolle staatlicher Organe bei der Bestimmung der Bildungspolitik - die Bildungshoheit - unterscheidet sich damit stark von der Bestimmung anderer Politikbereiche wie etwa der öffentlichen Sicherheit oder der Raumplanung. Beschlussfassung, Umsetzung und Weiterentwicklung der Bolognareform ist das wohl sprechendste Beispiel für die durch diese Dynamik bewirkte grundlegende Umgestaltung des nationalen Entscheidungsprozesses in der Bildungspolitik. ${ }^{15}$

${ }^{14}$ Zur Wirkungskette: Leistungsmessung und -vergleich, Standards, Bildungsberichte und Kompetenzorientierung: $U$. Münch Variantenreiche Bildungspolitik in der Bundesrepublik Deutschland, in: Hrbek/Hüttman/Schmid (Fn. 6), 59 ff.; Den „Niedergang der traditionellen staatsrechtlichen Regelungsmodi in der Bildungspolitik" beschreibt eindrücklich G. Folke Schuppert Föderalismus und Governance, in: Härtel (Fn. 2), Bd. 1, 223 ff., v.a. Rn. 39. Bereits an der Staatsrechtslehrertagung von 1972 hat I. von Münch Gemeinschaftsaufgaben im Bundesstaat, VVDStRL 31 (1972), 51 (60 f.) als 2. Berichterstatter darauf hingewiesen, dass der Verfassungsgeber mit dem rasanten Tempo der Bildungswissenschaften und der Bildungspolitik nicht mehr Schritt halten könne.

15 Beschlossen und unterzeichnet worden ist die Bologna-Deklaration am 19. Juni 1999 in einem informellen Kreis von 29 europäischen Bildungsministern - wobei seitens der Schweiz und Deutschlands nicht einmal das zuständige Regierungsmitglied, sondern die jeweiligen Staatssekretäre vertreten waren. Bei dieser Erklärung handelt es sich um eine reine Absichtserklärung ohne völkervertragsrechtlichen Charakter, also um soft law, siehe B. Ehrenzeller/A. Reisner Die Konstitutionalisierung von „Bologna“: Sonderfall oder Modell der Weiterentwicklung des kooperativen Föderalismus?, ZSR 2008 (I Heft 2), 229 ff. Die - trotz teilweise heftiger Kritik - eingeführte Bologna-Reform und deren Weiterentwicklung im Prozess der „open method of coordination“ hat offensichtlich eine tiefgreifende Neugestaltung des Hochschulwesens ausgelöst. Blickt man auf die vergangenen vierzehn Jahre seit der Ingangsetzung des Bolognaprozesses zurück, so ist die beschriebene Entgrenzung der nationalen Bildungspolitik überdeutlich erkennbar. Die demokratisch legitimierten Organe in den Staaten bestimmten diesen dynamischen Prozess nur sehr beschränkt mit. Dennoch haben sich Bund und Gliedstaaten in der Schweiz und in Deutschland nicht nur auf das Ziel und den Prozess der Schaffung eines wettbewerbsfähigen europäischen Hochschul- und Forschungsraumes eingelassen, sondern haben auch die notwendigen gesetzgeberischen und vollziehenden Umsetzungsbeschlüsse gefasst (Schweizerische Universitätskonferenz (SUK), Richtlinie und Kommentar zu den Bologna-Richtlinien zuhanden der Universitätskantone von der Schweizerischen Universitätskonferenz am 4. Dezember 2003 verabschiedet, online: <http:// www.crus.ch/wDeutsch/publikationen/richtlinien/Kommentar_deutsch.pdf $>$ abgerufen 


\section{Gewandelter Föderalismus}

Grundlegende Veränderungen fanden allerdings auch im föderalistischen Gefüge der beiden Bundesstaaten statt. ${ }^{16}$ Allen Verfassungsbarrieren zum Trotz ist es in praktisch allen gesellschaftlich und politisch relevanten Fragen $\mathrm{zu}$ einer weitgehenden Kompetenzverlagerung auf die Bundesebene resp. auf die europäische Ebene gekommen. Der offenbar unaufhaltsame Substanzverlust der Gliedstaaten an politischer Gestaltungskraft und die damit verbundene Entwicklung zum gubernativen Mitwirkungsföderalismus ${ }^{17}$ haben zu einer diffusen Verantwortungsverteilung zwischen Bund, Ländern und Kantonen geführt. ${ }^{18}$ Diesem sogenannten kooperativen Föderalismus inhärent ist eine starke Politikverflechtung. ${ }^{19}$ Das seit längerem bestehende Unbehagen im föderalistischen

am 20. September 2013). Zur Ingangsetzung und Umsetzung des Bolognaprozesses im Einzelnen siehe: Müller (Fn. 7), mit den einschlägigen Dokumenten und wertvollen Zusatzinformationen im Anhang (267-277).

16 Zum Grundverständnis des Föderalismus: Koller/Thürer et al. (Hrsg.) Principles of Federalism: Guidelines for Good Federal Practices - a Swiss contribution, 2012, 25 ff. Vgl. auch: B. Waldmann Föderalismus unter Druck - Eine Skizze von Problemfeldern und Herausforderungen für den Föderalismus in der Schweiz, in: M. Gredig/R. Mahaim et al. (Hrsg.) Peters Dreiblatt: Föderalismus, Grundrechte, Verwaltung: Festschrift für Peter Hänni, 2010, 1 ff. Aus rechtsvergleichender Sicht siehe: R. L. Watts Comparing Federal Systems, 2. Aufl., 1999 und: J. Kingaid/G. A. Tarr A Global Dialogue on Federalism: Constitutional Origins, Structure, and Change in Federal Countries, Bd. 1, 2005.

17 Dazu: K. Stern Die bundesstaatliche Ordnung auf dem Prüfstand, in: D. Merten (Hrsg.) Die Zukunft des Föderalismus in Deutschland und Europa, 2007, 13 (17 ff.); J. A. Frowein Gemeinschaftsaufgaben im Bundesstaat, VVDStRL 31 (1972), 13 (25 f.).

18 Gestärkt worden durch diese Entwicklung sind die Bundesregierung, der Bundesgesetzgeber und die Landes- und Kantonsregierungen mit ihren Verwaltungen wie auch die Regierungskonferenzen von Kantonen und Ländern. Siehe dazu S. Oeter Gesetzgebung und Exekutive im föderalen Staat, in: R. T. Baus/R. Blindenbacher/U. Karpen (Hrsg.) Competition versus cooperation: german Federalism in need of reform - a comparative perspective $=$ Wettbewerb versus Kooperation: der Reformbedarf des deutschen Föderalismus - eine vergleichende Perspektive, 2007, 104 ff. Der Autor sieht in der „diffusen Verantwortungsverteilung" das zentrale Föderalismusproblem (122). Siehe auch A. Kaiser Politiktheoretische Zugänge zum Föderalismus, in: Härtel (Fn. 2), Bd. 1, 165 ff. In der Schweiz ist, neben den Fachdirektorenkonferenzen, ein neues Organ, die Konferenz der Kantonsregierungen (KdK) entstanden. Siehe Vereinbarung über die Konferenz der Kantonsregierungen vom 8. Oktober 1993. R. Rhinow/M. Schefer Schweizerisches Verfassungsrecht, 2009, 171 ff., insb. Rn. 887; B. Waldmann Die Rechtsform der Konferenz der Kantonsregierungen $(\mathrm{KdK})$ de lege lata und de lege ferenda. Rechtsabklärung, 2005, online: <http://www.zrk.ch/dms/gutachten/liste_id_ 451_filename1_rnd5822.pdf $>$ abgerufen am 20. September 2013.

19 Der Politikverflechtung inhärent ist - jedenfalls in einem gewissen Ausmass die berühmte, schon fast zum Allgemeingut gewordene „Politikverflechtungsfalle“ 
Gefüge hat gerade in jüngerer Zeit die Föderalismusreformdebatte in Wissenschaft und Politik wieder aufleben lassen mit dem Ziel einer Stärkung der Eigenverantwortung der Gliedstaaten. ${ }^{20}$ Stärker gewachsen ist aber auch das Bewusstsein, dass der Föderalismus nicht einfach mit einer $\mathrm{Zu}$ ständigkeitsordnung gleichgesetzt werden kann, sondern in hohem Masse politischen Prozesscharakter hat. ${ }^{21}$ Darauf hat interessanterweise der damalige Privatdozent Herrfahrdt aus Greifswald an der Staatsrechtslehrertagung 1929 bereits hingewiesen. ${ }^{22}$

Allerdings: jeder Bundesstaat ist ein Unikat. Trotz hoher Vergleichbarkeit dieser generellen Entwicklung in Deutschland und der Schweiz dürfen grundlegende Unterschiede, nicht nur in Bezug auf die Grösse der Gliedstaaten, sondern auch in Bezug auf die konzeptionelle und institu-

(Fritz Scharpf), die zu einem Zwangsverhandlungssystem geführt habe, bei dem der kleinstmögliche Kompromiss erreicht, das Ausweichen von Konflikten und der status quo begünstigt und somit der politische Erneuerungsprozess blockiert werde. Dazu, anstelle vieler und mit Hinweis auf den Schöpfer der Theorie: Schuppert (Fn. 14), Rn. 16 ff. Vgl. auch D. Braun Reform- und Entscheidungsblockaden des Schweizer Föderalismus im Vergleich zu Deutschland, in: U. Wagschal/H. Rentsch (Hrsg.) Der Preis des Föderalismus: Avenir Suisse, 2006, 327 f. Der kooperative Föderalismus bezieht sich allerdings in Deutschland primär auf die Mitwirkung der Länder beim bundespolitischen Entscheidungsprozess, wogegen in der Schweiz darunter zumindest ebenbürtig die institutionelle Zusammenarbeit zwischen den Kantonen verstanden wird. Zum „Leitbild des ,kooperativen Föderalismus“" siehe: S. Oeter Integration und Subsidiarität im deutschen Bundesstaatsrecht, 1998, 266.

${ }^{20} \mathrm{Im}$ Ergebnis sollte, bei gelingender Föderalismusreform, den Gliedstaaten substanzielle Eigenstaatlichkeit und Eigenverantwortung zurückgegeben und so der föderalistische Wettbewerb gefördert werden. Die „Föderalismusreformen“ in Deutschland und der Schweiz dienen dementsprechend dem Ziel, die Handlungs- und Entscheidungsfähigkeit von Bund, Länder und Kantone zu stärken, die Zuständigkeiten und damit auch die Verantwortlichkeiten klarer zuzuweisen, Sachzuständigkeit und Finanzierungsverantwortung näher aufeinander abzustimmen sowie die Zweckmässigkeit und Effizienz der Aufgabenerfüllung zu erhöhen. Dazu: Rhinow/Schefer (Fn. 18), 171 ff. sowie H. Risse Föderalismusreform in der Sackgasse? Bericht über die Kommission von Bundestag und Bundesrat zur Modernisierung der bundesstaatlichen Ordnung, in: Merten (Fn. 17), 43 ff. und Stern (Fn. 17), 13 ff. und die Beiträge von W. Schäuble Der deutsche Föderalismus im Reformprozess, in: Baus/Blindenbacher/Karpen (Fn. 18), 29 ff.; R. Scholz Wettbewerbsföderalismus versus unitarischer oder kooperativer Föderalismus, in: Baus/Blindenbacher/Karpen (Fn. 18), 92 ff.; A. Koller Renaissance des Föderalismus?, in: Baus/Blindenbacher/Karpen (Fn. 18), 37 ff.; U. Karpen Der deutsche Föderalismus bedarf der Reform!, in: Baus/Blindenbacher/Karpen (Fn. 18), 47 ff.; H. J. Boehl Die deutsche Föderalismusreform von 2006, in: Baus/Blindenbacher/Karpen (Fn. 18), $29 \mathrm{ff}$.

${ }^{21}$ Vgl. Härtel in: Härtel (Fn. 2), Rn. 4.

${ }^{22}$ Aussprache über die Berichte am ersten Tag von F. Fleiner und J. Lukas VVDStRL 6 (1929), 57 (64 f.). 
tionelle Ausgestaltung des Föderalismus, nicht übersehen werden. ${ }^{23}$ Die bis heute nachwirkende - Entstehungsgeschichte des schweizerischen und des deutschen Föderalismus ist eine andere: die Schweiz ist als dezentraler und direktdemokratischer, Deutschland als unitarischer und repräsentativer Bundesstaat konzipiert. ${ }^{24}$ Als multikulturelle Willensnation ist für die Schweiz die Schaffung von Rechtseinheit, also die Zentralisierung von Zuständigkeiten, politisch begründungspflichtig. ${ }^{25}$ Demgegenüber wohnt dem deutschen Föderalismus, wie Konrad Hesse so eindrücklich aufgezeigt hat, eine rechtsvereinheitlichende Dynamik inne. ${ }^{26}$ Die unterschiedliche föderalistische Kultur zeigt sich beispielhaft auch daran, dass in Deutschland der Bund die ihm zustehenden konkurrierenden Gesetzgebungszuständigkeiten in der Regel voll ausnutzt und die Vollzugsvariationen für die Länder gesetzgeberisch eingrenzt. ${ }^{27}$ Die Bund-Länder-Ko-

23 Braun Reform- und Entscheidungsblockaden (Fn. 19), 325 ff.

24 D. Braun Dezentraler und unitarischer Föderalismus. Die Schweiz und Deutschland im Vergleich, Swiss Political Science Review, 20039 (1), 57 ff.

25 Die Nicht-Zentralisierung als grundsätzliches Ordnungsprinzip des schweizerischen Föderalismus zeigt sich nach wie vor, auch bei stark geschwundenen kantonalen Sachbereichszuständigkeiten, in der Steuerautonomie der Kantone, was auch einen bestimmten Steuerwettbewerb zwischen den Kantonen erlaubt. Vgl. Koller FS Straumann (Fn. 3), 28. Auch der, nebst relativ hoher kantonaler Steuerautonomie, vertikale Finanzausgleich bezweckt die Erhöhung der Eigenständigkeit der Kantone bei der Aufgabenerfüllung und nicht die Herstellung einheitlicher Lebensverhältnisse. W. Linder Kompetenzzuordnung und Wettbewerb im Föderalismus, in: Walter Eucken Institut (Hrsg.) Tagungsband Föderalismus und Subsidiarität - Kompetenzzuordnung und Wettbewerb in politischen Mehrebenensystemen, noch nicht publiziert: Publikation vorgesehen 2014, 8 betont, dass der Schweizer Finanzausgleich dem Ausgleich der Lasten zwischen Gebietskörperschaften, nicht aber dem interpersonalen Ausgleich dient.

${ }^{26}$ K. Hesse Der unitarische Bundesstaat, 1962; Dazu auch: G. Lehmbruch Der unitarische Bundesstaat in Deutschland: Pfadabhängigkeit und Wandel, in: A. Benz/ G. Lehmbruch (Hrsg.) Föderalismus. Analysen in entwicklungsgeschichtlicher und vergleichender Perspektive, Sonderheft der Politischen Vierteljahrsschrift, Band 32, 2001, (53 ff.), Linder (Fn. 25), 12 spricht vom ,verkappten Einheitsstaat“. Die Schaffung von Rechtseinheit hat einen eigenen, einen symbolischen Stellenwert für die „Kulturnation“ Deutschland, so Braun Dezentraler und unitarischer Föderalismus (Fn. 24), 59, 67. Die Länder spielen, im Unterschied zu den Kantonen, nicht die gleiche zentrale Rolle für die Integration und Identitätsstiftung im Bundesstaat. Nach Oeter Integration und Subsidiarität (Fn. 19), 300 f. mit Bezug auf Hesse (ebd.) sollte besser von einem zentral gelenkten Föderalismus gesprochen werden. Was vorliegt, sei ein „föderalistisch garnierter Einheitsstaat." Auch in Bezug auf die föderalistische Kultur zeigen sich Unterschiede: vgl. R. Sturm Zweite Kammer in Deutschland und Europa: Repräsentation, Funktion, Bedeutung, in: Härtel (Fn. 2), Bd. 1, Rn. 37 f. und R. Watts (siehe bei A. Koller FS Straumann (Fn. 3), 34).

27 Siehe Karpen in: Baus/Blindenbacher/Karpen (Fn. 18), 47 ff.: Die Entwicklung zum unitarischen Bundesstaat sei im Grundgesetz selbst angelegt. Zur föderalistischen Kultur Deutschlands: Sturm (Fn. 26), Rn. 37 f. 
operation ist in Deutschland eine allgegenwärtige Handlungsmaxime, wogegen der föderale Wettbewerb eine geringere Bedeutung hat. ${ }^{28}$ Deutschland weist denn auch eine weit höhere Politikverflechtung der Bundesund der gliedstaatlichen Ebene auf als die Schweiz. ${ }^{29}$ Gleicht sich somit die Grundtendenz in der föderalistischen Entwicklung der beiden Staaten, so ist ebenso sichtbar, dass mit gleichen Strukturen nicht unbedingt auch gleiche Funktionen und Wirkungen verbunden sind. ${ }^{30}$

\section{Der Bildungsföderalismus in Deutschland und in der Schweiz}

\section{Allgemeine Entwicklung}

Interessant ist nun zu beobachten, dass sich - gleichverlaufend in beiden Staaten - die Aufgabenerfüllung im Bildungsbereich im Vergleich zur allgemeinen Entwicklung des Föderalismus nicht synchron, sondern atypisch, fast gegenläufig entwickelt hat. Die gesellschaftlichen Veränderungen und die Europäisierung des Bildungsdiskurses haben nicht zur

28 Braun Dezentraler und unitarischer Föderalismus (Fn. 24), 63. Wie Linder (Fn. 25) darlegt, kann auch in der Schweiz nicht von einem wirklichen Wettbewerbsföderalismus gesprochen werden. Der Wettbewerb sei nicht in einem marktwirtschaftlichen Sinn zu verstehen, sondern als Wettbewerb in Bezug auf die Effektivität des politischen Prozesses und der Institutionen und die Qualität der öffentlichen Güter. Zum Wettbewerbsföderalismus: Schuppert (Fn. 14), Rn. 33 ff. und Braun Reform- und Entscheidungsblockaden (Fn. 19), $323(\mathrm{mwN})$. Siehe auch Scholz in: Baus/Blindenbacher/Karpen (Fn. 18), 92 ff., wonach Föderalistischer Wettbewerb weniger rechtlich als politisch zu verstehen ist.

29 Dazu: R. L. Watts Basic Issues of the Federal State: Competitive Federalism versus Co-operative Federalism, in: Baus/Blindenbacher/Karpen (Fn. 18), 85 ff. Oeter Gesetzgebung, in: Baus/Blindenbacher /Karpen (Fn. 18), 116, spricht von einer ,extremen Politikverflechtung". Der föderalistische Ausgleich liegt beim kooperativen Föderalismus in einer engen Einbindung in den bundespolitischen, stark vom Parteienwettbewerb geprägten Entscheidungsprozess und in einer eigentlichen Veto-Macht der Länder im Bundesrat. Wie Braun Dezentraler und unitarischer Föderalismus (Fn. 24), 67 f. betont, liegt in der Schweiz die Veto-Macht der Kantone nicht im Ständerat, sondern im Vollzug des Bundesrechts durch die Kantone. Auch der Einbindung der föderalistischen Mitwirkung in den direktdemokratischen Entscheidungsprozess kommt eine erhebliche Ausgleichsfunktion zu: vgl. B. Ehrenzeller Kooperativer Föderalismus und Demokratie, in: Waldmann (Hrsg.) 1. Nationale Föderalismuskonferenz. Der kooperative Föderalismus vor neuen Herausforderungen, 2005, $67 \mathrm{ff}$.

30 Braun Dezentraler und unitarischer Föderalismus (Fn. 24), 84; Koller FS Straumann (Fn. 3), 25, zeigen die ebenso sichtbaren Unterschiede doch auf, dass - wie sich die Politikwissenschaftler ausdrücken - äqui-funktionale Strukturen wie der Exekutivoder der Vollzugsföderalismus in beiden Bundesstaaten nicht gleichbedeutend sind mit gleicher Funktions- und Wirkungsweise. 
Zentralisierung und nicht zum Vollzugsföderalismus im Bildungswesen geführt. Die Schulhoheit, die grundsätzlich alle Schulstufen umfasst, liegt nach wie vor bei den Kantonen beziehungsweise den Ländern (ausdrücklich: Art. $62 \mathrm{BV}){ }^{31}$ Man könnte hier also eher von einem umgekehrten Mitwirkungsföderalismus sprechen.

Grundgesetz und Bundesverfassung beschränken sich auf wenige, wenn auch wichtige bundesstaatliche Leitplanken für das Schulwesen: Nach Art. 7 Grundgesetz steht das gesamte Schulwesen unter Aufsicht des Staates. Art. 19 der Bundesverfassung gewährleistet dagegen einen Grundrechtsanspruch auf ausreichenden und unentgeltlichen Grundschulunterricht, der obligatorisch ist, allen Kindern offen stehen muss und unter staatlicher Leitung oder Aufsicht steht (Art. 62 Abs. 2 BV). Bedeutungsvoll und bezeichnend zugleich ist, dass der Bundesgesetzgeber sich nicht als zuständig erachtet hat, diese bundesverfassungsrechtlichen Rahmenvorgaben auf Gesetzesstufe zu konkretisieren, also beispielsweise festzulegen, was unter „ausreichendem Grundschulunterricht“ zu verstehen ist..$^{32}$ In beschränktem Mass hat allerdings die bundesgerichtliche Rechtsprechung für eine einheitliche Auslegung gesorgt. ${ }^{33}$

${ }^{31}$ Ebenso zählt die mit der Bildungshoheit eng verbundene Kulturhoheit zum verbliebenen und keineswegs verblichenen gliedstaatlichen „Krongut“ der Länder und Kantone (dazu vorne Fn. 5) und Botschaft zur „eidgenössischen Kulturinitiative“ vom 18. April 1984, BBl 1984 II 501 ff.; H. Plotke Schweizerisches Schulrecht, 2. Aufl., 2003, 109 ff.; B. Ehrenzeller/M. Schott St. Galler Kommentar zu Art. 62 BV, Rn. 7 ff.

${ }^{32}$ F. Fleiner Bundesstaatliche und gliedstaatliche Rechtsordnung in ihrem gegenseitigen Verhältnis im Rechte Deutschlands, Österreichs und der Schweiz, VVDStRL 6 (1929), 2 (12/15). In diesem Sinne auch: B. Ehrenzeller Bewegung in der Schule: Der obligatorische Schulsport im Lichte von Art. 68 BV, in: M. Caroni/S. Heselhaus et al. (Hrsg.) Auf der Scholle und in lichten Höhen, FS Richli zum 65. Geburtstag, 2011, 679 (686) mwH und G. Biaggini Kommentar: Bundesverfassung der Schweizerischen Eidgenossenschaft, 2007, Art. 62 BV Rn. 2, 8. Der Bund hat damit die Konkretisierung der Schulpflicht weitgehend der kantonalen Regelung und den Rechtsanwendungsbehörden überlassen. Die Drohkulisse mit der - verloren gegangenen - eidgenössischen „Schulvogtabstimmung“ des Jahres 1882 scheint auch heute nicht ohne Wirkung. Der „Bundesschulvogt“ „töte das republikanische Selbstgefühl“. Dazu: F. Osterwalder Ein Bildungsraum Schweiz - ein tragfähiges Verfassungsmodell (Fn. 11) und Parlamentarische Initiative. Bildungsrahmenartikel in der Bundesverfassung: Bericht der Kommission für Wissenschaft, Bildung und Kultur des Nationalrats vom 23. Juni 2005 (Bericht WBK-N, Bildungsverfassung, BBl 2005 5479-5494, 5486 f.).

${ }_{33}$ R. Kägi-Diener St. Galler Kommentar zu Art. 19 BV, Rn. 26 ff. Ob das Bundesgericht allerdings, wie G. Biaggini Zur Tragweite der Schulsportklausel, in: FS Richli zum 65. Geburtstag (Fn. 32), 700 ff., vertritt, an Stelle des Bundesgesetzgebers die Mindestanforderungen an das Schulobligatorium, beispielsweise die zeitliche Dauer, festlegen könnte, ist fraglich. 
Auch die Stellung der Schule als öffentliche Institution ist ungebrochen. Bildung ist in öffentlicher Hauptverantwortung geblieben. Die Kantone und Länder tragen damit nicht nur die Verantwortung für die Organisation und die Finanzierung des Schulwesens, ${ }^{34}$ sondern sie bestimmen über die Lehrpläne auch weitgehend die inhaltlichen Fragen der Bildungsvermittlung und die Ausbildung der Lehrkräfte. Sie legen in ihren Verfassungen und Gesetzen die Bildungsziele fest. An den Kantonen und Ländern liegt es in erster Linie, den öffentlichen Bildungsauftrag zu erfüllen. ${ }^{35}$ Ihnen ist aufgetragen, den staatspolitisch zentralen, gesamtheitlichen Anspruch auf „Bürgerschaft durch Bildung“36 einzulösen, wie er schon vom Schweizer Pädagogen und Aufklärer Johann Heinrich Pestalozzi vorgebracht worden ist. ${ }^{37}$

Wie lässt sich erklären, dass aller Dynamik im Bildungswesen und aller gesellschaftlichen und politischen Veränderungen zum Trotz die Bildungshoheit bei den Kantonen und Ländern verblieben ist? Der Hauptgrund liegt wohl darin, dass sich die Stärke des öffentlichen Bildungswesens aus der Gleichwertigkeit der gliedstaatlichen Bildungssysteme ergibt. Das gilt insbesondere für die Maturitätsschulen: mit der Matura- resp. dem Abiturabschluss vermitteln sie den grundsätzlich freien Zugang zu den Hochschulen. Die bundesstaatsrechtliche Gleichstellung aller Gliedstaaten bedeutet somit im Bildungswesen, dass - trotz aller faktischen Unterschiedlichkeiten und Asymmetrien - Bildungsleistungen von gleichwertiger Qualität erbracht werden. Dies ist bisher so gewollt, auch wenn die

${ }^{34}$ Im Jahr 2005 trugen die Länder in Deutschland $67 \%$ des gesamten Bildungsbudgets (Fn. 13), 2 f.; In der Schweiz waren es, ohne Berücksichtigung der Forschungsförderung des Bundes, im Jahr $201082 \%$, die von den Kantonen getragen wurden (SBFI Beiträge des Bundes und der Kantone an den Bereich «Bildung, Forschung und Innovation» 2004-2016, 2012, 6, online: <http://www.sbfi.admin.ch/org/01645/index.html? lang $=\mathrm{de}>($ abgerufen am 20. September 2013)).

${ }^{35}$ Der öffentliche Bildungsauftrag ergibt sich aus verschiedenen internationalen Konventionen wie Art. 13 Abs. 2 Internationaler Pakt über wirtschaftliche, soziale und kulturelle Rechte (UNO-Pakt I), SR 0.103.1 oder Art. 28/29 Übereinkommen über die Rechte des Kindes (KRK), SR 0.107, aber auch konkretisierend aus dem nationalen Recht, so beispielsweise aus Art. 3 Interkantonale Vereinbarung über die Harmonisierung der obligatorischen Schule (HarmoS-Konkordat) vom 14. Juni 2007, veröffentlicht u.a. in der Erlasssammlung des Kantons St. Gallen: sSG 211.41.

${ }^{36}$ So P. Häberle Bürgerschaft durch Bildung als europäische Aufgabe, in: F. Hufen (Hrsg.) Verfassung - Zwischen Recht und Politik. FS zum 70. Geburtstag für HansPeter Schneider, 2008, 460 ff., wie auch R. Dahrendorf Bildung ist Bürgerrecht: Plädoyer für eine aktive Bildungspolitik, 1968.

37 Vgl. z.B. A. Heubaum Pestalozzi. Der Erzieher, in: R. Lehmann (Hrsg.) Die großen Erzieher. Ihre Persönlichkeit und ihre Systeme, Bd. 3. 1929, 345 ff. 
eingangs erwähnten Leistungsvergleiche diese Grundannahme teilweise in Frage stellen.

Schaut man genauer hin, so hat sich im scheinbar „festen Gehäuse“ der gliedstaatlichen Bildungshoheit Vieles bewegt, ${ }^{38}$ und zwar auf allen Ebenen. Wie in allen staatlichen Handlungsbereichen hat die Geltung der Grundrechte, insbesondere die Wahrung der Chancengleichheit und überhaupt der rechtsstaatlichen Grundsätze, auch im Bildungswesen rechtsvereinheitlichend gewirkt. Dasselbe gilt für die internationalen Konventionen wie den UNO-Sozialpakt (Art. 13), die oft unterschätzte Kinderrechtskonvention mit dem vorrangigen Ziel des Kindeswohls (Art. 11) oder die Lissabon-Konvention der UNESCO ${ }^{39}$ und natürlich die EU-Personenfreizügigkeit. Die internationalrechtlichen Verpflichtungen prägen in hohem Masse ein länderübergreifendes gemeinsames Verständnis für den öffentlichen Bildungsauftrag. Weit mehr als in andern Bereichen hat der internationale Bildungsdiskurs auch die Selbstkoordination der Länder befördert. ${ }^{40}$ Ohne die forcierte Selbstkoordination im Rahmen der Fachminister- resp. Fachdirektorenkonferenzen wäre die Zentralisierung des Bildungsbereichs nicht zu verhindern gewesen. ${ }^{41}$ Der politische und

${ }^{38}$ Vgl. P. Lerche Föderalismus als nationales Ordnungsprinzip, VVDStRL 21 (1964), $66(100)$.

39 Übereinkommen über die Anerkennung von Qualifikationen im Hochschulbereich in der europäischen Region (Lissabon-Konvention) vom 11. April 1997 (SR 0.414.8). Besondere Erwähnung bedarf das - von der Schweiz allerdings nicht ratifizierte 1. Zusatzprotokoll zur EMRK (Art. 2) wie auch neuerdings das - von der Bundesversammlung genehmigte aber noch nicht ratifizierte - Übereinkommen des Europarates zum Schutz von Kindern vor sexueller Ausbeutung und sexuellem Missbrauch (Lanzarote-Konvention), online: <http://conventions.coe.int/Treaty/Commun/QueVoulezVous. asp?CL=GER\&NT=201> (abgerufen am 20. September 2013). Bei diesen internationalrechtlichen Verpflichtungen handelt es sich zwar teilweise um direktanwendbare Ansprüche von Kindern und Eltern, die allerdings eng verbunden sind mit Bildungszielen und Bildungsmassnahmen und deshalb eher den Charakter von Sozialgestaltungsaufträgen haben. Einen Überblick über die im Hochschulbereich relevanten internationalen Abkommen vermittelt Müller (Fn. 7), 71-103.

${ }^{40}$ Vgl. U. Volkmann in: v. Mangoldt/Klein/Starck (Fn. 2), Art. 91a Rn. 2; Criblez (Fn. 8), 279 ff. mit den wichtigsten interkantonalen Vereinbarungen (282 ff.); S. Immerfall Der deutsche Bildungsföderalismus zwischen Aufbruch und Verflechtungsfalle macht sich die „Griechische Landschildkröte“ auf den Weg?, in: Blumenthal/Bröchler (Hrsg.) Föderalismusreform in Deutschland: Bilanz und Perspektiven im internationalen Vergleich, 2010, 197 ff.; Zur - wenig diskutierten - Problematik der Selbstkoordination der Länder: Oeter Integration und Subsidiarität (Fn. 19), 169 ff., 476. Zu den negativen und positiven Zügen der Selbstkoordination siehe auch die wegweisenden Überlegungen von Hesse (Fn. 26), 20 f. Vermöge der bundesstaatlichen Struktur ist erreicht worden, dass Unitarisierung nicht zugleich Zentralisierung bedeutet.

${ }^{41}$ Zweifellos dürfte auch die Finanzierungsverantwortung im Bildungswesen (vgl. Fn. 34) eine wichtige Rolle für die Erhaltung der Länderkompetenz gespielt haben, liegt 
ideologische Druck - Stichwort: deutsche Bildungskatastrophe ${ }^{42}$ - wäre zu gross gewesen.

Allerdings: die Kantone und Länder wären - angesichts des demographischen Wandels und der Mobilität, der deutlichen Erhöhung der Maturitätsquoten und Zunahme der Studierendenzahlen - ohne kräftige Unterstützung des Bundes nicht in der Lage gewesen, den Ausbau ihrer Hochschulen zu finanzieren. ${ }^{43}$ Über das Mittel der sogenannten ,goldenen Zügel“" hat der Bund massgeblich Einfluss genommen auf Bildung und Wissenschaft. So reibt sich denn auch - in Deutschland und, mit etwas weniger politischer Verve, in der Schweiz - die Bildungsföderalismusdebatte seit Ende der 60er Jahre des letzten Jahrhunderts bis heute hauptsächlich an der Rolle des Bundes als Mitfinanzierer und Mitgestalter des Hochschulbereichs. In der Spannungslage zwischen Verhinderung der Zentralisierung und notwendiger Mitwirkung des Bundes haben Deutschland und die Schweiz allerdings unterschiedliche bundesstaatsrechtliche Wege beschritten.

\section{Der deutsche Bildungsföderalismus}

In Deutschland sind im Jahre 1969, nachdem die Einführung einer umfassenden konkurrierenden Bundeskompetenz im Hochschulwesen gescheitert ist, die sogenannten „Gemeinschaftsaufgaben“ (Art. 91a./91b.) wie auch die Bundeskompetenz zum Erlass allgemeiner Grundsätze des Hochschulwesens (Art. 75 Abs. 1 Bst. 1a.) in das Grundgesetz aufgenommen worden. ${ }^{44}$ Viele Kritiker sahen gerade darin den institutionalisierten Sündenfall für Mischverwaltung, Verwischung der Verantwortung und Politikverflechtung. ${ }^{45}$ Warum sich die Gemeinschaftsaufgaben, trotz er-

doch die Finanzierung des Vorschul-, Grundschulbereichs und der Maturitätsschulen ausschliesslich oder weitgehend bei den Kantonen und Ländern, und auch im Hochschulbereich müssen diese primär für die Grundkosten von Lehre und Forschung ihrer Hochschulen aufkommen.

42 G. Picht Die deutsche Bildungskatastrophe, Christ und Welt, 1964 (5).

${ }^{43} \mathrm{Zu}$ den nationalen hochschulpolitischen Entwicklungen und Herausforderungen siehe: Müller (Fn. 7), 104-116. Nach A. Guckelberger Bildung und Föderalismus, in: Härtel (Fn. 2), Bd. 3, 224, erzwangen der erhebliche Finanzbedarf und die öffentliche Meinung den kooperativen Föderalismus im Bildungsbereich.

${ }^{44}$ Dazu: U. Volkmann in: v. Mangoldt/Klein/Starck (Fn. 2), Art. 91a Rn. 1. Durch die Gemeinschaftsaufgaben sind Bund und Länder zu einer Handlungs-, Finanzierungs- und Verantwortungseinheit im Hochschulwesen verbunden worden.

${ }^{45}$ Seitens der Vertreter der Politikwissenschaften kam von Anfang an härtere Kritik am Institut der Gemeinschaftsaufgaben als aus dem Kreise der Staatsrechtler. Vgl. dazu Berichterstatter J. Frowein Gemeinschaftsaufgaben (Fn. 17) und die anschliessende Diskussion, 17 ff. mwH. Siehe auch Oeter Integration und Subsidiarität (Fn. 19), 292 ff. 
kannter Fehlentwicklung, solange, bis ins Jahr 2006, als Verfassungsinstitut haben halten können, dürfte vor allem damit zu erklären sein, dass lange Zeit keine echte Alternative zu dieser Zusammenarbeit von Bund und Ländern in Sicht schien. In der Praxis sind denn auch die verfassungsrechtlichen Möglichkeiten der Bund-Länderkooperation bei weitem nicht genutzt worden. ${ }^{46}$ Gleichzeitig wusste die viel geschmähte Kultusministerkonferenz (KMK) weitergehende Vereinheitlichungsbestrebungen auszubremsen. ${ }^{47}$

Führten die Gemeinschaftsaufgaben eher zur faktischen Verzahnung und Abhängigkeit von Bund und Ländern, so nutzte der Bundesgesetzgeber seine Grundsatzkompetenz zur Hochschulrahmenordnung weitgehend im Sinne einer Vollgesetzgebung. ${ }^{48}$ Nachdem diese Kompetenzen im Zug der Föderalismusreform I abgeschafft worden sind, ${ }^{49}$ verbleiben nun dem Bund im Bereich der Förderung von Wissenschaft und Forschung nur noch beschränkte, sogenannte „unechte“ Gemeinschaftskompetenzen

46 Die gemeinsamen Organe wie die Bund-Länder-Kommission (BLK) wirkten im Übrigen wenig erfolgreich. Siehe: U. Volkmann in: v. Mangoldt/Klein/Starck (Fn. 2), Art. 91a. Rn. 3 und U. Volkmann in: v. Mangoldt/Klein/Starck (Fn. 2), Art. 91b Rn. 9 ff. Auch die an der Staatsrechtslehrertagung von 1972 (Fn. 17), (87 ff.) diskutierten Alternativen wie etwa eine gemeinsame Verbund- und Gesamtplanung erschien nicht überzeugend.

47 Immerfall (Fn. 40) setzt sich eingehend mit der Entwicklung und der Rechtfertigung der KMK auseinander. J. Kraus Elf Zwischenrufe eines überzeugten Föderalisten, in: Schultz/Hurrelmann (Fn. 2), 136 ff., 151 f. sieht in der KMK geradezu die „Inkarnation des Bildungsföderalismus“: Böse Zungen bezeichneten sie auch schon als „Griechische Landschildkröte". vgl. Immerfall (Fn. 40).

48 Nach Oeter Integration und Subsidiarität (Fn. 19), 335 wirkte auch die Rechtsprechung des Bundesverfassungsgerichtes insgesamt, ,unitarisch“. (Erst) mit den Entscheidungen zu den Juniorprofessuren (BVerfGE 111, 226) und den Studiengebühren (BVerfGE 112, 226) - wie vorgängig schon im Altenpflegeurteil (BVerfGE 106, 62) zeigte das Bundesverfassungsgericht dem Bund die Grenzen seiner Rahmengesetzgebungszuständigkeit auf. Nach E. Hansalek Die neue Kompetenz des Bundes im Hochschulrecht, NVwZ, 2006, 668, (668), waren nach diesen Urteilen keine wesentlichen bildungspolitischen Entscheide des Bundesgesetzgebers mehr möglich.

49 Ein illustrativer Überblick über die Entwicklung der Bildungskompetenzen in Deutschland findet sich bei: Guckelberger (Fn. 43), 223 ff. Siehe auch: J. Hellermann Kooperativer Föderalismus in Gestalt der Gemeinschaftsaufgabe nach Art. 91a ff. des Grundgesetzes, in: Härtel (Hrsg.) (Fn. 2), Bd. 2, 2012, 339 ff. Zusammenfassende Bewertung der Neuregelung zu Gemeinschaftsaufgaben und Lastenverteilung, in: J. Hellermann Kommentar der Gemeinschaftsaufgaben (Art. 91a, 91b), in: Ch. Starck (Hrsg.) Föderalismusreform, 2007, 133 ff., 165 ff. sowie: $U$. Münch in: Hrbek/Hüttman/Schmid (Fn. 6), 47 ff. Als offizieller Grund für die Abschaffung der Gemeinschaftskompetenzen im Bildungsbereich wurde angeführt, dass sich die Rahmengesetzgebung ,als ineffektiv erwiesen“ und ,auch im Übrigen nicht bewährt" habe (BT-Drs. 16/813, 8). 
(Art. 91b. GG): zur gemeinsamen Aufgabenerfüllung bedarf es der Vereinbarung von Bund und Ländern. ${ }^{50}$ Für die weitgehende Rückübertragung der Gesetzgebungshoheit im Hochschulwesen mussten die Länder aber einen Preis bezahlen, nämlich die neu eingefügte konkurrierende Bundeskompetenz zum Erlass von Vorschriften über die Hochschulzulassung und die Hochschulabschlüsse (Art. 74 Abs. 1 Ziffer 33 GG). ${ }^{51}$ Als grosse föderalistische Innovation wird das neu eingeführte Recht jedes einzelnen Landes gesehen, von der entsprechenden Bundesgesetzgebung mit einer eigenen Regelung abzuweichen (Art. 73 Abs. 3 Ziffer 6 GG). ${ }^{52}$ Dieses Abweichungsrecht der Länder stellt ein staatsrechtliches Novum dar, das nicht ohne potentielle Tücken ist: Macht der Bund extensiven Gebrauch von seiner an sich schmalen Kompetenz und weichen mehrere Länder von dieser Regelung ab, besteht die Gefahr der Rechtszersplitterung oder es kommt, um ein Abweichen gerade zu vermeiden, zu einer ausgehandelten Bundeslösung. Beides ist eigentlich nicht im Sinne der Verfassungsschöpfer.

\section{Der schweizerische Bildungsföderalismus}

In der Schweiz verlief der Bildungsföderalismus, wenn auch zeitlich parallel, in eine andere Richtung. Wohl drängte auch in der Schweiz der bildungspolitische Aufbruch der Sechzigerjahre in Richtung Zentralisierung, vor allem des Hochschulwesens. Und auch in der Schweiz endeten die Bestrebungen für eine verfassungsrechtliche Verstärkung der Rolle des Bundes in der Bildungspolitik in einer tiefgehenden Ernüchterung: der sogenannte Bildungsartikel scheiterte im Jahre 1973 in der Volksabstimmung am notwendigen Mehr der Stände. ${ }^{53}$ Dagegen haben die Kantone

${ }^{50} \mathrm{Vgl}$. B. Edelstein/J. Allmendinger Bildungsföderalismus - Déjà-vu mit Happy End?, in: Schultz/Hurrelmann (Fn. 2), 20 f., 45.

${ }^{51}$ Dazu: S. Oeter Neustrukturierung der konkurrierenden Gesetzgebungskompetenzen, Veränderung der Gesetzgebungskompetenz des Bundes, in: Föderalismusreform (Fn. 49), 30-33 und Guckelberger (Fn. 43), 243. Kritisch zu dieser neuen Bundeskompetenz: Hellermann (Fn. 49), Rn. 15, 17, 23, 28 ff., und v.a. 57.

52 Dazu: Hansalek (Fn. 48), 668; Oeter Neustrukturierung (Fn. 51), 39 f., begrüsst diese Neuerung - trotz erheblicher Kritik - im Sinne eines erhöhten „Experimentierspielraumes", der dem deutschen Bundesstaat nur gut tun könne.

53 Volksabstimmung vom 4. März 1973 mit entsprechendem Volks- und Ständemehr (siehe dazu B. Ehrenzeller/K. Sahlfeld St. Galler Kommentar, Vorbemerkung zur Bildungsverfassung, Rn. 8). Auf einen zweiten Anlauf für eine erweiterte Bildungskompetenz hat der Bund verzichtet. Einzige Ausnahme bildete die auf einer Volksinitiative beruhende Verfassungsänderung betr. die Koordination des Schulanfanges (Art. 27 Abs. $3^{\text {bis }} \mathrm{aBV}$ ), nachdem die Bemühungen zu einer Konkordatslösung unter den Kanto- 
unter sich schon im Jahre 1970 einen rechtsetzenden interkantonalen Vertrag geschlossen über die Harmonisierung der Schulstrukturen und die Zusammenarbeit im Bereich der obligatorischen Schule, das sogenannte Schulkonkordat. ${ }^{54}$ Durch dieses Konkordat erhielt auch die seit 1897 bestehende Konferenz der kantonalen Erziehungsdirektoren (EDK) eine formell-rechtliche Grundlage und einen permanenten Vollzugs- und Harmonisierungsauftrag mit dem Recht von Empfehlungen. ${ }^{55}$ Die EDK hat sich denn auch zur weitaus bedeutendsten interkantonalen Fachdirektorenkonferenz entwickelt. ${ }^{56}$ Doch die Grenzen der interkantonalen Zusammenarbeit zeigten sich dann vor allem in den Neunzigerjahren, als wichtige Reformanliegen im Hochschulbereich zur Debatte standen. ${ }^{57}$ Dies drängte den Bund nicht nur zu stärkerer finanzieller Unterstützung der Hochschulen, sondern auch, wenn auch auf schwacher Kompetenzbasis, zu gesetzgeberischem Handeln ${ }^{58}$.

nen gescheitert waren (Ehrenzeller/Schott St. Galler Kommentar zu Art. 62 BV, Rn. 68); Bericht WBK-N, Bildungsverfassung, BB1 2005 5479, 5488.

${ }^{54}$ Zum Konkordat siehe: M. Arnet Das Schulkonkordat vom 29. Oktober 1970, 2000. Zur Entwicklung des Schulwesens in der Schweiz siehe: G. Biaggini Kooperativer Föderalismus zwischen Freiwilligkeit und Zwang: Die neue schweizerische „Bildungsverfassung" als Experimentierfeld, in: Europäisches Zentrum für Föderalismus-Forschung Tübingen (Hrsg.) Jahrbuch des Föderalismus: Föderalismus, Subsidiarität und Regionen in Europa, 2007, 449 ff. und Derselbe Schulkoordination in der Schweiz: Der steinige Weg des ,Konkordats-Föderalismus“, in: Europäisches Zentrum für FöderalismusForschung Tübingen (Hrsg.) Jahrbuch des Föderalismus: Föderalismus, Subsidiarität und Regionen in Europa, 2009, 380 ff. sowie Bericht WBK-N, Bildungsverfassung, BB1 2005 5479, 5485 ff. Dem Schulkonkordat sind, ausser dem Kanton Tessin, alle Kantone beigetreten.

${ }_{55}$ Dazu: Ehrenzeller/Sahlfeld (Fn. 53), Rn. 10 und Bericht WBK-N, Bildungsverfassung, BBl $20055494 \mathrm{f}$.

56 Vgl. Criblez (Fn. 8), 286.

${ }^{57} \mathrm{Zu}$ den Herausforderungen des schweizerischen Hochschulwesens siehe Botschaft des Bundesrates zum Bundesgesetz über die Förderung der Hochschulen und die Koordination im schweizerischen Hochschulbereich (HFKG), Referendumsvorlage, BB1 $20117455 \mathrm{ff}$.

58 Dazu: Müller (Fn. 7), 124 ff. So musste das Bundesgesetz über die Fachhochschulen (Fachhochschulgesetz, FHSG, vom 6. Oktober 1995, SR 414.71) als Grundlage der neu zu errichtenden Fachhochschulen auf die Berufsbildungskompetenz des Bundes gestützt werden (gestützt auf Art. 27 Abs. 1, 27quater Abs. 2, 27 $7^{\text {sexies }}$ und 34 $4^{\text {ter }}$ Abs. 1 lit. g $\mathrm{aBV}$ ). Siehe auch Botschaft zu einem Bundesgesetz über die Fachhochschulen (FHSG) vom 30. Mai 1994, BBl 1994 III 789 ff. sowie Plotke (Fn. 31), 107 f. Als verfassungsrechtliche Grundlage des neuen Universitätsförderungsgesetzes (Bundesgesetz über die Förderung der Universitäten und über die Zusammenarbeit im Hochschulbereich (Universitätsförderungsgesetz, UFG) vom 8. Oktober 1999, SR 414.20) diente die Bundeskompetenz zur Hochschulunterstützung und zur Forschungsförderung, die gemäss neuer Bundesverfassung davon abhängig gemacht werden konnte, dass die Koordina- 
Dass die Verfassungslage im Bildungsbereich, auch nach der Totalrevision der Bundesverfassung im Jahre 1999, nicht befriedigen konnte, zeigte sich an politischen Vorstössen aus verschiedenen Kreisen. ${ }^{59}$ Vorerst scheiterten allerdings, vorab am Widerstand der Kantone, parlamentarische Bestrebungen in den Eidgenössischen Räten zur Schaffung eines Bildungsrahmenartikels mit dem Recht des Bundes, die Grundsätze der Bildung von gesamtschweizerischer Bedeutung festzulegen. ${ }^{60}$ Auch das Vorhaben des Bundesrates für einen neuen Hochschulverfassungsartikel war nicht erfolgsgekrönt. ${ }^{61}$ Aus bildungsföderalistischer Sicht sehr bedeutungsvoll war nun, dass die EDK selbst den parlamentarischen Kommissionen Vorschläge zur verfassungsrechtlichen Neugestaltung des gesamten Bildungsbereichs unterbreitete. Damit war der Durchbruch geschafft: Das Volk - und alle Stände - hiessen am 21. April 2006 die sogenannte neue Bildungsverfassung mit überwältigendem Mehr gut. ${ }^{62}$ Diese verpflichtet Bund und Kantone in der einleitenden, nicht kompetenzbegründenden Ziel- und Programmnorm dazu, im Rahmen ihrer Zuständigkeiten gemeinsam für eine hohe Qualität und Durchlässigkeit des Bildungsraumes Schweiz zu sorgen. Sie sind dabei zu umfassender Koordination und Zusammenarbeit verpflichtet (Art. 61a BV).

Zuständigkeitsrelevant hingegen sind zwei wesentliche Neuerungen, die den Kern der Bildungsverfassung bilden, nämlich einerseits das Konzept der koordinierten, nach Bildungsstufen differenzierten Steuerung des gesamtschweizerischen Bildungswesens über bestimmte Schlüsselstellen oder Eckwerte ${ }^{63}$ und andererseits das Grundkonzept der subsidiären Bun-

tion unter den Hochschulen sichergestellt ist (Art. 63/64 BV). Fragwürdig war diese verfassungsrechtliche Abstützung vor allem deswegen, weil im neuen Universitätsförderungsgesetz gemeinsame Entscheidungsorgane von Bund und Kantonen mit rechtsetzenden Kompetenzen vorgesehen worden waren. Die gesamtschweizerische Einführung des Bolognasystems (Bologna-Richtlinie, siehe Fn. 15) beruhte denn auch auf einem Beschluss des zentralen gemeinsamen Organs, der Schweizerischen Universitätskonferenz. Zur Verfassungsmässigkeit des UFG siehe Bericht WBK-N, Bildungsverfassung, BB1 $20055524 \mathrm{f}$.

${ }^{59}$ So wurden von mehreren Kantonen sogenannte Standesinitiativen an die Bundesversammlung eingereicht mit dem Ziel der Harmonisierung der Grundschule. Siehe: WBK-N, Bildungsverfassung, BB1 $20055491 \mathrm{f}$.

${ }^{60} \mathrm{Im}$ Vordergrund stand die parlamentarische Initiative von Nationalrat Hans Zbinden. Vgl. Bericht der WBK-N, Bildungsverfassung, BBl $20055499 \mathrm{f}$.

${ }^{61}$ Vgl. WBK-N, Bildungsverfassung, BBl 20055489 f. sowie die Zusammenstellung der parlamentarischen Vorstösse zum Hochschulbereich bei Müller (Fn. 7), Anhang 5.

${ }^{62}$ Abstimmungsresultat siehe: Ehrenzeller/Sahlfeld (Fn. 53), Rn. 19. Zum Begriff der Bildungsverfassung Ehrenzeller/Sahlfeld (Fn. 53), Rn. 5.

${ }^{63}$ Die Steuerung des Bildungswesens über „Schlüsselbereiche“ anstelle der materiellrechtlichen Regelung eines Sachbereichs erscheint auch in Deutschland als zukunfts- 
deskompetenzen. ${ }^{64}$ Für die Grund- und Sekundarschulstufe verankert Art. 62 Abs. 4 BV eine Harmonisierungspflicht der Kantone. Kommt diese Harmonisierung des Schulwesens im Bereich des Schuleintrittsalters und der Schulpflicht, der Dauer und Ziele der Bildungsstufen und von deren Übergängen sowie der Anerkennung von Abschlüssen nicht zustande, so erlässt der Bund in diesen Bereichen die notwendigen Vorschriften. ${ }^{65}$ Zur Wahrnehmung dieser subsidiären Bundeskompetenz durch den Bundesgesetzgeber ist es bisher nicht gekommen. Vielmehr ist im Rahmen der EDK die Interkantonale Vereinbarung über die Harmonisierung der obligatorischen Schule, das sogenannte HarmoS-Konkordat $^{66}$, ausgearbeitet und inzwischen, nach teilweise heftigen politischen Diskussionen und Volksabstimmungen, von 15 der 26 Kantone ratifiziert worden. ${ }^{67}$ HarmoS , seit dem 1. August 2009 in Kraft stehend, bildet nun die eigentliche Rechtsgrundlage für die konkreten Harmonisierungsaufträge: für die Bildungsziele und strukturellen Eckwerte der obligatorischen Schule, für den Fremdsprachenunterricht, und - was derzeit im Mittelpunkt der politischen Diskussion steht - für den Erlass sprach-

trächtig beurteilt zu werden: vgl. Oeter Gesetzgebung in: Baus/Blindenbacher/Karpen (Fn. 18), 55 f.

${ }^{64}$ Zum Konzept der „subsidiären Bundeskompetenzen“" siehe Ehrenzeller/Schott (Fn. 53), Rn. 57 ff. Biaggini Kommentar (Fn. 32), Art. 62 Rn. 11 ff. spricht von einer „bedingten Bundeskompetenz“. Derselbe kritisch-zurückhaltend gegenüber dem Konzept in: G. Biaggini Föderalismus quo vadis?, in: A. Auer (Hrsg.) Herausforderung HarmoS: Bildungspolitik, Föderalismus und Demokratie auf dem Prüfstein, 2010, 107 ff. (Dazu auch: Derselbe Schulkoordination (Fn. 54), 380 ff.).

${ }^{65}$ Beachtenswert ist, dass auch der am 23. September 2012 von Volk und Ständen als Gegenentwurf zur Volksinitiative ,jugend + musik“ angenommene neue Verfassungsartikel (Art. 67a BV) zur musikalischen Bildung diesen Harmonisierungsauftrag fortführt, indem er festhält, dass sich Bund und Kantone im Rahmen ihrer Zuständigkeiten für einen hochwertigen Musikunterricht an den Schulen einsetzen. Sollte ihnen die Harmonisierung der Ziele des Musikunterrichts an den Schulen nicht gelingen, so erlässt der Bund die notwendigen Vorschriften. Vgl. dazu die Botschaft des Bundesrates zur Volksinitiative ,jugend+musik“ (BBl $20101 \mathrm{ff}$.).

${ }^{66}$ Vgl. dazu: B. Ehrenzeller HarmoS im Lichte der Bildungsverfassung, in: Auer (Fn. 64), 23 ff.; H. Ambühl Konkordatsprozess. Entstehungsgeschichte, Zwischenbilanz zwei Jahre nach Inkrafttreten des Konkordates und Ausblick, in: Schweizerische Konferenz der Erziehungsdirektoren (Hrsg.) Die Interkantonale Vereinbarung über die Harmonisierung der obligatorischen Schule (Harmos-Konkordat) vom 14. Juni 2007, 2011, $32 \mathrm{ff}$.

${ }^{67}$ Hinweis auf den Stand der Ratifikationen, Ablehnungen und Sistierungen des Konkordates auf Homepage EDK (http://www.edk.ch/dyn/14901.php); festzustellen ist, dass alle Kantone der Romandie dem Konkordat beigetreten sind. Es gibt in der Westschweiz offenbar geringere Vorbehalte gegenüber der Schulharmonisierung als in der Deutschschweiz. 
regionaler, an nationalen Bildungsstandards orientierter Lehrpläne und Lehrmittel (Art. 8 HarmoS-Konkordat). ${ }^{68}$ Auch die 11 (der 26) Kantone, die HarmoS nicht beigetreten sind, richten ihre kantonale Bildungsgesetzgebung weitgehend am gesamtschweizerischen Harmonisierungsstandard aus. ${ }^{69}$ Noch nicht harmonisiert ist bisher der Sekundarschulbereich II, also die Maturitätsstufe. ${ }^{70}$ Es erweist sich offenbar als schwierig, gemeinsame Standards für die Hochschulreife zu entwickeln.

Anders sieht es die Verfassung im Hochschulbereich vor. Hier sind Bund und Kantone viel enger in die gemeinsame Verantwortung für die Koordination und für die Gewährleistung der Qualitätssicherung eingebunden (Art. 63a Abs. 3 BV). Zur Erfüllung dieser Aufgaben haben sie Verträge abzuschliessen und die Befugnisse, die für die Koordination notwendig sind, sind an gemeinsame Organe zu übertragen. Das Bundesgesetz, nicht die Verträge, regelt die Zuständigkeiten, die den gemeinsamen Organen übertragen werden können, und das Gesetz legt die Grundsätze von Organisation und Verfahren der Koordination fest (Abs. 4). Da jedoch der Bundesgesetzgeber allein ja keine gemeinsamen Organe von Bund und Kantonen schaffen kann, bedarf es eines parallelen Konkordates (Hochschulkonkordat) zum Bundesgesetz unter den Hochschulkantonen, welche ihrerseits der Schaffung dieser gemeinsamen Organe zustimmen müssen. Das Dach über die beiden stützenden Pfeiler des Bundesgesetzes und des Konkordates bildet eine Zusammenarbeitsvereinbarung. Erst durch diese Vereinbarung werden die gemeinsamen Organe konstituiert, mit rechtsetzenden und rechtsanwendenden Zuständigkeiten ausgestattet und auf gemeinsame Ziele festgelegt. Gelingt es nun Bund und Kantonen nicht, diese Koordination im Hochschulbereich zustande zu bringen, so erlässt der Bundesgesetzgeber Vorschriften über die Studienstufen und deren Übergänge, über die Weiterbildung und über die Anerkennung von Institutionen und Abschlüssen. Zudem kann der Bund die Unterstützung der Hochschulen an einheitliche Finanzierungs-

${ }^{68}$ Derzeit in Vernehmlassung (iSv Art. 147 BV) befindet sich der Lehrplan für die Deutschschweiz, der Lehrplan 21. (siehe dazu: www.lehrplan.ch). Interessant ist festzustellen, dass auch jene Kantone, die dem HarmoS-Konkordat (Fn. 35) nicht beigetreten sind, sich dennoch auf der Grundlage ihrer kantonalen Gesetzgebung an der gemeinsamen Erarbeitung des Lehrplanes 21 beteiligen.

${ }^{69}$ Gelingt somit die Umsetzung des HarmoS-Konkordates auf diesem ,pragmatischen Weg", so kann von einer gesamtschweizerischen Harmonisierung im Sinne von Art. 62 Absatz 4 BV gesprochen werden. Die Verfassungsbestimmung gibt ja nicht zwingend den Konkordatsweg vor, um das Ziel der Schulharmonisierung zu erreichen.

${ }^{70}$ Zur heutigen Regelung im Bereich der Maturitätsschulen siehe: Ehrenzeller/Sahlfeld (Fn. 53), Rn. 11; Biaggini Kooperativer Föderalismus (Fn. 54), 449 ff.; Plotke (Fn. 31), $103 \mathrm{f}$. 
grundsätze binden und von der Aufgabenteilung zwischen den Hochschulen in besonders kostenintensiven Bereichen abhängig machen (Abs. 5).

In Umsetzung dieses Verfassungsauftrages (Art. 63a Abs. 3-5 BV) verabschiedete die Bundesversammlung am 30. September 2011 das Bundesgesetz über die Förderung der Hochschulen und die Koordination im schweizerischen Hochschulbereich (HFKG) mit klarer Mehrheit. ${ }^{71}$ Liest man das Gesetz, so wird klar, dass der Bundesgesetzgeber tiefe Spuren im schweizerischen Hochschulraum gelegt hat. Dies, wie der Gesetzestitel sagt, in zweifacher Hinsicht: einerseits in Bezug auf die Ziele, die Organisation, die Zuständigkeiten und das Verfahren der gemeinsamen Koordinationsorgane sowie in Bezug auf die gesamtschweizerische hochschulpolitische Koordination und Aufgabenteilung, andererseits in Bezug auf die Finanzierung der schweizerischen Hochschulen. ${ }^{72}$ Aus föderalistischer Sicht von besonderer Bedeutung ist das oberste gemeinsame hochschulpolitische Organ, die Schweizerische Hochschulkonferenz. ${ }^{73}$ Sie tagt als Plenarkonferenz des Bundes und aller Hochschulkonkordatskantone sowie als Hochschulrat, dem neben dem Bildungsminister des Bundes (nur) vierzehn kantonale Bildungsdirektoren angehören (Art. 11/12 HFKG). ${ }^{74}$

71 Die Interkantonale Vereinbarung über den schweizerischen Hochschulbereich (Hochschulkonkordat) ist von der EDK am 20. Juni 2013 verabschiedet worden. Sie befindet sich derzeit im kantonalen Ratifikationsprozess. Die Zusammenarbeitsvereinbarung Bund-Kantone (ZSAV) kann erst geschlossen werden, wenn das Hochschulkonkordat in Kraft getreten ist. Der zwischen beiden Seiten abgestimmte Vereinbarungsentwurf und das Hochschulkonkordat sind einsehbar unter: <www.edk.ch/dyn/11662. php> (abgerufen am 20. September 2013).

72 Nach dem Zweckartikel des HFKG (Art. 1) sorgt der Bund zusammen mit den Kantonen für die Koordination, die Qualität und die Wettbewerbsfähigkeit des gesamtschweizerischen Hochschulbereichs. Es geht demnach nicht um die Koordination der einzelnen Hochschulen, sondern um die gesamtschweizerische Steuerung des Hochschulbereichs.

73 Kritisch zu dieser Bezeichnung: G. Biaggini Entwicklungen und Spannungen im Verfassungsrecht/Versuch einer Standortbestimmung zehn Jahre nach Inkrafttreten der Bundesverfassung vom 18. April 1999, in: Schweizerisches Zentralblatt für Staats- und Verwaltungsrecht (ZB1) 2010 (111), 1 (36). Weitere gemeinsame Organe von Bund und Kantonen sind die Rektorenkonferenz der schweizerischen Hochschulen und der Schweizerische Akkreditierungsrat (Art. 7 lit. b und c HFKG).

74 Während die Plenarversammlung (Art. 11 HFKG) über Fragen zu entscheiden hat, die alle Konkordatskantone betreffen, wie die Festlegung der finanziellen Rahmenbedingungen, so stehen dem kleineren, aber entscheidungsträchtigeren Organ, dem Hochschulrat (Art. 12 HFKG), jene Zuständigkeiten zu, die in erster Linie die Hauptträger der schweizerischen Hochschulen, darunter alle zehn Universitätskantone, betreffen, wie beispielsweise die Vorschriften über die Studienstufen, die institutionelle Akkreditierung der Hochschulen oder die Anerkennung von Abschlüssen. Keine Entscheidungskompetenz hat die Hochschulkonferenz aber in Bezug auf die Hochschulzulassung oder die Studiengebühren. 
Präsidiert werden beide Räte vom Bildungsminister des Bundes (Art. 14 HFKG). Damit kommt dem Bund bei der Steuerung im gesamtschweizerischen Hochschulbereich eine klare Führungsrolle zu. Das Entscheidungsverfahren ist aber so ausgestaltet, dass Beschlüsse der Organe nur zustande kommen, wenn der Bund und die qualifizierte Mehrheit der Kantonsvertreter zustimmen (Art. 16/17 HFKG). ${ }^{75}$ Der Schweizerischen Hochschulkonferenz sind bestimmte rechtsetzende Kompetenzen zur Steuerung des gesamtschweizerischen Hochschulwesens übertragen worden. ${ }^{76}$ Das HFKG als Koordinationsgesetz ist aber nicht ein dem deutschen Hochschulrahmengesetz (HRG) vergleichbares Rahmengesetz zur Regelung der allgemeinen Grundsätze des Hochschulwesens. Vielmehr bleibt es weiterhin den kantonalen Hochschulträgergesetzen ${ }^{77}$ überlassen, die Organisation der Hochschulen festzulegen und die vom Bundesrecht grundsätzlich gewährleistete Autonomie näher auszugestalten. ${ }^{78}$

Nun: Die schweizerische Regelung erscheint sehr komplex. ${ }^{79}$ Die neue Bildungsverfassung setzt in hohem Masse auf das Gelingen von Konkordatslösungen, um eine Bundesregelung zu vermeiden. An diesem soge-

\footnotetext{
${ }^{75}$ Im Hochschulrat bedarf es zusätzlich des Mehrs an Punkten, die den einzelnen Kantonsvertretern gemäss ihren Studierendenzahlen zugeteilt sind (Art. 17 Abs. 1 lit. c HFKG; Art. 7 Hochschulkonkordat).

${ }^{76}$ Deren allgemeinverbindliche Beschlüsse gehen - als unter Mitwirkung der Kantone entstandenes Bundesrecht - den Trägergesetzen der Hochschulkantone vor (so: Ehrenzeller/Sahlfeld (Fn. 53), Rn. 41).

77 Nebst der Koordination in Bezug auf die Eckwerte von Art. 63a Abs. 5 BV war es auch ein wichtiges Ziel der neuen schweizerischen Bildungsverfassung und -gesetzgebung, besser d.h. verlässlicher und berechenbarer als bisher zu gewährleisten, dass Bund und Kantone für den Hochschulbereich ausreichende finanzielle Mittel für Lehre und Forschung von hoher Qualität bereitstellen (Art. 41 HFKG). Dazu zählt neben der Bindung der Grundbeiträge des Bundes an die gemeinsam festgelegten Referenzkosten (Art. 44/49-52 HFKG) auch die Weiterführung der an den realen Studienkosten orientierten interkantonalen Beiträge für Studierende, die nicht an einer kantonseigenen Hochschule studieren (Interkantonale Universitätsvereinbarung (IUV) vom 20. Februar 1997, veröffentlicht u.a. in: ZHlex 415.17).

${ }^{78}$ Zur Hochschulautonomie gemäss Art. 63a Abs. 3 BV/Art. 5 HFKG siehe: B. Ehrenzeller Hochschulautonomie, in: Breitenmoser/Ehrenzeller et al. (Fn. 8), $203 \mathrm{ff}$.

${ }^{79}$ Der Ausgleich zwischen grossen und kleinen Kantonen, zwischen Universitätsund Nichtuniversitätskantonen scheint erst nach intensivem Ringen gefunden worden zu sein. Aus föderalistischer Sicht bemerkenswert ist die Lösung, die schliesslich getroffen worden ist zur Bestimmung der vier Kantonsvertreter im Hochschulrat, welche die sechzehn Nichtuniversitätskantone, die also nur Fachhochschulträger sind, repräsentieren. Entgegen den naheliegenden Bestrebungen einzelner Kantone, ein festes Rotationsprinzip einzuführen, ist es nun die Konferenz aller Vereinbarungskantone, welche diese Vertreter frei bestimmt (Art. 6 Abs. 3 Hochschul-Konkordat).
} 
nannten „Konkordatsföderalismus" 80 wird teilweise heftig kritisiert, dass er eine Art Zwangsjacke darstelle für nicht willige Kantone, dass er demokratisch wenig legitimiert und schwer veränderbar sei, dass er mit den Koordinationsorganen eine neue staatsrechtliche Ebene einbaue und letztlich auch nicht geeignet sei für die Lösung gesamtstaatlicher Probleme. Darauf wird am Schluss zurückzukommen sein. ${ }^{81}$

\section{Zusammenfassender Vergleich}

Fassen wir den deutsch-schweizerischen Vergleich der beiden föderalistischen Bildungsverfassungen zusammen, so erkennen wir Gemeinsamkeiten, aber auch erhebliche Unterschiede. Gemeinsam ist die verfassungsrechtliche Ausgangslage: Die Bildungshoheit liegt bei den Kantonen resp. Ländern. Geblieben, ja in der Bedeutung verstärkt worden, ist die gliedstaatliche Selbstkoordination und damit der horizontale kooperative Föderalismus. ${ }^{82}$ Den beiden Institutionen der Selbstkoordination der Länder und Kantone im Bildungsbereich, der KMK respektive der EDK, kommt eine zentrale Bedeutung zu, wobei die EDK als solche vertraglich stärker abgestützt ist. ${ }^{83}$ Unterschiedlich ausgestaltet sind dagegen die

${ }^{80}$ Biaggini Standortbestimmung (Fn. 73), 1 ff. und Biaggini Schulkoordination (Fn. 54), $380 \mathrm{ff}$.

81 Die kritischen Stimmen gegenüber dem „Konkordatsföderalismus“ beziehen sich nicht nur auf den Bildungsbereich. Eine ähnliche Entwicklung spielt sich auch im Sicherheits- und im Gesundheitsbereich ab, beispielhaft hierfür etwa das HooliganKonkordat (Konkordat über Massnahmen gegen Gewalt anlässlich von Sportveranstaltungen vom 15. November 2007 mit Änderungen vom 2. Februar 2012, veröffentlicht u.a. in: sSG 451.51), siehe dazu auch „Bericht des Bundesrates in Erfüllung des Postulats Malama 10.3045 vom 3. März 2010 Innere Sicherheit. Klärung der Kompetenzen“, vom 2. März 2012, in: BBl 2012 4459, 4482, 4573, 4588, oder im Bereich der Spitzenmedizin das Konkordat über die Koordination der Konzentration der Hochspezialisierten Medizin (HSMKO, online: <http://www.gdk.cds.ch/fileadmin/docs/public/gdk/Themen/ HSM/01_IVHSM_CIMHS_14032008_d.pdf> abgerufen am 20. September 2013). Zudem sieht das schweizerische Bundesgesetz über die Krankenversicherung (KVG) vom 18. März 1994 (SR 832.10) in Art. 39 Abs. $2^{\text {bis }}$ KVG ebenfalls eine subsidiäre Bundeskompetenz vor, wonach im Bereich der hochspezialisierten Medizin, wenn die Kantone sich nicht hinsichtlich einer gesamtschweizerischen Planung einigen, der Bundesrat festlegt, welche Spitäler für welche Leistungen auf den kantonalen Spitallisten aufzuführen sind.

${ }^{82}$ Der Bundesverfassungsgeber hat sogar für die interkantonale Zusammenarbeit einen eigenen Verfassungsrahmen geschaffen (Art. 48/48a BV).

$83 \mathrm{Vgl}$. vor allem Art. 1 des HarmoS-Konkordates (Fn. 35). In zahlreichen interkantonalen Vereinbarungen kommt der EDK eine institutionelle Koordinationsrolle zu, beispielsweise in Art. 13 ff. des HarmoS-Konkordates (Fn. 35) und im Hochschulkonkordat (Fn. 71). Demgegenüber verfügt die KMK nur über eine Vereinbarung (Abkom- 
Rolle des Bundes und die vertikale Mitwirkung der Gliedstaaten im Bildungsbereich. ${ }^{84}$

Der grundsätzliche Unterschied in der föderalistischen Ausgestaltung der beiden Bildungsverfassungen ist aber vor allem konzeptioneller Natur. Die Bundesverfassung verortet die Verantwortung von Bund und Kantonen für die Bildung in einen gemeinsamen und umfassend koordinierten Bildungsraum Schweiz. Dieser ist differenziert ausgestaltet nach Bildungsstufen und Koordinationszielen. ${ }^{85}$ Die Schweiz hat also nicht einfach eine neue Zuständigkeitsverteilung vorgenommen, sondern vor allem im Hochschulbereich einen eigenen Governanceansatz gewählt und das Regieren im Mehrebenensystem verfassungsrechtlich verankert. ${ }^{86}$ Angestrebt wird nicht ein Gesamtplan, wohl aber eine Gesamtsicht des Bildungswesens. Gleichzeitig hat der Bundesgesetzgeber Grundsätze der Finanzierung des Hochschulbereichs durch Bund und Kantone aufgestellt. ${ }^{87}$ Durch diese Verbindung von Sach- und Finanzkompetenzen soll

men über das Sekretariat der Ständigen Konferenz der Kulturminister der Länder in der Bundesrepublik Deutschland vom 20. Juni 1959 sowie Abkommen über den Beitritt der neuen Staaten vom 25. Oktober 1991 online: <http://www.kmk.org/fileadmin/ veroeffentlichungen_beschluesse/1959/1959_06_20_Abkommen-KMK.pdf $>$ abgerufen am 20. September 2013). Zum Vergleich von KMK und EDK siehe: D. Braun Hochschulföderalismus zwischen Kooperationszwang und Blockadegefahr - Deutschland und die Schweiz im Vergleich, Swiss Political Science Review Sonderheft 2010 (Hochschulpolitik/Berufsbildungspolitik), 715 (723 ff.).

${ }^{84}$ Der schweizerische Bundesgesetzgeber verfügt, von der Berufsbildung und der Weiterbildung abgesehen, über keine konkurrierenden Bildungskompetenzen. Ein Abweichungsrecht, analog Art. 72 Abs. 3 GG, ist der Bundesverfassung fremd. Auch sieht die Bundesverfassung nicht vor, dass bestimmte Bereiche vertraglich zwischen Bund und Kantonen geregelt werden (analog zu Art. 91b GG). Dagegen verfügt der Bund über eine parallele Forschungsförderungskompetenz im Hochschulwesen (Art. 64 BV). Von zentraler Bedeutung ist auch der SNF (Statuten, online: <http://www.snf.ch/ SiteCollectionDocuments/statuten_08_d.pdf > abgerufen am 20. September 2013), der zur Hauptsache mit Bundesgeldern finanziert wird.

${ }^{85}$ Der Bildungsraum umfasst alle Bildungsstufen von der Grundschule bis zur Hochschule. Die in Deutschland bestehende Harmonisierungslücke wird auch als „Bildungsschisma" bezeichnet: vgl. Amos (Fn. 6), 29.

${ }^{86}$ Braun Hochschulföderalismus (Fn. 83).

${ }^{87}$ Als Ziel des koordinierten Hochschulraumes Schweiz nennt Art. 3 lit. g HFKG die „Finanzierung der Hochschulen nach einheitlichen und leistungsorientierten Grundsätzen“. Abschnitt 7 des Gesetzes ist dementsprechend der „Finanzierung“ gewidmet. Wichtige Pfeiler der Hochschulfinanzierung bilden auch künftig die interkantonalen Hochschulbeiträge gemäss Interkantonaler Universitätsvereinbarung (Fn. 77) und Interkantonaler Fachhochschulvereinbarung (FHV) ab 2005 vom 12. Juni 2003 (veröffentlicht ua. in: ZHlex 414.12), worauf Art. 11 des Hochschulkonkordates (Fn. 71) verweist. 
gerade vermieden werden, dass der Bund im Mehrebenensystem zwar keine Sachkompetenzen hat, aber über die „goldenen Zügel“ (Anreizstrukturen $)^{88}$ das Hochschulwesen dennoch weitgehend steuert. ${ }^{89}$

Deutschland dagegen hat gerade einen andern Schluss aus der vergangenen Entwicklung des Bildungsföderalismus gezogen: Geprägt von der Erfahrung, dass Bundesregelungen zu Einheitlichkeitsformeln führen, hat Deutschland im Zeichen der Reföderalisierung der Bildung bei der Föderalismusreform I, jedenfalls formal, eine Kompetenz- und Politikentflechtung vorgenommen und Bundeskompetenzen zu Gunsten der Länder abgebaut. ${ }^{90}$ Jedenfalls vom Grundgesetz her scheint der Bund aus der Bildungsverantwortung weitgehend entlassen zu sein.

\section{Gesamtwürdigung: Die Zukunftsfähigkeit des Bildungsföderalismus}

Der Bildungsföderalismus auf dem Prüfstand!

Einer bildungspolitischen Notwendigkeit entspringt der Bildungsföderalismus ja nicht, wohl aber dem staatspolitischen Interesse an der Erhaltung der Bildungshoheit der Länder und Kantone als eines Kernbereichs föderaler Gestaltungsmacht. Eine umfassende Zentralisierung der Gesetzgebung im gesamten Bildungsbereich würde zweifellos in beiden Staaten, in der Schweiz als multikultureller Nation in besonderem Masse, ein Herzstück aus dem föderalistischen Gefüge herausbrechen..$^{91}$ Auch eine Bildungsrahmenordnung des Bundes, wie sie von bildungsföderalismuskritischen Stimmen, so schon von Peter Saladin an der Staatsrechtslehrertagung 1972, gefordert worden ist, würde die gliedstaatliche Eigen-

${ }_{88}$ Schuppert (Fn. 14), Rn. 54. Zum Steuerungsbegriff: A. Benz Steuerung im Bildungswesen - begrenzte Notwendigkeit und notwendige Begrenzung (Fn. 11), 15.

${ }^{89}$ Zur unterschiedlichen Regelung der Bildungsfinanzierung in Deutschland und der Schweiz sowie zum Zusammenhang von Steuerautonomie und Bildungsausgaben: siehe $J$. Wieland Ist Bildung eine Gemeinschaftsaufgabe? Verfassungsrechtliche Aspekte, in: Schultz/Hurrelmann (Fn. 2), 54 ff. Auf den wichtigen Zusammenhang von Föderalismus und Finanzverfassung "als aufeinander bezogene dynamische Systeme" weist Schuppert (Fn. 14), Rn. 44 ff.

${ }_{90}$ Zweifel an echter Entflechtung und substanzieller Kompetenzverlagerung: T. Hoymann/U. Münch Föderalismusreform 1969: Warum die Länder ihre Hochschulgesetzgebungskompetenz dem Bund überliessen und in der Föderalismusreform 2006 (teilweise) wieder zurückholten, in: Jahrbuch des Föderalismus: Föderalismus, Subsidiarität und Regionen in Europa, 2011, 205 ff.; M. Heintzen in: Starck (Fn. 49), 49 f.; auch F. Scharpf Tagungsprotokolle (Fn. 11), 25.

${ }^{91}$ Nach der Rechtsprechung des Bundesverfassungsgerichts muss den Ländern im Bereich von Bildung und Kultur ein substanzielles Mass an Hausgut verbleiben (Oeter Integration und Subsidiarität (Fn. 19), 582). 
verantwortung deutlich erlahmen lassen. ${ }^{92}$ Wenig überzeugend sind aber auch jüngst wieder lauter gewordene deutsche Stimmen, welche die Bildungskompetenzen, auch im Hochschulbereich, den Ländern vollständig zurückgeben und den Wettbewerbsföderalismus etablieren möchten. ${ }^{93}$ Die Idee einer durchgehenden Föderalisierung des Bildungsbereichs verkennt die Entwicklung, die Dynamik wie auch die Besonderheiten der Bildungspolitik. Die Länder - die Kantone sowieso - wären weder sachlich noch finanziell in der Lage, die gesamte Bildungsverantwortung allein zu tragen. ${ }^{94}$ Es ist nicht zu übersehen: Deutschland und die Schweiz sind heute nationale Bildungsräume, die ihrerseits Teil sind des europäischen Bildungs-, Hochschul- und Forschungsraumes. Das bedeutet aber auch, dass es in wichtigen Fragen einer national koordinierten Bildungspolitik bedarf. Dazu ist eine, wie auch immer ausgestaltete, Regelungsstruktur im Mehrebenensystem nötig. Die Kernfrage ist also: Sind die bildungsföderalistischen Institutionen dafür geeignet, die beschränkten Steuerungsmöglichkeiten in der Bildungspolitik wirksam wahrzunehmen?

Grundlage jeder föderalistischen Ordnung ist die Zuständigkeitsregelung. Deutschland hat sich für eine weitgehende Verantwortungszuweisung zu Gunsten der Länder entschieden, wogegen die Schweiz die horizontale und vertikale Politikverflechtung verfassungsrechtlich geradezu verankert hat. Politikverflechtung an sich ist aber weder gut noch schlecht und jedenfalls im Bildungsbereich unvermeidbar. ${ }^{95}$ Entscheidend dürfte letztlich nicht sein, was und wie viel die Gliedstaaten allein entscheiden können. Ausschlaggebend ist vielmehr, ob die Handlungs-und Entscheidungsfähigkeit von Bund und Gliedstaaten bei ihrer Aufgabenerfüllung, trotz Politikverflechtung, gewahrt ist. ${ }^{96}$ Es ist wenig wahrscheinlich, dass Deutschland mit der neuen Ordnung den Ausbruch aus der „extremen Politikverflechtung" in der Bildungspolitik wirklich geschafft hat. Jeden-

92 P. Saladin Aussprache zu Gemeinschaftsaufgaben im Bundesstaat, VVDStRL 31 (1972), 85 (93 ff.), sowie Holzwege des kooperativen Föderalismus, in: Festschrift Bundesrat H. P. Tschudi: zum 60. Geburtstag, 1973, 237 ff. (251). Vgl. auch bei Criblez (Fn. 8), 294.

${ }^{93}$ Stern (Fn. 17), $20 \mathrm{f}$.

${ }^{94}$ Eine solche Entflechtung wäre daher auch wenig realistisch. Vgl. Braun Reform und Entscheidungsblockaden (Fn. 19), 329 ff.

95 Oeter Gesetzgebung (Fn. 18), 562 f. weist auf die „hohe systemische Rationalität“ hin. Die „Mehrebenenverflechtung“ sichere ein „multistabiles“ Gleichgewicht der Entscheidungsstrukturen.

96 Oeter Gesetzgebung (Fn. 18), 398, spricht in diesem Zusammenhang von einem Paradigmenwechsel: Das neue Paradigma sei eine gesamtstaatliche - auf Bund und Länder aufgeteilte - Aufgabenerfüllung. Siehe auch Derselbe Integration und Subsidiarität (Fn. 19), 398 sowie Meyer-Hesemann (Fn. 13), 16 ff. 
falls werden Zweifel an der angestrebten Wirkung der Föderalismusreform I geäussert. ${ }^{97}$ Die Zusammenarbeit dürfte auf eine andere Ebene, auf intergouvernementale Verhandlungsformen, verlagert worden sein, was eine neue Politikverflechtung zur Folge hat.

Der von der Schweiz gewählte formelle Weg der interkantonalen Harmonisierungspflicht des Schulwesens setzt auf die Kraft und die Eigenverantwortung der Kantone, setzt sie aber auch unter den faktischen Zwang des Mitmachens. Ein Abseitsstehen kann für einen Kanton negative Folgen haben. ${ }^{98}$ Gelingt den Kantonen die Harmonisierung nicht oder nicht glaubwürdig genug, was letztlich in der Beurteilungskompetenz der Bundesversammlung liegt, so fallen die Schranken für den Bundesgesetzgeber. ${ }^{99}$ Dieser latente Druck - gewissermassen „im Schatten der Hierarchie"100 - mag auf den ersten Blick föderalismusfeindlich erscheinen, ist aber von den Kantonen gerade deshalb akzeptiert worden, weil er konsensfördernd wirkt und die widerstrebenden institutionellen Eigeninteressen besser in einen nationalen Entscheidungsprozess einbindet. ${ }^{101}$

Deutlich schwieriger gestaltet sich die Herausforderung im Hochschulbereich. Zweifellos hängt das neu vorgesehene Entscheidungsverfahren

97 Braun Hochschulföderalismus (Fn. 83) bezeichnet die Föderalismusreform als „Entflechtung und Beibehaltung der Verflechtung“. Immerfall (Fn. 40), 210 spricht von einer fortbestehenden dilemmatischen Verschränkung von Ausgleich verschiedener Schulpolitiken der Länder einerseits und Bedürfnis nach gemeinsamer Wahrnehmung der gesamtstaatlichen Verantwortung andererseits (200). In diesem Sinne auch Guckelberger (Fn. 43), Rn. 67; Scholz in: Baus/Blindenbacher/Karpen (Fn. 18), 93 f. und Hellermann (Fn. 49), Rn. 57, 67.

98 Criblez (Fn. 8), 286 ff.

99 Kommt die erforderliche Koordination im Schulwesen nicht zustande, so verpflichtet die BV den Bundesgesetzgeber zum Handeln (Art. 62 Abs. 4/63a Abs. 5 BV). Die Feststellung, ob und wieweit diese Voraussetzung erfüllt ist, liegt allerdings im Ermessen der Bundesversammlung, die eine Gesamtbeurteilung vornehmen wird. Vgl. WBK-N, Bildungsverfassung, BBl 20055505 f., 5522, 5529 f. Es erscheint deshalb auch nicht zwingend, dass alle Kantone dem Konkordat beitreten. Es genügt auch ein faktisches Mitmachen bei der Harmonisierung.

100 R. Mayntz/F.W. Scharpf Gesellschaftliche Selbstregelung und politische Steuerung, 1995, 28. Braun Hochschulföderalismus (Fn. 83), 726 spricht paraphrasierend von Schatten der Bundeslösung.

101 Darin liegt ja auch, im Sinne von Hesse (Fn. 26) der gewaltenteilende Aspekt der gliedstaatlichen Zusammenarbeit. So auch M. Große Hüttmann/J. Schmid Das Thema Bildungspolitik und die Perspektiven der Föderalismus-Forschung, in: Hrbek/Hüttman/Schmid (Fn. 6), 229 ff. Den Kantonen scheint es mit dem HarmoS-Konkordat (Fn. 35) auch tatsächlich gelungen zu sein, verschiedene politische Bestrebungen zur punktuellen Bundesregelung im Volksschulbereich, beispielsweise beim Fremdsprachenunterricht, neuerdings auch beim Musikunterricht (siehe Fn. 65) abzuwenden, vgl. Ehrenzeller HarmoS (Fn. 65), 28 f. 
der gemeinsamen Organe in hohem Masse davon ab, wie überzeugend der Bund seine Führungsrolle wahrnimmt und wie sich die Kantone einzubringen vermögen. Entscheidungsblockaden in den gemeinsamen Organen sind zwar nicht unmöglich, aber aufgrund des qualifizierten Mehrs an Kantonsstimmen doch wenig wahrscheinlich. Dennoch bleibt letztlich der Notausgang aus der Politikverflechtungsfalle über eine mögliche Bundesregelung offen.

Im Vergleich zur formal klaren Verantwortungszuweisung in Deutschland ist der schweizerischen Bildungsordnung mangelnde demokratische Legitimation vorgeworfen worden. ${ }^{102}$ Die Kritik erstaunt insofern, als ja mit der Bildungsverfassung dafür gerade eine verfassungsrechtliche Basis gelegt worden ist. Sowohl das HarmoS-Konkordat wie das Hochschulkonkordat haben den ordentlichen Genehmigungsprozess durch die kantonalen Parlamente, unter Einschluss der Referendumsmöglichkeit, durchlaufen oder er steht noch bevor. ${ }^{103}$ Sind Bund und Kantone in der Gestaltung der Bildungspolitik unausweichlich aufeinander angewiesen, so ist dem Gebot von Demokratie und Rechtsstaatlichkeit mehr Genüge getan, wenn dafür politisch verantwortliche Institutionen und formelle Entscheidungsverfahren geschaffen werden, als wenn dieser Prozess weitgehend der informellen Mitwirkung überlassen wird.

Die kritischen Stimmen bemängeln auch den starken Exekutivföderalismus und die fehlende Entscheidungsfreiheit der parlamentarischen Genehmigungsverfahren bei Konkordaten. Der Bildungsbereich wird allerdings seit jeher weniger über materielle Rechtsnormen als über Organisationserlasse, damit exekutiv, bestimmt. Das wäre im Falle einer bun-

102 Kritisch A. Auer Ein wachsendes Unbehagen, Vorwort, in: Auer (Fn. 64), der von einem „chronischen demokratischen Defizit“ spricht. Vgl. auch in demselben Band: Biaggini Föderalismus Quo vadis (Fn. 64) sowie Derselbe Kooperativer Föderalismus (Fn. 54).

103 Vgl. Ehrenzeller HarmoS (Fn. 66), 33 f. und Ehrenzeller/Reisner (Fn. 15), 229 ff. Der unter demokratischem Gesichtspunkt wohl heikelste Punkt ist die Frage der Veränderbarkeit des einmal Beschlossenen. Bundesgesetze wären leichter abänderbar als Verträge unter vielen Kantonen. Angesichts ihrer Dynamik muss auf der einen Seite vermieden werden, dass Bildungspolitik zum föderalistischen Experimentierfeld wird. Auf der andern Seite ist die neue bildungsföderalistische Ordnung längerfristig nur tragfähig, wenn es in ihrem Rahmen gelingt, Schwächen oder Fehlentwicklungen des Systems oder einzelner Steuerungselemente, beispielsweise der Bildungsstandards oder der Lernpläne, rechtzeitig zu erkennen und die notwendigen Verbesserungen tatsächlich an die Hand zu nehmen. Vgl. auch $V$. Martenet HarmoS dans le paysage fédéraliste et démocratique suisse, in: Auer (Fn. 64), 102 f. Für die Frage der Revidierbarkeit von beschlossenen Koordinationslösungen sind deshalb nicht nur die Vertragsgrundlagen relevant, sondern ebenso, wenn nicht noch stärker die Umsetzungsbeschlüsse und -massnahmen. 
desgesetzlichen Regelung nicht anders. Auch ist die Bildungspolitik schon immer durch differenzierte demokratische Legitimationsverfahren und unterschiedliche kritische Öffentlichkeiten gekennzeichnet. ${ }^{104}$ So gesehen, sind mit der Bildungsverfassung und den referendumsfähigen Koordinations- und Steuerungserlassen eher mehr öffentlicher Diskurs und mehr demokratische Mitsprache als bisher ermöglicht worden.

Wie zukunftsfähig, ja wie zukunftsweisend ist nun also der Bildungsföderalismus? Vielleicht ist es gar nicht schlecht, dass wir heute nicht mit einem definitiven „Ja“ oder „Nein“ antworten können. Der Bildungsföderalismus ist offensichtlich im Wandel begriffen, was mit Chancen für innovative Lösungen, aber auch mit Unsicherheiten und Risiken verbunden ist. Nicht alles ist rechtlich fassbar in den herkömmlichen bundesstaatsrechtlichen Kategorien. Die föderalistische Kultur wird zum Tragen kommen müssen, wozu, in den treffenden Worten von Denis de Rougement, „'amour de la compléxité" mit dazu gehört. ${ }^{105}$ Die jeder föderalistischen Ordnung inhärente Spannung zwischen Vielfalt und Einheit, Subsidiarität und Integration müssen Bund und Kantone ertragen und wollen. Wenn Subsidiarität bedeutet, im Bildungsbereich mehr Freiheit, mehr politischen und pädagogischen Gestaltungsfreiraum, mehr und differenzierte demokratische Mitwirkung, soziale Einbindung und Nähe zum realen Bildungsgeschehen zu ermöglichen, wenn föderale Vielfalt eher dazu führt, aus unterschiedlichen Lösungen und aus Fehlentwicklungen gegenseitig zu lernen und Neues zu entwickeln, dann hat gerade der Bildungsföderalismus mehr innere Rechtfertigung als die zentralistische einheitliche Regelung. Gleichzeitig ist im Bundesstaat die Wahrung der gesamtstaatlichen Interessen nicht allein Sache des Bundes. Die Berechtigung gesamtstaatlicher Koordination und Vereinbarungen zwischen den Gliedstaaten untereinander oder mit dem Bund beurteilt sich daher letztlich auch daran, wie sehr es den Ländern und den Kantonen gelingen wird, in gemeinsamem Ringen untereinander und mit dem Bund den bildungspolitischen Gesamtinteressen Geltung zu verschaffen. Eine grosse Herausforderung mit Unwägbarkeiten zweifellos. Doch föderaler Wille und Erfahrungsschatz zu deren Bewältigung sollten nicht unterschätzt werden.

${ }^{104}$ So sind der öffentliche Diskurs, die Betroffenenbeteiligung und Autonomiegewährung, aber auch die soziale Einbindung wichtige Ausprägungen demokratischer Legitimation im Bildungswesen. In diesem Sinne beispielsweise Oeter Gesetzgebung (Fn. 18), 397.

105 Denis de Rougemont Les maladies de l'Europe (Vortrag vom 8.9.1946), abgedruckt in: L'Europe en jeu (1948), 29 ff. 
Leitsätze des 1. Referenten über:

\section{Der Bildungsföderalismus auf dem Prüfstand}

\section{I. (In-)Fragestellung}

(1) Bildungsföderalismus ist kein Begriff des Verfassungsrechts. Bildungsföderalismus soll nachfolgend verstanden werden als verfassungsrechtliche Zuständigkeit der bundesstaatlichen Organe zur Gestaltung der Bildungspolitik.

II. Veränderungsprozess im Bereich von Bildung und Föderalismus

1. Veränderungsdynamik im Bildungsraum

(2) Es ist zu einer Entgrenzung der Bildungspolitik in vertikaler und horizontaler Richtung gekommen: vertikal im Sinne der Europäisierung und Globalisierung bei gleichzeitiger Autonomisierung der Schulen, horizontal im Sinne der Verschmelzung der Bildungspolitik mit andern Gesellschaftspolitiken. Gleichzeitig stehen wir mitten in einem Prozess der Expertisierung und Ökonomisierung des Bildungsbereichs.

(3) Diese Entwicklung hat zu neuen bildungspolitischen Strukturbildungen - zu einer eigenen "Educational Governance» - geführt. Unabhängig von verfassungsrechtlichen Zuständigkeitsordnungen sind lokale, regionale, nationale und internationale Bildungsräume entstanden, in denen unterschiedliche Akteure, Institutionen und Funktionen in ihrer jeweiligen Eigenlogik aufeinandertreffen.

(4) Durch grossangelegte Leistungsevaluationen wie die PISA-Studien entstehen enorme Datenvergleichsmengen, die zu mehr Transparenz und höherer Rationalität des Bildungssystems führen (Stichwort: Empirische Wende). Diese Leistungsvergleiche bewirken zwischen und innerhalb der Staaten eine eigene Dynamik und stellen die bildungspolitischen Behörden unter Rechtsfertigungs- und Anpassungsdruck. 
2. Gewandelter Föderalismus

(5) Die offenbar unaufhaltsame Entwicklung zum gubernativen Mitwirkungsföderalismus geht einher mit einer diffusen Verantwortungsverteilung und mit starker Politikverflechtung zwischen Bund und Gliedstaaten. Ziel der jüngeren Föderalismusreformen in Deutschland und der Schweiz war deshalb die Stärkung der Eigenstaatlichkeit und Eigenverantwortlichkeit der Länder und Kantone.

(6) Trotz hoher Vergleichbarkeit der Föderalismusentwicklung der beiden Staaten dürfen die Unterschiede nicht übersehen werden: die Schweiz ist als dezentraler und direktdemokratischer, Deutschland als unitarischer und repräsentativer Bundesstaat konzipiert: in der Schweiz ist die Schaffung von Rechtseinheit durch Bundeslösung politisch begründungspflichtig, wogegen dem deutschen Föderalismus eine rechtsvereinheitlichende Dynamik innewohnt.

\section{Der Bildungsföderalismus in Deutschland und in der Schweiz}

\section{Allgemeine Entwicklung}

(7) Im Unterschied zur allgemeinen Föderalismusentwicklung ist es im Bildungsbereich gewissermassen zu einem umgekehrten Mitwirkungsföderalismus gekommen. Die bundesstaatsrechtliche Gleichstellung der Gliedstaaten bedeutet im Bildungswesen, dass - trotz aller faktischen Unterschiedlichkeiten - Bildungsleistungen von gleichwertiger Qualität erbracht werden.

(8) Angesichts der Dynamik der Bildungspolitik konnte eine Zentralisierung der Bildungskompetenzen nur durch eine forcierte Selbstkoordination der Gliedstaaten verhindert werden. Die Bildungsföderalismusdebatte reibt sich seit den vergangenen 60er Jahren vor allem an der unausweichlichen Rolle des Bundes als Mitfinanzierer und Mitgestalter des Hochschulbereichs. Dabei haben die Schweiz und Deutschland unterschiedliche Wege beschritten.

\section{2. $\quad$ Der deutsche Bildungsföderalismus}

(9) Durch die Föderalismusreform I sind die Bundeskompetenzen im Hochschulbereich (Gemeinschaftsaufgaben und Erlass allgemeiner Grundsätze des Hochschulwesens) formal weitgehend den Ländern zurückübertragen worden, ausser im Bereich der Hochschulzulassung und der Hochschulabschlüsse (Art. 74 Abs. 1 Ziffer 33 GG). Das Abweichungsrecht, das den Ländern neu gegenüber Bundesregelungen in diesen beiden Bereichen zusteht (Art. 73 Abs. 3 Ziffer 6 GG), ist eine tückenreiche föderalistische 
Innovation: es besteht die Gefahr der Rechtszersplitterung oder der paktierten Bundesgesetzgebung.

\section{Der schweizerische Bildungsföderalismus}

(10) Mit der neuen Bildungsverfassung der Schweiz vom 21. April 2006 werden Bund und Kantone zu einem koordinierten Bildungsraum Schweiz verbunden. Sie sorgen gemeinsam für eine hohe Qualität und Durchlässigkeit des Bildungsraumes und sie sind zur Koordination und Zusammenarbeit verpflichtet (Art. 61a BV). Zwei grundlegende, zuständigkeitsrelevante Neuerungen kennzeichnen die schweizerische Bildungsverfassung: das Konzept der koordinierten, nach Bildungsstufen differenzierten und auf bestimmte Eckwerte bezogenen Steuerung des gesamtschweizerischen Bildungswesens sowie das Konzept der subsidiären, beschränkten Bundeskompetenzen.

(11) Auf der Grundschul- und Sekundarschulstufe trifft die Kantone eine auf die verfassungsrechtlichen Eckwerte bezogene Harmonisierungspflicht (Art. 62 Abs. 4 BV). Gelingt ihnen diese Koordination nicht, so kann der Bund die notwendigen Vorschriften erlassen. Mit dem HarmoS-Konkordat ist den Kantonen die erforderliche Harmonisierung im Grundschulbereich weitgehend gelungen: auch die 11 (der 26) Kantone, die dem Konkordat nicht beigetreten sind, richten ihre kantonale Bildungsgesetzgebung am gemeinsamen Harmonisierungsstandard aus und arbeiten im Vollzug mit den andern Kantonen zusammen. Schwieriger erweist sich die Harmonisierung der Maturitätsstufe.

(12) Im Hochschulbereich haben Bund und Kantone qua Verfassung die Koordination des gesamtschweizerischen Hochschulbereichs durch gemeinsame Organe zu gewährleisten. Die zwei Säulen - das Bundesgesetz über die Förderung der Hochschulen und die Koordination im Hochschulbereich (HFKG) sowie die Interkantonale Vereinbarung über den schweizerischen Hochschulbereich (Hochschulkonkordat) - stehen fest resp. befinden sich im kantonalen Ratifikationsprozess. Das übergreifende Dach bildet die Vereinbarung zwischen dem Bund und den Konkordatskantonen über die Zusammenarbeit im Hochschulbereich (Zusammenarbeitsvereinbarung). Bringen die gemeinsamen Organe die gesamtschweizerische Koordination nicht zustande, so verfügt der Bund im Hochschulbereich über das Recht, die auf die verfassungsrechtlichen Eckwerte bezogenen bundesgesetzlichen Vorschriften zu erlassen.

(13) Das zentrale politische Koordinationsorgan ist die Schweizerische Hochschulkonferenz. Sie steht unter Leitung des Bundes. Beschlüsse kommen jedoch nur zustande, wenn der zuständige Bundesrat und die qualifizierte Mehrheit der Kantonsvertreter zustimmen. 
(14) Die schweizerische Bildungsverfassung baut in hohem Masse auf das Gelingen von Konkordatslösungen. An diesem sogenannten "Konkordatsföderalismus» wird kritisiert, dass er für die Kantone eine "Zwangsjacke» darstelle, demokratisch wenig legitimiert sei und mit den Koordinationsorganen eine neue staatsrechtliche Ebene einbaue. Letztlich seien gesamtschweizerische Konkordate nicht geeignet für die Lösung gesamtschweizerischer Probleme.

\section{Zusammenfassender Vergleich}

(15) Deutschland und die Schweiz haben unterschiedliche Schlüsse aus der Entwicklung des Bildungsföderalismus der letzten Jahrzehnte gezogen. Der Hauptunterschied der beiden Bildungsverfassungen ist konzeptioneller Natur: die Bundesverfassung stellt die gemeinsame Sorge von Bund und Kantonen für einen koordinierten Bildungsraum Schweiz in den Vordergrund und sieht dafür einen nach Bildungsstufen differenzierten Governanceansatz vor. In Deutschland dagegen ist mit der Föderalismusreform I die formale Kompetenzverschränkung gerade entflochten und damit die Länderverantwortung für das Bildungswesen stark aufgewertet worden. Der Bund scheint aus der Bildungsverantwortung weitgehend entlassen zu sein.

\section{Gesamtwürdigung: die Zukunftsfähigkeit des Bildungsföderalismus}

(16) Eine Zentralisierung der Bildungskompetenzen würde in beiden Bundesstaaten ein Herzstück aus dem föderalistischen Gefüge herausbrechen. Eine stark vereinheitlichende und die gliedstaatliche Eigenverantwortung schwächende Wirkung hätte auch eine Bildungsrahmenordnung des Bundes.

(17) Eine vollständige Rückverlagerung der Bildungsverantwortung in die Kantone und Länder wird der Dynamik der Bildungspolitik nicht gerecht. Diese wären weder sachlich noch finanziell in der Lage, diese Verantwortung im gesamten Bildungsbereich allein, ohne Bund, wahrzunehmen.

(18) Kernfrage ist, ob die bildungsföderalistischen Institutionen geeignet sind, die beschränkten Steuerungsmöglichkeiten in der Bildungspolitik wirksam wahrzunehmen. Die Zukunftsfähigkeit des Bildungsföderalismus beurteilt sich nicht danach, was und wie viel die Gliedstaaten allein entscheiden können, sondern ob - trotz unvermeidbarer Politikverflechtung - die Handlungs- und Entscheidungsfähigkeit von Bund und Gliedstaaten bei ihrer Aufgabenerfüllung gewahrt ist.

(19) Der tatsächliche Ausbruch aus der Politikverflechtung im Bildungsbereich dürfte mit der Föderalismusreform I kaum gelungen sein: dem Ab- 
bau an formaler Kompetenzverschränkung steht das erhöhte Gewicht neuer Formen der intergouvernementalen Politikverflechtung gegenüber.

(20) Die in der schweizerischen Bildungsverfassung verankerte Koordinations- und Zusammenarbeitspflicht, ergänzt durch die subsidiären Bundeskompetenzen, baut auf die Kraft und Eigenverantwortung der Kantone, setzt sie aber unter Konsensdruck und bindet deren institutionelle Eigeninteressen in einen nationalen Entscheidungsprozess ein.

(21) Mit der Schaffung politisch verantwortlicher Institutionen und der Verankerung formeller Entscheidungsprozesse wird der Forderung nach stärkerer demokratischer Legitimierung der Bildungspolitik mehr Genüge getan als mit der Erhöhung der informellen Mitwirkungsmöglichkeiten von Bund und Gliedstaaten.

(22) Wie zukunftsfähig die neuen bundesstaatsrechtlichen Wege sind, die Deutschland und die Schweiz im Bildungsföderalismus beschritten haben, lässt sich heute nicht definitiv beantworten. Doch besteht Grund zur Annahme, dass der Weg des Bildungsföderalismus besser als die zentralistische Lösung geeignet ist, politische und pädagogische Gestaltungsfreiräume zu sichern sowie mehr demokratische Mitwirkung und soziale Einbindung zu ermöglichen, und auch eher dazu führt, aus unterschiedlichen Lösungen und aus Fehlentwicklungen zu lernen. Letztlich wird die Zukunft des Bildungsföderalismus stark davon abhängen, ob es den bildungsföderalistischen Institutionen gelingen wird, den bildungspolitischen Gesamtinteressen Geltung zu verschaffen. 

Erster Beratungsgegenstand:

\section{Der Bildungsföderalismus auf dem Prüfstand}

2. Referat von Professorin Dr. Astrid Wallrabenstein, Frankfurt/Main*

Inhalt

Seite

I. Föderalismusreform und Bildungsföderalismus . . . . . . . . 42

1. Reföderalisierung der Bildungspolitik? . . . . . . . . . . . 42

a. Föderalismus und „Unitarismus“. . . . . . . . . . . . . 42

b. Gemeinsam gegen den Bund . . . . . . . . . . . . . 46

2. Erklärungsangebote ................ . . . 50

a. Föderale Unitarisierungsinstitutionen . . . . . . . . 50

b. Gemeinsame Diagnose - unterschiedliche Therapieansätze........................ 51

II. Gemeinsamer Nenner: Wettbewerb. . . . . . . . . . . . 55

1. Bildungswettbewerbsföderalismus . . . . . . . . . . . 55

a. Wettbewerb im Bildungswesen . . . . . . . . . . 56

b. Wettbewerbsföderalismus . . . . . . . . . . . 57

2. Funktionsbedingungen. . . . . . . . . . . 59

a. Praktische Voraussetzungen eines Nachfragewett-
bewerbs . . . . . . . . . . . . . . 5 59

b. Inkompatibilität mit demokratischer Entscheidungsfindung. . . . . . . . . . . . . . . 60

c. Finanzökonomische Rationalitäten . . . . . . . . 61

d. Wettbewerb und Parteiendemokratie. . . . . . . . . 62

III. Bildungswettbewerb und Unitarisierung . . . . . . . . . . . 63

1. Grundrechte als „Bundeslehrplangrundsätze“ . . . . . . 64

a. Der Krabat-Fall . . . . . . . . . . . . . . . . . . . . 64

b. Grundrechtsbindung bei der Unterrichtsgestaltung . . . 64

c. Revisibilität der Unterrichtsgestaltung . . . . . . . . 65

2. Einbettung in steuerungswissenschaftliche Überlegungen . 67

* Einer frühen Diskussion des Konzepts in einem Kreis von Kolleginnen und Kollegen verdanke ich viel. Für die Unterstützung bei der Ausarbeitung danke ich meinen Mitarbeiterinnen Anuscheh Farahat und Jana Schäfer-Kuczynski. 
IV. Bildungsföderalismus als Verfassungsvergleichung . . . . . 68

1. Kernfrage: Schule und Staat . . . . . . . . . . . . . . 68

2. Verhältnis von öffentlicher und privater Schule. . . . . . . 68

a. Grundgesetz: zwei Systeme . . . . . . . . . . . . . . 68

b. Aktuelle Debatte: Wettbewerb zwischen öffentlichen und privaten Schulen?. . . . . . . . . . . . . . . . 69

c. Vielfalt durch unterschiedliche Bildungsgewährleistungsverpflichtungen in den Landesverfassungen . . . . . . 70

3. Hausunterricht statt Schulpflicht? . . . . . . . . . . . 71

V. Schluss . . . . . . . . . . . . . . . . . . 72

\section{Föderalismusreform und Bildungsföderalismus}

\section{Reföderalisierung der Bildungspolitik?}

\section{a. Föderalismus und ,Unitarismus"}

„Schluss mit den Extrawürsten!“ lautete der Titel eines Gastbeitrags in der Süddeutschen Zeitung zum Bildungsföderalismus. Sein Autor war Edmund Stoiber, ,einer der Väter der Föderalismusreform“. ${ }^{1}$

Als bayerischer Ministerpräsident hatte er mit dem SPD-Fraktionsvorsitzenden Franz Müntefering die Gemeinsame Föderalismuskommission von 2003 bis $2004^{2}$ geleitet. Bei ihren Beratungen forderte Bayern zusammen mit Baden-Württemberg und Hessen energisch eine Stärkung der Unabhängigkeit der Länder vom Bund in Bildungsfragen. Hieran scheiterte sogar die Kommission. ${ }^{3}$ Ihre Vorarbeiten wurden jedoch gleich zu Beginn der Großen Koalition aufgegriffen und 2006 als Föderalismus-

1 http://www.sueddeutsche.de/karriere/bildungspolitik-in-deutschland-schluss-mitden-extrawuersten-1.980470, Abruf 17.10.2013.

${ }^{2}$ Kommission von Bundestag und Bundesrat zur Modernisierung der bundesstaatlichen Ordnung, zu ihrer Arbeit s. Dt. Bundestag und Bundesrat (Hrsg.) Dokumentation der Kommission von Bundestag und Bundesrat zur Modernisierung der bundesstaatlichen Ordnung, 2005 und http://www.bundesrat.de/cln_320/nn_8344/DE/ foederalismus/foederalismus-node.html?_nnn=true\#doc23034bodyText4, Abruf 17.10. 2013.

3 S. etwa H.-J. Papier NJW 2007, 2145 (2146); U. Häde JZ 2006, 930 (931); I. Richter RdJB 2005, 3 (4); F. Wollenschläger RdJB 2007, 8 (9); U. Mager RdJB 2005, 312; H. Meyer Die Föderalismusreform 2006, 2008, 34. 
reform I verabschiedet. ${ }^{4}$ Den Bedingungen der genannten Länder entsprechend enthielt sie auch Änderungen bei den Bildungskompetenzen. ${ }^{5}$

Die Stoßrichtung des zitierten Gastbeitrag aus dem Jahr 2010 erweckt den Eindruck, die Reform sei über das Ziel hinausgeschossen, erlaube mehr „Extrawürste“, als gut tue. Erwartbar wäre solch eine Kritik eher von anderer Seite. ${ }^{6}$ So hielt etwa Edelgard Bulmahn, frühere SPD-Bundesbildungsministerin, die Änderungen der Bildungskompetenzen für dramatische Fehlentscheidungen. ${ }^{7}$ Hat sich nun Edmund Stoiber vom Föderalisten zum Unitarier ${ }^{8}$ gewandelt?

Seine Position wird nachvollziehbar, ${ }^{9}$ wenn man zwei Ebenen klar auseinander hält. ${ }^{10}$ Formal stehen sich Föderalismus und Zentralismus gegen-

${ }^{4}$ BGBl. 2006 I 2034 und 2098; zur Föderalismusreform I insg.: H.-J.Papier NJW 2007, 2145; U. Häde JZ 2006, 930; P. Selmer JuS 2006, 1052; J. Ipsen NJW 2006, 2801; H.-W. Rengeling DVBl. 2006, 1537.

5 Art. 91b Abs. 2 GG n.F. sieht als Gemeinschaftsaufgabe nicht mehr die Bildungsplanung (Art. 91b GG a.F.), sondern die Feststellung der Leistungsfähigkeit des Bildungswesens im internationalen Vergleich vor. Finanzhilfen des Bundes sind nach Art. 104b GG nur noch bei Gegenständen der Bundesgesetzgebungskompetenz zulässig. Im Hochschulbereich wurde die Rahmenkompetenz des Art. 75 GG a.F. gestrichen und stattdessen die konkurrierende Gesetzgebungskompetenz für Hochschulzulassung und Hochschulabschlüsse in Art. 74 Abs. 1 Nr. 33 GG vorgesehen. Von der Gemeinschaftsaufgabe Hochschulbau in Art. 91a Abs. 1 Nr. 1 GG a.F. blieb nur die Förderung von Forschungsbauten an Hochschulen gemäß Art. 91b Abs. 1 S. 1 Nr. 3 GG erhalten. Vgl. insg. zu den Verfassungsänderungen: J. Ennuschat/C. Ulrich VBlBW 2007, 121; F. Wollenschläger RdJB 2007, 8 (17 ff.).

${ }^{6}$ Siehe nur: $J$. Wieland in: ders./D. Dohmen (Hrsg.) Bildungsföderalismus und Bildungsfinanzierung, 2011, 6 (35 f.); J. Wieland ZG 2012, 266 (267).

$7 \mathrm{http} / / / \mathrm{www}$. spiegel.de/unispiegel/studium/foederalismusreform-gute-nachtbildung-a-383915.html, Abruf 17.10.2013.

${ }^{8}$ So die etablierte Gegenüberstellung in der deutschen staatsrechtlichen Debatte, s. etwa für die frühe Bundesrepublik $S$. Oeter Integration und Subsidiarität im deutschen Bundesstaat, 1998, 143 ff.; in den 1950er und 60er Jahren: $234 \mathrm{ff}$.

9 Dessen ungeachtet ist sie für einen bayerischen Politiker überraschend. In der Geschichte der Bundesrepublik haben sich gerade bayerische Politiker und Wissenschaftler als Föderalisten in Abgrenzung zu Unitariern verstanden und damit nicht nur die Organisationsform des Bundesstaates hochgehalten, sondern sich auch gegen die materiellen Vereinheitlichungstendenzen des Bundes gewandt, vgl. insb. aus der Frühphase der Bundesrepublik H. Nawiasky Die Grundgedanken des Grundgesetzes für die Bundesrepublik Deutschland, 1950; s. auch die Zusammenfassung bei Oeter Bundesstaat (Fn. 8), 153 ff.

10 Ebenso K. Hesse FS Müller, 1970, 141 (143 Fn. 3); H. Klatt Aus Politik und Zeitgeschichte B 28/86, 3 (5). Im Unterschied zur älteren Begriffsverwendung, s. etwa bei G. Anschütz Der deutsche Föderalismus in Vergangenheit, Gegenwart und Zukunft, VVDStRL 1 (1924), 11, der auf H. Triepel Unitarismus und Föderalismus, 1907, zurückgreift: Der Bundesstaat stehe zwischen Staatenbund und Einheitsstaat, Föderalismus beschreibe die Annäherung des Bundesstaates an den Staatenbund und auf der anderen Seite Unitarismus die Annäherung an den Einheitsstaat. Zu dieser noch in der 
über. Inhaltlich kann man Vielfalt und Differenz oder Einheit und Gleichheit wollen. Formale und inhaltliche Position hängen nicht zwingend zusammen. Vielfalt und Differenz sind auch in einem Zentralstaat denkund organisierbar. ${ }^{11}$ Umgekehrt sind materielle Einheit ${ }^{12}$ und Gleichheit ${ }^{13}$ in einem Föderalstaat möglich. Der unitarische Bundesstaat hat sich so zum Leitbild des deutschen Föderalismus entwickelt. ${ }^{14}$ Für den Bildungssektor formulierte Stoiber dies so: ${ }^{15}$ „Mit der Souveränität der Länder

Weimarer Republik geführten Debatte um die staatsrechtliche Einordnung des deutschen Bundesstaates s. auch J. Lukas Bundesstaatliche und gliedstaatliche Rechtsordnung in ihrem gegenseitigen Verhältnis im Rechte Deutschlands, Österreichs und der Schweiz, VVDStRL 6 (1929), 25 mwN; vgl. auch die Kontroverse zwischen $R$. Smend Verfassung und Verfassungsrecht, 1928, insb. 116 ff., 125 ff., und $H$. Kelsen Der Staat als Integration, 1930, insb. 76 f., 90 f. Eingehend zu dieser Debatte: S. Korioth Integration und Bundesstaat, 1990, $99 \mathrm{ff}$.

11 Vgl. M. M. Feeley/E. Rubin Federalism, 2008, 17 ff., die Föderalismus von anderen Formen der Binnendifferenzierung von Staatlichkeit unterscheiden und hierbei besonderen Schwerpunkt auf Dezentralisierung legen.

${ }^{12}$ Von zentraler Bedeutung war seit Verabschiedung des Grundgesetzes daher die Bedeutung der „Einheitlichkeit der Lebensverhältnisse“ als Legitimation von Bundeshandeln, insb. in der Bedürfnisklausel des Art. 72 Abs. 2 GG a.F.; vgl. hierzu die prägnante Darstellung bei Oeter Bundesstaat (Fn. 8), 147 f., zum Aushandeln der Klausel zwischen Alliierten und Parlamentarischem Rat, 201 ff., zur frühen Rechtsprechung des Bundesverfassungsgerichts, $533 \mathrm{ff}$., zur Bedeutung in der finanzverfassungsrechtlichen Auseinandersetzung; s. auch die knappe an parteipolitischer Zuordnung orientierte Darstellung bei S. Boysen Gleichheit im Bundesstaat, 2005, 53; P. Selmer Grundsätze der Finanzverfassung des vereinten Deutschlands, VVDStRL 52 (1993), 10 (19 f.). Die Formel „Einheit durch Vielfalt“ wird insbesondere mit Bezug auf Kulturföderalismus ausgegeben etwa bei J. Isensee HStR VI, 3. Aufl. 2008, § 123 Rn. 15, 217 ff. Die Verknüpfung von unitarischer Orientierung und dem Festhalten an der Idee eines (einheitlichen) deutschen Gesamtstaates beherrschte nicht nur die kritische, teils sogar ablehnende Haltung gegenüber der föderalen Bundesrepublik (vgl. insb. W. Weber Weimarer Verfassung und Bonner Grundgesetz, 1949; ders. in: ders. (Hrsg.) Spannungen und Kräfte im westdeutschen Verfassungssystem, 1951, 65 ff.). Sie blieben als Vorstellung von nationaler Einheit auch allgemein in der Staatslehre präsent als Teil des bis 1989 unerfüllten Verfassungsauftrags zur Wiedervereinigung, dabei äußerte sich die Einheitsvorstellung insbesondere im Demokratieverständnis, hierzu s. A. Wallrabenstein Das Verfassungsrecht der Staatsangehörigkeit, 1999, insb. 122 ff., 150 ff., zur Verknüpfung mit dem Wiedervereinigungsgebot; den Bezug zur Bundesstaatslehre stellt A. Hanebeck Der demokratische Bundesstaat des Grundgesetzes, 2004, insb. 78 ff., 116 ff., her, jeweils mwN.

13 Boysen Gleichheit (Fn. 12), konkret zur Reichweite der Gleichheitsgrundrechte und ihrer Wirkung im Bundesstaat: 100 ff., 123 ff., 171 ff.

14 Prägend K. Hesse Der unitarische Bundesstaat, 1962, 14 ff.; aufgegriffen wurde der Begriff prominent bei Selmer Finanzverfassung (Fn. 12), 20; auch P. M. Huber Klarere Verantwortungsteilung von Bund, Ländern und Kommunen?, DJT-Gutachten 2004, D45 ff.

$15 \mathrm{http}: / / w w w . s u e d d e u t s c h e . d e /$ karriere/bildungspolitik-in-deutschland-schluss-mitden-extrawuersten-1.980470, Abruf 17.10.2013. 
muss auch eine Selbstbeschränkung im gesamtstaatlichen Interesse verbunden sein. Hier ist vor allem auch die Kultusministerkonferenz künftig noch stärker gefragt: Bildungspolitik muss einen gemeinsamen Nenner haben, der auch Deutschland heißt." 16

Auch Bildungswissenschaftler ${ }^{17}$ beschreiben immer wieder das Auseinanderfallen von staatsrechtlicher föderaler Struktur und öffentlicher Erwartung ${ }^{18}$ einer materiell bundesweit einheitlichen Bildungslandschaft. ${ }^{19}$ Dies betrifft genau genommen nur die Bildung in Schule und Hochschule, auf die ich mich in diesem Vortrag beschränke. ${ }^{20}$ Sie verlangt von der

${ }^{16}$ Letztlich klingt hier die unitarische Zielrichtung der Figur der Bundestreue an, wie sie in der frühen Bundesrepublik entwickelt wurde, vgl. bei Oeter Bundesstaat (Fn. 8), 239 ff.; umfassend und mit einem vielseitigeren, Einheit und Pluralismus sichernden Verständnis H. Bauer Die Bundestreue, 1992, 306; ebenso z.B. B.-O. Bryde Die Einheit der Verwaltung als Rechtsproblem, VVDStRL 46 (1988), 181 (190).

${ }_{17}$ M. Rürup Der Föderalismus als institutionelle Rahmenbedingung im deutschen Bildungswesen, Onlinejournal Trends in Bildung international 2005, 2 f.; $U$. Münch in: I. Härtel (Hrsg.) Hb Föderalismus I, 2012, § 7 Rn. 36; mit Kritik gegen den Trend, Bildungsföderalismus als „Gespenst“ anzusehen, H.-E. Tenorth RdJB 2008, 249 (250).

${ }_{18} \mathrm{Zu}$ dieser öffentlichen Erwartung: http://www.faz.net/aktuell/politik/inland/ allensbach-umfrage-deutsche-wollen-einheitlichere-bildungspolitik-1580435.html, Abruf 17.10.2013. Vgl. aus dem rechtswissenschaftlichen Schrifttum die Kontroverse auf der Tagung 1965, etwa im Redebeitrag von G. Dürig Aussprache zu: Verwaltung und Schule, VVDStRL 23 (1966), 261 (262 f.); oder Klatt Aus Politik und Zeitgeschichte (Fn. 10), 5.

${ }^{19} \mathrm{Im}$ rechtswissenschaftlichen Schrifttum zum Bildungsrecht wird diese materielle Unitarisierung wesentlich den Grundrechten - und der Rechtsprechung des Bundesverfassungsgerichts - zugeschrieben, vgl. I. Richter DÖV 1979, 185 (186); M. Jestaedt HStR VII, 2009, § 156 Rn. 20, 43 ff.; H. Wißmann Die Verwaltung 45 (2012), 307 (313 f.). Dies ist als Beschreibung der Entwicklung zutreffend, allerdings nicht zwingend. Dass sich Unterschiede zwischen den Ländern immer im Rahmen der Grundrechte halten müssen, ist bei einem auch menschenrechtlich rückgebundenen Grundrechtsverständnis selbstverständlich. Dass es aber nur immer eine grundrechtskonforme Ausgestaltung des Bildungswesens geben kann, ist damit nicht präjudiziert. Zu Gleichheit im Bundesstaat vgl. Boysen Gleichheit (Fn. 12), 86 ff., zur unitarisierenden Wirkung der Grundrechte und ihrer Grenzen; im Bildungskontext für föderale Vielfalt werbend bereits I. Richter, DÖV 1979, 185; s. zur Unitarisierung durch Grundrechte unten unter III.

${ }^{20}$ Für die berufliche Bildung hat der Bund die Gesetzgebungskompetenz, soweit die betriebliche Ausbildung und die beruflichen Anforderungen betroffen sind, S. MüllerFranken HStR VIII, 2010, $\$ 172$ Rn. 31 f.; vgl. auch die pointierte Rede gegen eine ausschließliche Schulhoheit der Länder von K. A. Bettermann Aussprache zu: Verwaltung und Schule, VVDStRL 23 (1966), 269 (272 f.). Die Verflechtung mit den Ländern entsteht hier erst dadurch, dass für die berufsschulische Ausbildung die Länder zuständig sind und Bund und Länder an diesem Konzept festhalten, aber - unter dem Dach der Kultusministerkonferenz - die Kooperation suchen. Konkret will die KMK durch „eine Rahmenvereinbarung zu einer Übereinstimmung der Gestaltung beruflicher Bildung in den Ländern“ beitragen und hat zu diesem Zweck zahlreiche Vereinbarungen getroffen. 
Landesbildungspolitik Kooperation und Koordination zur Erfüllung dieser Politikerwartung. Daher ist es politikwissenschaftlich nicht überraschend, dass die Länder bisher keinen erkennbaren Nutzen aus der Stärkung ihrer Bildungshoheit gezogen haben. ${ }^{21}$

\section{b. Gemeinsam gegen den Bund}

Eine Aktivierung der Länder und dadurch eine stärkere Pluralisierung der Bildungspolitik war auch nicht die politische Stoßrichtung der Verfassungsänderungen. Vielmehr ging es um die Beschränkung der bildungspolitischen Gestaltungsmöglichkeiten des Bundes. ${ }^{22}$ Er sollte keine Bildungsrepublik ausrufen dürfen.

Dennoch ist es so gekommen. ${ }^{23}$ Auf der Internetseite der Bundesregierung steht Bildung an zweiter Stelle. Speziell für die Schulbildung heißt es dort: „Seit der Föderalismusreform sind die Zuständigkeiten im Bildungswesen klar verteilt. Die in der Pisa-Studie deutlich gewordenen Mängel und der wachsende Fachkräftebedarf können nur von Bund und Ländern gemeinsam behoben werden. “24

Dazu zählen unter anderem die Vereinbarung von Rahmenlehrplänen und Vereinbarungen über die Lehrerausbildung. Siehe im Einzelnen: http://www.kmk.org/bildung-schule/ berufliche-bildung.html, Abruf 17.10.2013. Unter dem Gesichtspunkt der Politikverflechtung lässt sich fragen, warum hierüber politisch gar nicht diskutiert wurde.

${ }^{21}$ Kritisch insg. für die Föderalismusreform F.W.Scharpf Föderalismusreform, 2009, 117; für das Bildungsrecht H.-P. Füssel in: H. Avenarius/H.-P. Füssel (Hrsg.) Schulrecht, 8. Aufl. 2010, 26; anders V. Haug Jahrbuch des Föderalismus 2010, 176 (177 ff., 182 f.), allerdings wäre jede der drei Reformen, die Haug als Beleg anführt, auch ohne Verfassungsänderung möglich gewesen.

${ }_{22}$ Da Kultur und Bildung gemeinhin als „Hausgut“ der Länder bezeichnet werden, bedeutet die Behauptung gegen Bundeseinfluss vielleicht so etwas wie eine Selbstbestätigung der eigenen Existenzberechtigung, in diese Richtung U. Münch in: A.-G. Gagnon/R. Sturm (Hrsg.) Föderalismus als Verfassungsrealität, 2011, 173 (177 ff.); vgl. mit nüchterner Skepsis $P$. M. Huber RdJB 2007, 4 (5).

${ }^{23} \mathrm{http} / / / w w w . f a z . n e t / a k t u e l 1 /$ politik/inland/nationaler-bildungsbericht-merkel-ruftbildungsrepublik-aus-1545858.html, Abruf 17.10.2013; dem schloss die Bundeskanzlerin eine Bildungsreise an. Im Herbst folgte ein Bildungsgipfel, den Bund und Länder gemeinsam veranstalteten, zur kritischen Bilanz s. etwa: http://www.welt.de/politik/ article2611577/Bildungsgipfel-endet-mit-Bund-Laender-Blockade.html, Abruf 17.10. 2013; http://www.zeit.de/online/2008/43/bildungsgipfel-vorbericht, Abruf 17.10.2013. http://www.spiegel.de/unispiegel/studium/gipfel-in-dresden-bund-und-laender-uneinsueber-bessere-bildungs-finanzierung-a-585873.html, Abruf 17.10.2013; zum schulpolitischen Engagement der Bundesregierung bietet Münch in: Gagnon/Sturm (Fn. 22), 179, einen Überblick.

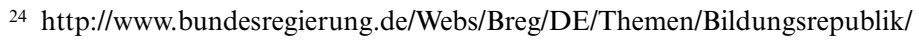
Schulbildung/_node.html, Abruf 17.10.2013. Die Fortführung des Ganztagsschul-Förderprogramms des Bundes zeigt, dass die Bundesregierung offenbar keinen Bedarf an 
So viel „Klarheit“ war kaum das Ziel, das die Änderung der Gemeinschaftsaufgaben (Art. 91b GG) von der Bildungsplanung zur Bildungsberichterstattung erreichen sollte. Vielmehr sollten eine Auflösung der Politikverflechtung, eine Trennung der Kompetenzen und Transparenz erreicht werden. ${ }^{25}$ Gemessen daran ist nicht nur die Änderung der Gemeinschaftskompetenzen missglückt. ${ }^{26}$

Auch die verfassungsrechtliche Regelung des finanziellen Engagements des Bundes im Bildungs- und Hochschulwesen ist weder transparenter noch weniger verflochten als zuvor. Hier liegen die eigentlichen politischen Konflikte. ${ }^{27}$ Sie beruhen auf grundsätzlich unterschiedlichen Herangehensweisen: Die eine Seite ${ }^{28}$ - insbesondere die SPD - denkt vom Finanzbedarf für eine bessere Bildungspolitik her. In der bestehenden Finanzverfassung ${ }^{29}$ haben die Länder hierfür keine ausreichenden finanziellen Ressourcen. ${ }^{30}$ Bildungsausgaben sind in allen Ländern der mit Abstand größte Haushaltsposten. ${ }^{31}$ Anders als die meisten anderen Ressorts können die Kultusministerien bei allfälligen Sparrunden nicht auf

einer inhaltlichen Neuausrichtung ihrer Bildungspolitikfelder sieht, vgl. hierzu http:// www.handelsblatt.com/politik/deutschland/bund-setzt-foerderung-fort-die-

ganztagsschule-soll-2020-der-normalfall-sein/3020674.html, Abruf 17.10.2013.

${ }_{25}$ Mit besonderem Bezug zum Bildungsbereich: Münch in: Härtel (Fn. 17), § 7 Rn. 19; dies. Jahrbuch des Föderalismus 2009, 225; dies. Jahrbuch des Föderalismus 2007, 224; allg. S. Korioth FS Papier, 2013, 133 (135).

${ }^{26}$ Kritisch wie hier zu den verschiedenen Grundgesetzänderungen im Bildungsbereich P. M. Huber RdJB 2007, 4. Für den Hochschulbereich gilt nichts anderes als für die Bildung: Das politische Ziel war ursprünglich, die Forschungsförderung des Bundes aufrecht zu erhalten, aber die Beteiligung des Bundes bei der Ausbildung an den Hochschulen - also der Lehre - zu beenden. Zugleich sollte aber universitäre Forschung nicht schlechter gestellt werden als außeruniversitäre Forschung. Dadurch war eine theoretische Unterscheidung zwischen Forschungs- und Lehrangelegenheiten an der Hochschule notwendig - etwas, was sich angesichts des humboldtschen Bildungsideals und den daran orientierten Strukturen der Universität nicht sinnvoll darstellen lässt, besonders unsinnig zudem bei der Zuordnung von Hochschulbauten, deren Errichtung ja gerade Gemeinschaftsaufgabe war. Im Gesetzgebungsprozess wurde schließlich doch noch eine Bundesförderung auch der Lehre ermöglicht, freilich um den Preis einer alles andere als klaren Regelung, vgl. U. Münch Jahrbuch des Föderalismus 2009, 225 (227, 232).

${ }^{27} \mathrm{Vgl}$. insg. zur Bildungsfinanzierung im Bundessstaat W. Renzsch Jahrbuch des Föderalismus 2012, 234.

${ }_{28}$ Vgl. insb. J. Wieland ZG 2012, 266 (267 ff.); Wieland in: ders./Dohmen (Fn. 6), 35 ff.; D. Dohmen in: Wieland/ders. (Fn. 6), 49.

${ }^{29}$ Ihre Reform wurde sowohl bei der Föderalismusreform I als auch II zurückgestellt und soll nun in einer Föderalismusreform III in Angriff genommen werden.

${ }_{30}$ Auch S. Immerfall in: J. v. Blumenthal/S. Bröchler (Hrsg.) Föderalismusreform in Deutschland, 2010, 197 (208); Knappe Zeiten prognostiziert auch M. Winkler DVB1. 2013, 1069 (1078).

31 Vgl. differenziert W. Renzsch Jahrbuch des Föderalismus 2012, 234. 
die „Pflichtigkeit“" ihrer Aufgaben ${ }^{32}$ - die Ausführung von Bundesgesetzen - verweisen. ${ }^{33}$ Relevante Steuergesetzgebungskompetenzen stehen den Ländern nicht zu. ${ }^{34}$ Schließlich schließt die neue Schuldenbremse (Art. 109 Abs. 3, 115 Abs. 2, 143d Abs. 1 GG) ${ }^{35}$ eine Kreditaufnahme für Bildungsausgaben aus. ${ }^{36}$ Unter diesen Bedingungen erscheint das Ende des Zuflusses von Bundesmitteln in die Landesbildungsetats wie die Extubation eines nicht spontan atmenden Patienten. Für die andere Seite insbesondere die Länder Hessen, Bayern und Baden-Württemberg dürfte dieses Risiko eines Kollapses finanzschwacher Länder als Beleg dafür dienen, dass Länderfusionen zur immer wieder geforderten Neugliederung des Bundes alternativlos sind. ${ }^{37}$ Argumentiert wurde allerdings damit, dass die Finanzhilfen des Bundes das Einfallstor für inhaltliche Einflussnahme auf die Bildungspolitik darstellen. Sie zu verhindern sei das Kernanliegen der Reform. ${ }^{38}$

32 Die Kritik, dass die Bundesländer eher den Charakter herausgehobener Selbstverwaltungskörperschaften haben, ist nicht neu: bereits in der Frühphase des Grundgesetzes Weber Weimarer Verfassung und Bonner Grundgesetz (Fn. 12), 13; neuerdings z.B. S. Korioth FS Papier, 2013, 133 (136 ff.).

${ }_{33}$ Daher sind KMK-Vereinbarungen im Akteursinteresse der Kultusministerien, um im Kabinett die Ressourcen zu verteidigen: vgl. zu diesem „Instrument“, das es bei Mehrebenenstrukturen den einzelnen Akteuren ermöglicht, Ressourcen gegen andere Ressorts zu verteidigen: $A$. Benz in: G. F. Schuppert (Hrsg.) Governance-Forschung, 2. Aufl. 2006, 95 (97 f.); ebenso bereits F. Wagener in: J. J. Hesse (Hrsg.) Politikverflechtung im föderativen Staat, 1978, 149, speziell für die „Ressort-Kumpanei“ aufgrund der ebenenübergreifenden Planung.

${ }^{34} \mathrm{Zu}$ den Beschränkungen des Art. 105 Abs. 2a GG (örtlich und nur, soweit nicht vergleichbare Bundessteuer): M. Jachmann in: H. v. Mangoldt/F. Klein/C. Starck (Hrsg.) Grundgesetz Kommentar, 6. Aufl. 2010, Art. 105 Rn. 54; M. Heintzen in: I. v. Münch/ P. Kunig (Hrsg.) GG II, 6. Aufl. 2012, Art. 105 Rn. 58; zur realen Bedeutung dieser Kompetenzen: Jachmann ebd., Art. 105 Rn. 54, 66 f.; Heintzen ebd., Art. 105 Rn. 61.

35 Eingeführt mit der Föderalismusreform II 2009, BGBl. 2009 I 2284; dazu: S. Korioth JZ 2009, 729; B. Fassbender NVwZ 2009, 737; I. Kemmler DÖV 2009, 549 (554 f.); C. Lenz/E. Burgbacher NJW 2009, 2561 (2564 f.).

${ }^{36} \mathrm{Zu}$ den letztgenannten Argumenten auch Immerfall in: v. Blumenthal/Bröchler (Fn. 30), $208 \mathrm{f}$.

${ }^{37}$ Die Forderung nach einer Neugliederung der Länder wird insbesondere mit dem Konzept eines Wettbewerbsföderalismus (dazu unten) in Verbindung gebracht, vgl. G. F. Schuppert in: Härtel (Fn. 17), § 9 Rn. 34, 54 ff.; auch bereits im Kontext zum Finanzausgleich ders. Staatswissenschaften und Staatspraxis 6 (1995), 675 (692); B. Stamm/G. Merkl ZRP 1998, 467; E. Schmidt-Jortzig DÖV 1998, 746 (750); der eingangs zitierte Gastbeitrag Stoibers erhält so auch eine konsistente Tiefenschicht: Neben der Einheitlichkeit der Bildungspolitik wird als zweites eine Neugliederung der Bundesländer gefordert. Kritisch gegen von Finanzausgleichsfragen getriebene Neugliederungsüberlegungen $P$. Häberle Die Verwaltung 24 (1991), 169 (202).

38 Die 2006 dann gefundenen Regelungen werden daher auch als „lex Edelgard“ 
Dieses Ziel wurde indessen nicht erreicht. Zwar wurden mit dem neuen Art. 104b GG Finanzhilfen des Bundes auf die Bereiche eigener Gesetzgebungsbefugnisse begrenzt. Aber diese wurden eben nicht beseitigt. Anstelle der Rahmengesetzgebung für die allgemeinen Grundsätze des Hochschulwesens (Art. 75 GG a.F.) erhielt der Bund nun die konkurrierende Gesetzgebung für die Hochschulzulassung und die Hochschulabschlüsse. Zweifelnde Abgeordnete wurden mit dem Hinweis für die Reform gewonnen, dass bei geschickter Handhabung diese Verfassungsänderungen dem Bund weiterhin ausreichend Spielraum bieten. ${ }^{39}$ Die Verlängerung des Hochschulpaktes bis 2020 bestätigt dies. ${ }^{40}$ Es rundet das Bild ab, dass bereits die Schaffung der Rahmengesetzgebung im Jahr 1969 den unitarisch gesinnten Abgeordneten mit den gleichen Argumenten schmackhaft gemacht wurde ${ }^{41}$ :

Es ist nicht relevant wo und wie, nur dass Bund und Bildung bzw. Bund und Hochschule zusammen in einem Verfassungssatz vorkommen. Im Bereich der Bildungspolitik hat also die Föderalismusreform ihr Ziel der Politikentflechtung durch klare Kompetenzverteilung und Transparenz nicht erreicht. ${ }^{42}$

(M. Spiewack Lex Edelgard, Die Zeit vom 26.5.2006) bzw. „Lex Bulmahn“ (M. Rürup Jahrbuch des Föderalismus 2008, 172 [176]) bezeichnet.

39 Vgl. T. Hoymann/U. Münch Jahrbuch des Föderalismus 2011, 205 (210); U. Münch Jahrbuch des Föderalismus 2009, 225 (229 f.); dies. in: Gagnon/Sturm (Fn. 22), 180, unter Berufung auf K. Sager in: R. Holtschneider/W. Schön (Hrsg.) Die Reform des Bundesstaates. Beiträge zur Arbeit der Kommission zur Modernisierung der bundesstaatlichen Ordnung 2003/2004 bis zum Abschluss des Gesetzgebungsverfahrens 2006, 2007, 117 (132).

40 Zum Hochschulpakt und zur Schulpolitik des Bundes: Münch in: Gagnon/Sturm (Fn. 22), 177 ff., 179 ff.; schon unter der alten Verfassungslage war das Ganztagsschulprogramm strittig (s. M. Winkler DVB1. 2013, 1069 [1076 f.]), was die politischen Akteure jedoch nicht hinderte, es auch nach der Föderalismusreform I weiter laufen zu lassen. Seitdem fördert der Bund das Begleitprogramm „Ideen für mehr! Ganztätig lernen“ und die Begleitforschung "Studie zur Entwicklung von Ganztagsschulen“, siehe: http://www.bmbf.de/de/1125.php?hilite=Investitionsprogramm+Zukunft+

Bildung+und+Betreuung, Abruf 17.10.2013.

${ }^{41}$ T. Hoymann/U. Münch Jahrbuch des Föderalismus 2011, 205 (215).

${ }^{42}$ Kritisch ebenfalls: H. Scheller in: K. Detterbeck/W. Renzsch/S. Schieren (Hrsg.) Föderalismus in Deutschland, 2010, 225 (242 ff.); U. Münch in: R. Hrbek/M. Große Hüttmann/J. Schmid (Hrsg.) Bildungspolitik in Föderalstaaten und der Europäischen Union: Does Federalism Matter?, 2012, 47 (49 f.); zu den „flexiblen“ Finanzfragen: 50 ff.; dies in: Gagnon/Sturm (Fn. 22), 177 f.; auch M. Rürup Jahrbuch des Föderalismus 2008, 172 (174), erkennt keine nennenswerte Reduktion des Bundeseinflusses, allerdings auch deshalb, weil er ihn bereits zuvor als weniger groß einschätzt als häufig behauptet. 


\section{Erklärungsangebote}

Dieser Befund sucht nach Erklärung.

\section{a. Föderale Unitarisierungsinstitutionen}

Auf einer ersten Deutungsebene lässt sich auf die Selbstbehauptungskräfte der bestehenden Institutionen, konkret der Kultusministerkonferenz (KMK), verweisen.

Kritikern des deutschen Föderalismus galt gerade sie als Paradebeispiel für Politikblockade durch ineffiziente und schwerfällige Entscheidungsstrukturen. ${ }^{43}$ Daher wurde zu Beginn der Reformdiskussion auch ihre Abschaffung zugunsten neuer Institutionen erörtert. ${ }^{44}$

Die gemeinsame Föderalismuskommission 2004 war mit „Generalisten“ besetzt, auch um das Reformziel der Politikentflechtung nicht den Beharrungskräften der unterschiedlichen Fachexperten auszuliefern. ${ }^{45}$ Das Scheitern der Kommission hat den bildungspolitischen Fachinteressen nicht geschadet. ${ }^{46}$ Denn 2006 folgte die Reform der politischen Dyna-

43 Der Hintergrund für die „Blockade-Performanz“ des KMK ist bildungspolitisch: Bis in die 1960er Jahre herrschte in der Bildungspolitik weitgehend ein deutschlandweiter Konsens ohne nennenswerte parteipolitische Konfrontationen. Zu ihm gehörte auch die Orientierung auf eine Gesamtschule hin (s. Empfehlung des Bildungsrates für Modellversuche Ende der 1960er). Dies kritisierte etwa W. G. Vitzthum Die Bedeutung gliedstaatlichen Verfassungsrechts in der Gegenwart, VVDStRL 46 (1988), 8 (41), als politischen Einigungsdruck. Verfassungsrechtlich handelt es sich um die auch hier aufgezeigte Kritik: landesverfassungsrechtliche Autonomie ist politisch gar nicht durchsetzbar. In den 1970er Jahren preschte zuerst der hessische Kultusminister L. v. Friedeburg voran. Auch in anderen Bundesländern und im Bund, in dem die SPD seit 1969 den Bundeskanzler stellte, profilierte sich die SPD mit der Gesamtschule in der Bildungspolitik. Die CDU positionierte sich nun mit bemerkenswerter Massenmobilisierung dagegen - was für die SPD die Studentenproteste waren, war für die CDU der Protest gegen die Gesamtschule. In diesem „Schulkampf“ benutzten die CDU-geführten Bundesländer die nach dem Einstimmigkeitsprinzip arbeitende KMK zur Blockade der bundesweiten Schulentwicklung. Maßgebliches Vehikel war die gegenseitige Anerkennung des Abiturs als allgemeine Hochschulzugangsberechtigung.

44 P. Häberle AöR 124 (1999), 549 (577 ff., 579 f. mwN). Vgl. insgesamt zur KMK, der Kritik an ihr und dem Reformprozess seit Ende der 1990er Jahre: Immerfall in: v. Blumenthal/Bröchler (Fn. 30), 197.

45 Auf der anderen Seite handelte es sich um die politisch entscheidenden Akteure, so dass Vetopositionen aufgebaut werden konnten, die letztlich auch zum Scheitern der Kommission geführt haben. Aus der Perspektive eines deliberativen Politikverständnisses daher kritisch A. Sattler Deliberativer Föderalismus, 2012, 123 ff., insb. 230 ff.

46 Ebenso P. M. Huber RdJB 2007, 4, (5 f.). Zur Gleichzeitigkeit von staatsrechtlichen Trennungs-Überlegungen und fachpolitischen Kooperationen während der Föderalismusreform s. auch Münch in: Gagnon/Sturm (Fn. 22), 177 f. 
mik der Koalitionsverhandlungen. Für den Bildungsbereich, über den die Föderalismuskommission ja keine Einigkeit hatte erzielen können, kamen so letztlich doch die Fachpolitiker zum Zuge. ${ }^{47}$ Der überkommenen kooperativen Herangehensweise entsprechend bereitete die KMK schon parallel zum parlamentarischen Verfahren die Grundlagen für die weitere Zusammenarbeit des Bundes und der Länder vor. ${ }^{48}$ Da sie auch die Blockade-Kritik durch organisatorische Reformen aufgriff, stärkte sie ihre Position. ${ }^{49}$

Mit der KMK besteht freilich auch ihr Föderalismusverständnis fort, das eine unitarische Bildungspolitik durch Abkommen, Programme und Beschlüsse verschiedener Gremien mit Bund- und Ländervertretern unter ihrer Regie verfolgt. ${ }^{50}$

\section{b. Gemeinsame Diagnose - unterschiedliche Therapieansätze}

Eine Deutungsschicht tiefer lässt sich fragen, ob sich die Durchsetzung der Fachinteressen gegenüber der Forderung nach Politikentflechtung auch mit Schwachstellen des Reformkonzepts erklären lässt.

Eine solche Schwachstelle wurde bereits angesprochen. Indem die Föderalismuskommission Finanzfragen ausgeklammert hatte, ${ }^{51}$ konnten

${ }^{47}$ Konkret wurden die Vorschläge in der Koalitions-Arbeitsgruppe Bildung und Forschung erarbeitet, s. Bericht der $K M K$ zur Föderalismusreform „Entflechten - Überleiten - Neu Gestalten“ (http://www.kmk.org/fileadmin/pdf/foederalismus/Entflechten Ueberleiten_Neu_Gestalten_Aktualisiert.pdf), 9; Kritisch, da auch hier die fachpolitischen Notwendigkeiten vernachlässigt worden seien: Scheller in: Detterbeck/Renzsch/ Schieren (Fn. 42), 244.

${ }^{48} K M K$ „Entflechten - Überleiten - Neu Gestalten“ (http://www.kmk.org/fileadmin/ pdf/foederalismus/Entflechten_Ueberleiten_Neu_Gestalten_Aktualisiert.pdf), $16 \mathrm{f}$.

49 Immerfall in: v. Blumenthal/Bröchler (Fn. 30), 201 ff.; speziell zum Innovationspotential der KMK: $U$. Münch Jahrbuch des Föderalismus 2010, 189 (192 ff.); für die Föderalismusreform: V. Haug Jahrbuch des Föderalismus 2010, 176 (179 ff., 186 f.)

${ }_{50} \mathrm{Vgl}$. Bericht der $K M K$ zur Föderalismusreform „Entflechten - Überleiten - Neu Gestalten“ (http://www.kmk.org/fileadmin/pdf/foederalismus/Entflechten_Ueberleiten_ Neu_Gestalten_Aktualisiert.pdf), 46: „Ausblick: [...] Die KMK hat von Beginn an den sich aus der Föderalismusreform ergebenden Gewinn an Handlungs- und Innovationsfähigkeit der Länder begrüßt. Gleichzeitig hat sie jedoch auch die sich aus dem ,Mehr an Freiheit" ergebende größere gesamtstaatliche Verantwortung hervorgehoben. Institutionell wird sie dieser Verantwortung durch die mit dem Bund vereinbarten Gremien im Bereich der Gemeinschaftsaufgabe ,Feststellung der Leistungsfähigkeit des Bildungs-

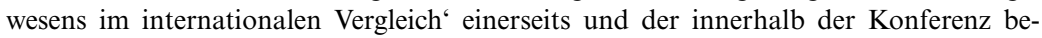
schlossenen neuen Gremienstrukturen gerecht. [...]".

${ }^{51}$ Kritisch etwa H.-J. Papier NJW 2007, 2145 (2148); C. Waldhoff Die Verwaltung 39 (2006), 155 (165 ff.); U. Häde JZ 2006, 930 (935, 939); und jüngst: S. Korioth FS Papier, 2013, 133 (138 ff.); etwas optimistischer: P. Selmer JuS 2006, 1052 (1059). 
die Länder bei kostenträchtigen Kompetenzzuwächsen gar nicht erst die Billigung durch die Fachexperten erwarten. Daher erstaunt es nicht, dass als Gewinner der Föderalismusreform der Bund ausgemacht wird. ${ }^{52}$

Vielleicht liegt eine weitere Schwäche der Föderalismusreform aber auch in ihrem Anliegen selbst begründet.

Der Impuls für die Reform ging von einer schon seit Jahrzehnten formulierten und immer stärker verbreiteten Kritik an der aktuellen Struktur und Realität des deutschen föderalen Systems aus. ${ }^{53}$ Sie entzündete sich am Leitbild des kooperativen Bundesstaates, ${ }^{54}$ das spätestens mit der Finanzreform 1969 auch im Grundgesetz verankert war. ${ }^{55}$ Es war weniger

52 So jedenfalls für die Bildungspolitik P. M. Huber RdJB 2007, 4 (7); allgemein: S. Korioth FS Papier, 133 (136, 138 ff.); jedenfalls skeptisch bezüglich des Erfolgs der Entflechtung: H.-J. Papier NJW 2007, 2145 (2149); P. Selmer JuS 2006, 1052 (1058); aA J. Ipsen NJW 2006, 2801 (2804); H.-W. Rengeling DVBl. 2006, 1537 (1549).

${ }^{53}$ In der Sozial- und Politikwissenschaft: F. W. ScharpflB. Reissert/F. Schnabel Politikverflechtung, 1976; F. W. Scharpf Politische Vierteljahresschrift 26 (1985), 323; ders. Optionen des Föderalismus in Deutschland und Europa, 1994, 133; ders. in: Hesse (Fn. 33), 21 (30), ders. Föderalismusreform, 2009, 30 ff., 49 ff.; Klatt Aus Politik und Zeitgeschichte (Fn. 10), 3; ders. Verwaltungsarchiv 78 (1987), 186 (194, 197, 201); für den politischen Prozess in den 1980er Jahren: H. Klatt in: A.B. Gunlicks/R. Voigt (Hrsg.) Föderalismus in der Bewährungsprobe, 1991, 228 ff.; in der Rechtswissenschaft: zunächst insb. G. Kisker Kooperation im Bundesstaat, 1971; aus dem umfangreichen späteren Schrifttum etwa Oeter Bundesstaat (Fn. 8), 461 ff.; Schuppert in: Härtel (Fn. 17), § 9 Rn. 20; Huber Klarere Verantwortungsteilung (Fn. 14), D29 f.

${ }^{54}$ Den Durchbruch für dieses Leitbild stellte das sog. Troeger-Gutachten aus dem Jahr 1966 dar, das angesichts der diagnostizierten Defizite resümierte, dass „Der Föderalismus unserer Zeit [...] nur ein kooperativer Föderalismus sein [kann].“: Kommission für die Finanzreform, Gutachten über die Finanzreform in der Bundesrepublik Deutschland, 1966, 20, Rn. 76. Der Begriff des „kooperativen Föderalismus“ wurde auch rasch in der Literatur aufgegriffen: $U$. Scheuner DÖV 1966, 513 (518 ff.); W. Patzig DVBl. 1966, 389; A. Hüttl DVBl. 1967, 433 (435 ff.); R. Kunze Kooperativer Föderalismus in der Bundesrepublik, 1968, 1 ff.; K. Hesse FS Müller, 1970, 141 (142 ff.); Kisker Kooperation im Bundesstaat (Fn. 53); zur „Karriere“ dieses Begriffes in Deutschland ausführlich: Oeter Bundesstaat (Fn. 8), $266 \mathrm{ff}$.

${ }_{55}$ Hierzu Kisker Kooperation im Bundesstaat (Fn. 53), 282 ff.; Oeter Bundesstaat (Fn. 8), 272 ff.; W. Renzsch Finanzverfassung und Finanzausgleich, 1991, 209 ff., insb. 259; ausführlich zum Troeger-Gutachten: $R$. Grawert Der Staat 7 (1968), 63 ff.; W. Henle DÖV 1966, 608 ff. Aus heutiger Sicht ist interessant, dass dem Troeger-Gutachten die Vorstellung einer keynesianischen Konjunkturpolitik zugrunde lag, die eine einheitliche Steuerung der Fiskal- und Kreditpolitik aller Haushalte - von Bund, Ländern und Kommunen - verlangt. Heute werden auch unter anderen ökonomischen Theorieannahmen mit einer Schuldenbremse der Länder in der Bundesrepublik, aber auch mit den Überlegungen zu einer Fiskalunion auf europäischer Ebene Überlegungen angestellt, die für die föderale Kompetenzordnung ganz ähnliche Konsequenzen haben. 
auf die Abgrenzung der Aufgaben und Aktivitäten von Bund und Ländern gerichtet als vielmehr auf die Überwindung der differenzierten Kompetenzzuordnung durch gemeinsame Politikgestaltung. ${ }^{56}$ Das zentrale Problem des kooperativen Föderalismus war nach dieser Kritik die durch das gemeinsame Agieren entstehende Politikverflechtung. ${ }^{57}$ Ihre wichtigsten Folgeerscheinungen seien Blockaden, Ineffizienz und Langsamkeit wegen $\mathrm{zu}$ hohen Konsensbedarfs. ${ }^{58}$ Verantwortung sei nicht mehr zurechenbar, weil zu viele Akteure in komplexen Prozessen beteiligt seien. ${ }^{59}$ Die mangelnde Transparenz führe zu mangelnder Kontrolle. ${ }^{60}$

Intensität und Durchschlagskraft verdankt diese Kritik dem Umstand, dass sich unter ihr ganz unterschiedliche staatstheoretische Vorstellungen sammeln konnten. ${ }^{61}$ Wer etwa einen schlankeren Staat, effektivere Steuerung und neue Governance fordert, kann die bestehenden Strukturen des kooperativen Föderalismus als Quell mangelnder Effizienz ${ }^{62}$ ausmachen. ${ }^{63}$

56 Oeter Bundesstaat (Fn. 8), 293 f., stellt diese Entwicklung in die Planungsgläubigkeit dieser Zeit; dazu auch etwa N. Luhmann Politische Planung, 1971, 66 ff.; $F$. W. Scharpf Die Verwaltung 4 (1971), 1; E.-W. Böckenförde Der Staat 11 (1972), 249 ff. Besonderes Augenmerk galt der verfassungsrechtlichen Institutionalisierung der Gemeinschaftsaufgaben, vgl. B. Tiemann Gemeinschaftsaufgaben von Bund und Ländern in verfassungsrechtlicher Sicht, 1970; J. A. Frowein Gemeinschaftsaufgaben im Bundesstaat, VVDStRL 31 (1973), 13; I. v. Münch Gemeinschaftsaufgaben im Bundesstaat, VVDStRL 31 (1973), 51; A. Dittmann Bildungsplanung als Gemeinschaftsaufgabe, 1975, 33 ff., insb. $36 \mathrm{f}$.

${ }^{57}$ Begriffsprägend F. W. Scharpf, vgl. ScharpflReissert/Schnabel Politikverflechtung (Fn. 53), 9; schon zuvor kritisch gegenüber den Gemeinschaftsaufgaben $K$. Hesse FS Müller, 1970, 153; Kisker Kooperation im Bundesstaat (Fn. 53), 285 ff.; F. Klein Der Staat 11 (1972), 289 (308 ff.); O. Barbarino DÖV 1973, 19 (20 f.); s. aber auch die gerade nicht negative Begriffsverwendung bei J. Kersten FS Papier, 2013, 103, für eine Weiterentwicklung von Demokratiekonzeptionen im europäischen Mehrebenensystem.

58 ScharpflReissert/Schnabel Politikverflechtung (Fn. 53), insb. 230 ff.; Scharpf Optionen des Föderalismus (Fn. 53), 133; ders. Föderalismusreform (Fn. 53), 30 ff., 49 ff.; Schuppert in: Härtel (Fn. 17), §9 Rn. 20.

59 Oeter Bundesstaat (Fn. 8), 456; H.-H. Trute FS Schneider, 2008, 302 (306); D. Grimm FS Papier, 2013, 49 (54).

${ }^{60}$ H. Klatt Verwaltungsarchiv 78 (1987), 186 (194, 197, 201); ders. Aus Politik und Zeitgeschichte B 31/82, 3 (8 ff.).

${ }^{61}$ Die sich freilich nicht ausschließen, s. etwa die Unterscheidung zwischen Effizienzkosten und Demokratiekosten bei D. Grimm FS Papier, 2013, 49 (53).

${ }^{62}$ Zur Effizienz: H. Eidenmüller Effizienz als Rechtsprinzip, 3. Aufl. 2005; K. Mathis Effizienz statt Gerechtigkeit?, 3. Aufl. 2009; zur begrenzten rechtlichen Qualität des Effizienzprinzips: M. Martini Der Markt als Instrument hoheitlicher Verteilungslenkung, 2008, 197 ff., 232.

${ }^{63}$ H. Klatt in: R. Meier-Walser/G. Hirscher (Hrsg.) Krise und Reform des Föderalismus, 1999, 64 (71); ders. Verwaltungsarchiv 78 (1987), 186 (194); ders. Aus Politik und 
Eine demokratietheoretische Kritik kann die komplexen Kooperationen wegen der Unmöglichkeit politischer Verantwortungszurechnung geißeln. ${ }^{64}$ Transparenz und Zurechnung sind dabei gleichzeitig zentrale Voraussetzungen eines deliberativen Demokratieverständnisses ${ }^{65}$ und ebenso eines Modells, das Legitimation über Verantwortungsketten konstruiert. ${ }^{66}$ Schließlich genügt es auch, rein staatsrechtlich auf die „Selbstverantwortung" des Bundes bzw. der Länder abzustellen. ${ }^{67}$

Aus dem gemeinsamen Befund werden aber keineswegs gleiche Therapiefolgerungen abgeleitet. Wer effektive, nur wenige Stationen umfassende Entscheidungsprozesse für sinnvoll hält, wird fordern, dass die fachlich Kompetenten auch die rechtlichen Kompetenzen erhalten. Parlamente werden nur funktional für die Schaffung von Akzeptanz eingebunden, um die „Compliance“ der Rechtsunterworfenen zu stärken. Aus demokratietheoretischer Perspektive ist hingegen umgekehrt die Exekutivlastigkeit des kooperativen Föderalismus von Übel. ${ }^{68}$ Ziel ist deshalb eine Verlage-

Zeitgeschichte (Fn. 60), 8, 22; F. W. Scharpf Politische Vierteljahresschrift 26 (1985), 323; Schuppert in: Härtel (Fn. 17), § 9 Rn. 28; H.-H. Trute in: Härtel (Fn. 17), § 28 Rn. 22.

${ }^{64}$ Huber Klarere Verantwortungsteilung (Fn. 14), D33; s. auch die Analyse der Föderalismusreform bei $S$. Kadelbach Autonomie und Bindung der Rechtsetzung in gestuften Rechtsordnungen, VVDStRL 66 (2007), 9 (19 f.); Oeter Bundesstaat (Fn. 8), 456, 569 f.; B.-O. Bryde in: Redaktion Kritische Justiz (Hrsg.) Demokratie und Grundgesetz, 2000, 59 ( 64 ff.); Hanebeck Demokratischer Bundesstaat (Fn. 12), 278 ff., 312 ff.

${ }^{65}$ Grundlegend J. Habermas Faktizität und Geltung, 1992, insb. 221 ff., 435 ff.; aus der Rechtswissenschaft B.-O. Bryde Staatswissenschaften und Staatspraxis 5 (1994), 305 (321 ff.), G. Frankenberg Die Verfassung der Republik, 1996, 35 ff., 92 ff.; auf die Bedeutung von Öffentlichkeit und Transparenz weist auch T. Gro $\beta$ Rechtswissenschaft 2011, 125 (144, 147), hin, der aber auch das begrenzte Legitimationspotential von Transparenz betont. Als Kritik am Legitimationskettenmodell: J. Kersten FS Papier, 2013, 103 (108 ff.).

${ }^{66}$ Dieses Demokratieverständnis liegt der Kritik von E.-W. Böckenförde FS Schäfer, 1980, 182 (186), zugrunde: Böckenförde konstatiert für den unitarischen Bundesstaat zugleich eine Tendenz zur Allparteienregierung (191), diese Entwicklung ist für ihn jedoch alternativlos, da sie zwangsläufig aus der Idee der „Einheitlichkeit der Lebensverhältnisse" folge (194); grundlegend zum Modell der Legitimationsketten: E.-W. Böckenförde HStR II, 3. Aufl. 2004, § 24 Rn. 16 ff. Ähnlich bezüglich der Kritik kooperativer Strukturen: G. Kisker DÖV 1977, 689 (692), ders. in: E. Benda (Hrsg.) Probleme des Föderalismus, 1985, 23 (32 f.); A. Musil Wettbewerb in der staatlichen Verwaltung, 2005, 107 ff., 117 ff., $181 \mathrm{f}$.

${ }^{67}$ J. Isensee HStR VI (Fn. 12), § 126 Rn. 124.

${ }^{68}$ Die bei weiterreichender Unabhängigkeit der Experten noch gesteigert würde. Kritik an der Exekutivlastigkeit formulieren etwa G. Kisker DÖV 1977, 689 (694 f.); E.-W. Böckenförde FS Schäfer, 1980, 182 (186); W. Leisner DÖV 1968, 389 (390). Zur Relevanz parlamentarischer Verantwortlichkeit: Musil Wettbewerb in der staatlichen Verwaltung (Fn. 66), 120, 158. 
rung von Entscheidungen gerade in die Parlamente. ${ }^{69}$ Dabei ist es eine Frage der Optimierung von Demokratie, ob Landes- oder Bundesparlament die richtige Entscheidungsebene ist. ${ }^{70}$ Die Antwort hierauf ist ihrerseits dem politischen Prozess zu überantworten.

Deshalb ist es nicht überraschend, dass auch in der Staatsrechtslehre trotz einhelliger Kritik am bestehenden System keine Einigkeit über ein besseres besteht. Ebenso wenig verwundert es dann, dass die politischen Akteure die staatsrechtlichen Impulse zwar aufnahmen, aber in der Gesetz gewordenen Reform letztlich so unterschiedliche Ziele vereinten, dass vom Ursprungsanliegen, der Beseitigung der Politikverflechtung, nur wenig übrig blieb. ${ }^{71}$

\section{Gemeinsamer Nenner: Wettbewerb}

\section{Bildungswettbewerbsföderalismus}

Dies bedeutet aber nicht, dass die Föderalismusreform in der Bildungspolitik ohne Effekt verhallt wäre.

Denn sie fällt in den gleichen Zeitraum, für den die Bildungswissenschaften eine neue Dynamik und sogar einen Paradigmenwechsel in der Schul- wie auch in der Hochschulpolitik ausmachen. ${ }^{72}$ Daher ist es nachvollziehbar, dass die bildungspolitischen Akteure die Föderalismusreform in ihren eigenen Kontext stellen. ${ }^{73}$

${ }^{69}$ C. Möllers in: J. Aulehner et al. (Hrsg.) Föderalismus - Auflösung oder Zukunft der Staatlichkeit?, AssÖR 1997, 81 (108 f.); eine zentrale Rolle der Parlamente kann aus beiden demokratietheoretischen Kritikperspektiven eingefordert werden: Bryde in: Redaktion Kritische Justiz (Fn. 64), 70; E.-W. Böckenförde FS Schäfer, 1980, 182 (186).

${ }^{70}$ B.-O. Bryde in: B. Sitter-Liver (Hrsg.) Herausgeforderte Verfassung. Die Schweiz im globalen Kontext, 1999, 223; ders. in: Redaktion Kritische Justiz (Fn. 64), 59.

${ }^{71}$ Die deshalb teils harsche Kritik (S. Korioth FS Papier, 2013, 133 [138]; P. Selmer JuS 2006, 1052 [1058]; H.-J. Papier NJW 2007, 2145 [2148]) betrifft die Föderalismusreform insgesamt. Für die Bildungskompetenzen gilt keine Ausnahme. Im Gegenteil findet sich auch hier prononcierte Kritik: $U$. Münch Jahrbuch des Föderalismus 2009, 225 (227, 229 f.); dies. in: Gagnon/Sturm (Fn. 22), 179 f. Strukturell ähnlich auch das Resümee von Oeter Bundesstaat (Fn. 8), 290, zur Finanzreform 1969: Konsistentes Reformprogramm in Form des Troeger-Gutachtens, traditionelle Denkweisen und aktuelle, nicht zuletzt vom internationalen Vergleich beeinflusste Ideen verbanden sich zu einem unitarischen Ziel, das in der konkreten Reform aus Notwendigkeit des politischen Kompromisses jedoch deutlich verwässert wurde.

72 J. Baumert Vortrag auf der Tagung „Wege in einen leistungsfähigen Bildungsföderalismus" bei der Robert-Bosch-Stiftung in Berlin am 14./15.2.2013 (www.boschstiftung.de/content/language1/html/42639.asp, Abruf 17.10.2013).

${ }^{73}$ S. etwa bei $H$.-E. Tenorth Vortrag auf der Tagung ,Wege in einen leistungsfähigen Bildungsföderalismus“ (Fn. 72); ders. ZfPäd 2003, 69 (75 ff.). 
Dies bietet sich umso mehr an, als bildungspolitischer Wandel und Föderalismusreform einen gemeinsamen Nenner haben, nämlich die Bezugnahme auf Wettbewerb als neues Leitbild. Wettbewerb ist das Leitbild der neuen Governance im Bildungssektor (unter a.). Zugleich ist Wettbewerb auch das Leitbild eines „neuen“ Föderalismusverständnisses, das das weithin kritisierte Modell des kooperativen Föderalismus ablösen soll (unter b.).

\section{a. Wettbewerb im Bildungswesen}

Mehrere Länder haben - meist unter dem Stichwort Schulautonomie ${ }^{74}$ - die Gestaltungsmöglichkeiten der Schulen erweitert. Schulen sollen eigene Profile entwickeln, verabschieden hierfür Programme und erhalten Einfluss auf die Personalentwicklung. ${ }^{75}$ Teilweise wurde die sogenannte Sprengelpflicht für die Grundschulen aufgehoben, so dass Eltern bereits in der Primarstufe die Wahl zwischen verschiedenen Schulen haben. ${ }^{76}$ Manche Länder überlassen auch die Verkürzung der Gymnasialzeit von neun auf acht Jahre als Option den einzelnen Schulen. ${ }^{77}$

Noch deutlicher war der Wandel im Hochschulbereich, ${ }^{78}$ der schon 2005 und 2009 intensiv in diesem Kreis behandelt wurde. ${ }^{79}$ Seine wichtigsten Stichworte sind Veränderungen der Hochschulverfassungen mit Stärkung der Zentralverwaltungen und Dekanate, die Pluralisierung der universitären Binnenstrukturen und eine Neuordnung der Studiengänge und Abschlüsse als Bachelor und Master.

Beide Entwicklungsprozesse erhielten wesentliche Anstöße auf internationaler Ebene. ${ }^{80}$ In der Hochschulpolitik war dies vor allem der Bologna-

${ }^{74}$ Hierzu s. etwa M. Rürup Innovationswege im deutschen Bildungssystem, 2007, 27, 107 ff., 265 ff.; H. Avenarius in: Avenarius/Füssel (Fn. 21), 260 f.; einen Überblick bietet auch $H$. Wißmann JöR n.F. 60 (2012), 225 (233 ff.).

75 Vgl. bei H. Wißmann Die Verwaltung 45 (2012), 307 (324 ff.).

76 S. auch bei H. Wißmann Die Verwaltung 45 (2012), 307 (318).

77 S. für Hessen: http://verwaltung.hessen.de/irj/HKM_Internet?cid= 1763142a038afa2d4fe719af8584f525, Abruf 17.10.2013; die Umstellung der Gymnasialschulzeit von neun auf acht Jahre in den alten Bundesländern geht auf den Beschluss der Kultusministerkonferenz vom 6.3.2008 zurück, dazu und zum Umsetzungsstand vgl. http://www.kmk.org/bildung-schule/allgemeine-bildung/sekundarstufe-iigymnasiale-oberstufe.html, Abruf 17.10.2013.

${ }^{78}$ S. insb. Monopolkommission, Wettbewerb als Leitbild der Hochschulpolitik, 2000 (Sondergutachten 30); vgl. den Überblick der rechtsberatenden Empfehlungen bei M.-E. Geis Universitäten im Wettbewerb, VVDStRL 69 (2010), 364 (366 f.).

${ }^{79} R$. Hendler und $U$. Mager Die Universität im Zeichen von Ökonomisierung und Internationalisierung, VVDStRL 65 (2006), 238 und 274; M.-E. Geis und C. Bumke Universitäten im Wettbewerb, VVDStRL 69 (2010), 364 und 407.

${ }^{80}$ Zur nicht nur geografischen „Entgrenzung“ der Bildungspolitik vgl. K. S. Amos in: Hrbek/Große Hüttmann/Schmid (Fn. 42), 21. 
Prozess, ${ }^{81}$ aber auch die Resonanz auf internationale Hochschulrankings. ${ }^{82}$ In der Bildungspolitik wird mit dem Schlagwort „PISA-Schock“"83 die neue Wahrnehmung ${ }^{84}$ internationaler Vergleiche beschrieben. ${ }^{85}$ Die KMK spricht als Folge dieser Entwicklung von einem Paradigmenwechsel. ${ }^{86}$ Man verfolge eine neue Governance-Philosophie, ${ }^{87}$ mit outcomeSteuerung und Qualitätssicherung durch die Entwicklung von Bildungsstandards, Teilnahme an Vergleichsstudien und mit einer regelmäßigen Bildungsberichtserstattung. Für die Hochschulen hätten sich Wettbewerb und Leistungsorientierung zu den wesentlichen Steuerungsfaktoren entwickelt, deren Instrumente insbesondere finanzierungsrelevante Zielvereinbarungen, Evaluationen und Exzellenzwettbewerbe seien. ${ }^{88}$

\section{b. Wettbewerbsföderalismus}

Auch in der staatsrechtlichen Föderalismusdiskussion hat der Begriff des Wettbewerbs Konjunktur. ${ }^{89}$

${ }^{81}$ Hierzu etwa P. Ziedeck Bologna-Prozess in Deutschland, 2013; gegen entsprechende Studienreformen für die Rechtswissenschaft etwa H.-J. Papier/M. Schröder NJW 2012, 2860; kritisch zur Akkreditierung U. Quapp DÖV 2011, 68; M. Siever Qualitätssicherung durch Programm- und Systemakkreditierung im deutschen Hochschulsystem, 2011.

${ }^{82}$ Ausgangsidee der Exzellenzinitative des Bundes war die Vorstellung, ein deutsches Harvard erreichen zu wollen, s. etwa FAZ vom 6.1.2004 „Ein ,deutsches Harvard“ sorgt für Diskussionsstoff “, http://www.faz.net/aktuell/politik/inland/eliteuniversitaetein-deutsches-harvard-sorgt-fuer-diskussionsstoff-1145017.html, Abruf 17.10.2013; zu Hochschulrankings vgl. E. Braum Nationale und internationale Hochschulrankings im Vergleich und ihr Einfluss auf strategische Entscheidungen der deutschen Hochschulen, Diplomarbeit Goethe-Universität Frankfurt 2009, 40 f.; zur Entwicklung der Exzellenzinitiativen seit 2006/07 I. Roessler Was war? Was bleibt? Was kommt? 15 Jahre Erfahrung mit Rankings und Indikatoren im Hochschulbereich, September 2013 (http://www. che.de/downloads/CHE_AP_167_Erfahrungen_mit_Rankings_und_Indikatoren.pdf).

${ }^{83}$ Zur Reaktion vgl. P. Knodel et al. (Hrsg.) Das „PISA-Echo“, 2010.

${ }^{84}$ Dabei handelt es sich eher um eine veränderte Wahrnehmung, denn auch in der Vergangenheit hatte die Bundesrepublik an Vergleichsstudien teilgenommen und ähnlich abgeschnitten, ohne dass dies eine größere Resonanz in der deutschen Bildungspolitik und -wissenschaft fand.

${ }^{85}$ S. etwa B. Fahrholz Nach dem Pisa-Schock - Plädoyer für eine Bildungsreform, 2002.

${ }^{86}$ Etwa: Bildungsstandards der Kultusministerkonferenz, 2004, 6.

${ }^{87}$ Zum Governance-Ansatz im Bildungswesen: M. Rürup in: R. Langer (Hrsg.) „Warum tun die das?“, 2008, 175 (177 f.); allgemein: Schuppert (Hrsg.) (Fn. 33); Benz in: Schuppert (Fn. 33), $99 \mathrm{f}$.

${ }^{88}$ S. http://www.kmk.org/wissenschaft-hochschule.html, Abruf 17.10.2013.

${ }^{89}$ Zum Leitbildcharakter für die Föderalismusreform mit entsprechender Kritik etwa H. Bauer DÖV 2002, 837; U. Volkmann in: v. Mangoldt/Klein/Starck (Fn. 34), Art. 91a Rn. 4. 
Schon die frühe politikwissenschaftliche Kritik am kooperativen Föderalismus der Bundesrepublik wurde nicht nur unter dem Schlagwort der Politikverflechtung ${ }^{90}$ geführt. Der Idee eines Konsensföderalismus wurde in den 1980er Jahren die des Konkurrenzföderalismus gegenübergestellt. ${ }^{91}$ Ausgangspunkt war die Konzeption von Demokratie als einem Parteienwettbewerb, der durch die Verflechtung im föderalen System behindert werde. ${ }^{92}$ Damit die Parteien zueinander in Konkurrenz um politische Ideen treten, sollten die Länder ihre Gestaltungsmöglichkeiten als Chance für einen Ideenwettbewerb begreifen..$^{93}$

In den 1990er Jahren gewann der Begriff des Wettbewerbsföderalismus eine ganz andere, praktischere Bedeutung. ${ }^{94}$ Die Geberländer im Finanzausgleich, Hessen, Baden-Württemberg und Bayern, hingen der Vorstellung an, Länder stünden im Bund zueinander im Wettbewerb ähnlich wie Unternehmen am Markt. ${ }^{95}$ So begründeten sie, dass „die Früchte des Handelns“ eines Landes dort bleiben müssten, „,wo die Leistung erbracht wurde". .96

Auch in der Rechtswissenschaft wurden Begriff und Idee eines Wettbewerbsverhältnisses der Länder aufgegriffen. ${ }^{97}$ Die finanzpolitische Kon-

90 S. dazu oben Fn. 53, 57.

${ }_{91}$ Klatt Aus Politik und Zeitgeschichte (Fn. 60), 3.

92 Maßgeblich G. Lehmbruch Parteienwettbewerb im Bundesstaat, 1976, 158 ff.; 170 ff., s. auch D. Grimm in: E. Benda/W. Maihofer/H.-J. Vogel (Hrsg.) HdBVerfR, 2. Aufl. 1995, § 14 Rn. 70 f. Fn. 139.

${ }_{93}$ Klatt Aus Politik und Zeitgeschichte (Fn. 60), 22 - übrigens innerhalb der bestehenden verfassungsrechtlichen Rahmenbedingungen.

${ }_{94}$ Als Beispiel für die ökonomische Konzeption von Föderalismus etwa L.P. Feld in: H.-J. Blanke/W. Schwanengel (Hrsg.) Zustand und Perspektiven des deutschen Bundesstaates, 2005, 171; ihr folgte dann auch: Klatt in: Meier-Walser/Hirscher (Fn. 63), 64 ff.: Aus Konkurrenzföderalismus als Ideenwettbewerb der Länder wird nun ein Wettbewerbsföderalismus iSd finanzökonomischen Stärke eines Landes. Daher fordert Klatt Anforderungen an die Finanzverfassung zur Herstellung von „Chancengleichheit“.

95 Ähnlich auch die Referate von C. Waldhoff Finanzautonomie und Finanzverflechtung in gestuften Rechtsordnungen, VVDStRL 66 (2007), 216 (252 ff.) und J. Hey Finanzautonomie und Finanzverflechtung in gestuften Rechtsordnungen, VVDStRL 66 (2007), 277 (283 ff.): Allerdings dürfe man den (Abgaben-)Wettbewerb der Länder bzw. Staaten nicht mit einem Marktwettbewerb von Individuen oder Unternehmen gleichsetzen; erst bei entsprechender Rahmensetzung sei er möglich und sinnvoll.

$96 \mathrm{Vgl}$. etwa für bundesweite Umverteilungseffekte in der Sozialversicherung: B. Stamm/G. Merkl ZRP 1998, 467 (471); für den Finanzausgleich vgl. die Darstellung der Position der Länder Bayern, Baden-Württemberg und Hessen bei Schuppert in: Härtel (Fn. 17), § 9 Rn. 33 ff.

${ }_{97}$ E. Schmidt-Jortzig DÖV 1998, 746; C. Calliess in: Aulehner et al. (Fn. 69), 293 (297 ff.); ders. DÖV 1997, 889 (892); H. P. Bull DÖV 1999, 269; eher deskriptiv H.-P. Schneider NJW 1991, 2448 (2450); H. Bauer DÖV 2002, 837; Kritisch: Huber Klarere Verantwortungsteilung (Fn. 14), D44 f.; analytisch zur Vorstellung von einem Wettbe- 
notation wurde dabei durch Anleihen am politologischen Konzept eines Ideenwettbewerbs ${ }^{98}$ ergänzt. Länder sollten miteinander in Wettbewerb um die beste Form der Aufgabenverwirklichung treten. Die föderale Struktur biete gewissermaßen Laboratorien für die Erprobung von Innovationen. ${ }^{99}$

\section{Funktionsbedingungen}

Daher liegt es nahe, Bildungswettbewerb und Wettbewerbsföderalismus begrifflich als Bildungswettbewerbsföderalismus zu fassen. Stellt man ihn auf den Prüfstand, sind seine Funktionsbedingungen zu hinterfragen. Dabei spricht alles dagegen, dass Bildungsföderalismus als Wettbewerb der Länder um die beste Bildungspolitik gelingen kann. ${ }^{100}$

\section{a. Praktische Voraussetzungen eines Nachfragewettbewerbs}

Erstens gibt es in Bezug auf Bildung keinen Nachfragewettbewerb ${ }^{101}$ zwischen den Ländern. Der Umzug einer Familie in ein anderes Bundesland wird nur in besonderen Einzelfällen wegen eines besseren Schulangebotes erfolgen. ${ }^{102}$ „Marktrelevant“" ist dies nicht.

Im Hochschulbereich wählen zwar die Studierenden ihre Universität aus, so dass im Grundsatz ein Nachfragewettbewerb möglich ist. Das

werb von Rechtsordnungen: A. Peters und T. Giegerich Wettbewerb von Rechtsordnungen, VVDStRL 69 (2010), 7 und 57.

${ }_{98}$ Zum Konzept des Ideenwettbewerbs, der in der Demokratie als Parteienwettbewerb erfolgt, vgl. nur M. Morlock in: H. Dreier (Hrsg.) GG-Kommentar, Bd. II, 2. Aufl. 2006, Art. 21 Rn. 26; s. auch A. Hatje Demokratie als Wettbewerbsordnung, VVDStRL 69 (2010), $135 \mathrm{mwN}$.

${ }_{99}$ Diese Funktion betonen etwa: Lehmbruch Parteienwettbewerb (Fn. 92), 160 f.; L. P. Feld in: Blanke/Schwanengel (Fn. 94), 179 f.; skeptischer: H. Bauer DÖV 2002, 837 (842 ff.). Eine grundlegende empirische Studie zum Innovationspotential der Gliedstaaten im US-amerikanischen Kontext, wo der Laborcharakter eine zentrale Rechtfertigung föderaler Gestaltung darstellt, bietet: J. L. Walker The diffusion of innovations among american states, American Political Science Review, 63 (1969), 880. Vgl. zum Laborcharakter in der US-amerikanischen Diskussion grundlegend die dissenting opinion von Justice Brandeis, in U.S.S.C., New State Ice Co. v. Liebmann, 285 U.S. 262 (311).

${ }^{100}$ Skeptisch auch Immerfall in: v. Blumenthal/Bröchler (Fn. 30), 208 ff., mit etwas anderen Argumenten.

${ }_{101}$ Zur Nachfrager-Perspektive beim Wettbewerb von Rechtsordnungen: Peters Wettbewerb (Fn. 97), 17 ff.

102 Rürup in: Langer (Fn. 87), 181; Immerfall in: v. Blumenthal/Bröchler (Fn. 30), 209. 
Land, in dem die Universität belegen ist, dürfte aber regelmäßig nicht relevant sein.

Einziger landesrechtlicher Faktor bei der Auswahl des Studienortes dürften die Studiengebühren sein. ${ }^{103}$ Sie sind die sprichwörtliche Ausnahme, die die Regel bestätigt: Vielleicht wurde ihre Einführung noch von dem Ziel getragen, mit den Einnahmen die universitäre Ausbildung zu verbessern. ${ }^{104}$ Aber ihre Abschaffung erfolgte in keinem Land nach den Steuerungsmustern eines Nachfragewettbewerbs. Sie hatte keinen Bezug zu realen oder auch nur denkbaren Effekten auf einem „Studienplatzmarkt". Vielmehr erfolgte sie in Erfüllung politischer Wahlversprechen ${ }^{105}$ oder in Bayern auf direktdemokratische Initiative hin. ${ }^{106}$

\section{b. Inkompatibilität mit demokratischer Entscheidungsfindung}

Studiengebühren sind damit eines der raren Beispiele für funktionierende Demokratie auf Landesebene, nämlich für politische Entscheidungen entsprechend der - im Wahlergebnis gespiegelten - Mehrheitsmeinung der Bevölkerung. ${ }^{107}$ Der Entscheidungsprozess folgt also nicht ökonomischen Rationalitätskriterien. Für das Funktionieren eines Länder-

${ }^{103}$ Allgemein J. Kugler Allgemeine Studiengebühren und die Grundrechte der Studierenden, 2009, 3 ff., 123 ff.; aus ökonomischer Sicht für Studiengebühren W. Richter/ B. Wigger Forschung und Lehre 11/2010, 804. Dass Studiengebühren alleinige Länderkompetenz sind und nicht durch Bundesrecht vorgegeben werden dürfen: BVerfGE 112, 226; dazu: V. Sporleder-Geb/M. Stüber RdJB 2005, 395; R. Stettner JZ 2005, 619. Bereits auf der Jahrestagung 2009 hat Geis dargelegt, warum Studiengebühren als Wettbewerbsinstrument um Studierende verfehlt sind und allenfalls der Verzicht eines Bundeslandes auf Studienbeiträge eine gewisse Rolle spielen könne: Geis Universitäten im Wettbewerb (Fn. 78), $377 \mathrm{ff}$.

${ }^{104}$ In Bayern, LT-Drs. 15/4396, und Baden-Württemberg, LT-Drs. 13/4858, stellte der Gesetzgeber insb. auch auf den internationalen Wettbewerb ab, der eine finanzielle Stärkung zur Verbesserung der Studienbedingungen verlange; in Nordrhein-Westfalen, NRW LT-Drs. 14/725, wird besonders die Aktivierung der Studierenden betont; in Hessen, LT-Drs. 16/5747, weist der Gesetzgeber auf den Konkurrenzdruck anderer Bundesländer mit Studiengebühren hin.

105 Ausdrücklich in Baden-Württemberg LT-Drs. 15/902; in NRW, LT-Drs. 15/97, und Hessen, LT-Drs. 15/17, verweist die Gesetzesbegründung auf den fehlenden Rückhalt in der Bevölkerung, der sich durch Massenproteste und Massenklageverfahren zeige. In allen Bundesländern wurden (wenn auch nicht dynamisierte) Kompensationsleistungen des Landes an die Universitäten eingeführt.

106 Bay. LT-Drs. 16/15926, 3; in Hamburg hingegen war ein Volksbegehren zu Studiengebühren nicht zulässig, vgl. R. Kleindiek FS Bryde, 2013, 175 (183).

107 Allg. zu direktdemokratischen Instrumenten: M. Möstl und M. Schuler-Harms Elemente direkter Demokratie als Entwicklungsperspektive, VVDStRL 72 (2013), 355 und 417; insb. zum bayerischen Volksbegehren gegen Studiengebühren Möstl ebd., 385. 
wettbewerbs ist dies misslich. Aus demokratischer Sicht ist gerade dies gut so. ${ }^{108}$

Hier zeigt sich, dass die Idee des Wettbewerbsföderalismus nicht demokratische, sondern fachadministrative Entscheidungsträger voraussetzt. Nur ihnen lässt sich Entscheidungsrationalität in welcher Spielart auch immer unterstellen. Wettbewerbsföderalismus ist also ein Konzept, das Exekutivföderalismus voraussetzt. 109

Die exekutivische Ausrichtung speziell eines Bildungswettbewerbsföderalismus besteht zudem noch bei der Wettbewerbsrahmengestaltung. In anderen Politikbereichen, in denen dem Bund Gesetzgebungskompetenzen zustehen, lässt sich das Konzept eines Wettbewerbsföderalismus noch als Form der Gewaltenteilung verstehen: Die Länder konkurrieren bei der Gesetzesausführung. Der Wettbewerbsrahmen hierfür wird aber durch Bundesgesetz, und damit von der Legislative vorgegeben. Der Rahmen des Bildungswettbewerbsföderalismus wird hingegen kooperativ von den Ländern, und hier von ihren Exekutiven gesetzt - es handelt sich also um den Governancemodus der Selbstregulierung. ${ }^{110}$

\section{c. Finanzökonomische Rationalitäten}

Ein dritter Einwand ergibt sich aus den finanzökonomischen Rahmenbedingungen eines Länderwettbewerbs. Unterstellt, die Länder hätten ausreichende Finanzmittel, ${ }^{111}$ um Bildungsinvestitionen zu tätigen, so sprächen doch die Gründe ökonomischer Rationalität dagegen. Wegen der hohen Mobilität der Bevölkerung realisieren sich Bildungsinvestitionen nur teilweise im dem Land, das die Investitionen getätigt hat. Wettbewerbsmodelle, die den Investitionsanreiz erhalten wollen, verlangen deshalb einen Ausgleich zwischen den Ländern oder andere Strategien, um die Externalisierung der Gewinne aufzufangen. ${ }^{112}$

${ }_{108}$ Wie artifiziell und wenig ertragreich eine wettbewerbliche Reformulierung demokratischer Entscheidungsfindung ist, zeigt M. Kotzur Demokratie als Wettbewerbsordnung, VVDStRL 69 (2010), 171 (201 ff.).

${ }^{109}$ Darin unterscheidet er sich nicht vom kooperativen Föderalismus, Kritik daran etwa bei H. Bauer DÖV 2002, 837 (840); zum Wettbewerbsföderalismus als Exekutivföderalismus vgl. indirekt H. P. Bull DÖV 1999, 269 (271); K.-P. Sommermann in: v. Mangoldt/Klein/Starck (Fn. 34), Art. 20 Rn. 55; Huber Klarere Verantwortungsteilung (Fn. 14), D44.

110 Dazu G. F. Schuppert Die Verwaltung Beiheft 4/2001, 201.

111 Kritisch Immerfall in: v. Blumenthal/Bröchler (Fn. 30), 208; s. auch Dohmen Bildungsföderalismus (Fn. 6), 75 f.

${ }_{112}$ Vgl. Immerfall in: v. Blumenthal/Bröchler (Fn. 30), 209; anders setzt R. Sturm in: Hrbek/Große Hüttmann/Schmid (Fn. 42), 35 (39 ff.), an: da die Bildungskompetenzen normativ den Ländern zugewiesen seien, müssten sie auch die Fiskalhoheit inkl. Einnahmenkompetenzen nach sich ziehen. 
Zudem stünden Bildungsinvestitionen stets in Konkurrenz mit sämtlichen anderen Landesausgaben. Ihnen gegenüber wären sie strukturell schwächer, da Bildungsgewinne nur mit großer zeitlicher Verzögerung realisiert werden könnten und auch dann nur schwer messbar bestimmten Investitionsentscheidungen zuzuordnen wären. ${ }^{113}$ Ökonomisch rationale Argumente sprechen daher nicht für gesteigerte Bildungsinvestitionen einzelner Länder. ${ }^{114}$

\section{d. Wettbewerb und Parteiendemokratie}

Lässt man die finanziellen Aspekte außer Betracht und konzentriert sich nochmals auf das Modell eines Ideenwettbewerbs, so wird schließlich aus politikwissenschaftlicher Sicht der grundlegende Webfehler des Wettbewerbsföderalismus als Vorschlag für den deutschen Bundesstaat deutlich.

Träger der Ideen zur Gestaltung eines Politikbereichs sind in der Bundesrepublik Deutschland die Parteien. Die Kritik am kooperativen Föderalismus der Bundesrepublik beruht, wie dargestellt, ${ }^{115}$ auf der These, dass durch die föderale Politikverflechtung der Parteienwettbewerb gelähmt werde.

Das gilt aber auch umgekehrt: Nicht nur die föderale Kompetenzverflechtung behindert Parteienwettbewerb, sondern die Parteiendemokratie behindert einen föderalen Ideenwettbewerb. ${ }^{116}$ Parteien stehen beim Ringen um die politische Macht in einem klassischen Verdrängungswettbewerb zueinander. ${ }^{117}$ Die Entwicklung neuer Ideen und Konzepte ist dabei zwar angelegt, aber zugleich auch begrenzt. Neben und womöglich auch unabhängig von sachlichen Kriterien, die für ein neues Politikkonzept sprechen, kommt es für eine Partei darauf an, wie sich das neue Konzept in der parteipolitischen Auseinandersetzung auszahlt. Das Scheitern der Schulreform der schwarz-grünen Hamburger Koalition ${ }^{118}$ ist eindrückli-

113 Vgl. Immerfall in: v. Blumenthal/Bröchler (Fn. 30), 208 ff.; Rürup in: Langer (Fn. 87), 180 f.; $O$. Busch Wie groß ist der Brain-Drain innerhalb von Deutschland, ifo Dresden Berichte 2007, $50 \mathrm{f}$.

114 So auch i.E. Dohmen Bildungsföderalismus (Fn. 6), 75 f.; daher werden Bundesmittel als ökonomisch sinnvolle Quelle für Investitionen gefordert; zur verfassungsrechtlichen Umsetzung dieser Forderung: J. Wieland ZG 2012, 266 (273).

115 S.o. unter I.2.b. und II.1.b.

${ }^{116}$ Hierzu und zum folgenden: Rürup in: Langer (Fn. 87), 182 ff., insb. der Vergleich mit Patenten.

117 Zum Parteienwettbewerb grundlegend J. Schumpeter Kapitalismus, Sozialismus und Demokratie, 7. Aufl. 1993, 427 ff.; Lehmbruch Parteienwettbewerb (Fn. 92); vgl. auch Morlock in: Dreier (Fn. 98), Art. 21 Rn. 26; Hatje Demokratie (Fn. 98), 135.

118 Vgl. hierzu Münch in: Gagnon/Sturm (Fn. 22). 
ches Beispiel dafür, zu welchen Konsequenzen die Vernachlässigung dieser Dimension für die Parteien führen kann.

Aber auch erfolgreiche neue Ideen können in einem föderalen System, dessen politische Architektur von Parteien geprägt wird, nicht einfach von anderen Bundesländern übernommen werden. Denn sie werden ähnlich wie Patente der Parteien behandelt: Mit ihnen identifizieren sich die Parteien und festigen ihre Marktposition. Wenn der politische Gegner sie - ausnahmsweise - übernehmen will, dann nur unter Änderung etwa der zentralen Begriffe und unter Betonung der Unterschiede.

Bisherige Veränderungen im Bildungsbereich lassen sich nach diesem Muster deuten. So wird etwa verständlich, warum die Zusammenlegung von Haupt- und Realschule in fast jedem Land unter einer eigenen Bezeichnung und mit deutlichen Unterschieden erfolgt, ${ }^{119}$ ohne dass etwa die bestehenden zweigliedrigen Systeme nach dem best practice-Ansatz verglichen worden wären. ${ }^{120}$

Im Ergebnis ist festzuhalten: Auch dort, wo das Grundgesetz keine Politikverflechtung erzwingt, funktioniert ein Ideenwettbewerb der Bundesländer nicht so, wie es das Modell eines Bildungswettbewerbsföderalismus verlangen würde.

\section{Bildungswettbewerb und Unitarisierung}

Dennoch ist die Idee eines Bildungswettbewerbsföderalismus nicht ohne Belang. Das neue Governance-Konzept im Bildungswesen, ${ }^{121}$ das auf Wettbewerb der Schulen setzt, wird durch die Vorstellung gestärkt, das Bildungswesen sei auch auf verfassungsrechtlicher Ebene als Wettbewerb, nämlich als Wettbewerbsföderalismus konzipiert.

Ein solcher Wettbewerb der Schulträger bringt allerdings keine Vielfalt im Sinne föderaler Unterschiede hervor. Vielmehr führt die Gestaltung seiner rechtlichen Rahmenbedingungen zur Unitarisierung des Bildungsrechts.

${ }^{119}$ Zur Vielfalt der unterschiedlichen Varianten eines zweigliedrigen Schulsystems s. den Überblick bei H. Wißmann JöR n.F. 60 (2012), 225 (235 Fn. 32).

120 Münch in: Hrbek/Große Hüttmann/Schmid (Fn. 42), 54 ff., führt die starke Ausdifferenzierung der Länder in dieser Frage eher auf ein Nachlassen des bildungspolitischen Engagements in CDU und CSU zurück.

121 Zum Begriff der Governance im Bildungswesen s.o. Fn. 87. 
1. Grundrechte als „Bundeslehrplangrundsätze“

a. Der Krabat-Fall

Dies lässt sich anhand einer aktuellen Entscheidung des Bundesverwaltungsgerichts ${ }^{122}$ zeigen: ${ }^{123}$

In einer siebten Gymnasialklasse wurde das Jugendbuch Krabat von Otfried Preußler besprochen und dabei auch die Verfilmung von Marco Kreuzpaintner besucht. Die Eltern eines Schülers wollten ihn von dieser Filmvorführung befreien lassen, damit er nicht der Darstellung schwarzer Magie ausgesetzt wird. Das Bundesverwaltungsgericht hat dies abgelehnt. ${ }^{124}$

\section{b. Grundrechtsbindung bei der Unterrichtsgestaltung}

Zentrale Frage ist, ob der Film Unterrichtsgegenstand sein darf. ${ }^{125}$ Bejaht man sie, bleiben nur zwei Konfliktlösungsmöglichkeiten: Entweder

122 BVerwG vom 11.9.2013 - 6 C 12/12 - juris; Vorinstanz OVG Münster, NWVB1 2012, 235 ff., Rn. 36 ff.

123 Ein anderer Gegenstandsbereich, an dem sich das hier aufgezeigte Problem illustrieren ließe, sind Entscheidungen über Kopftücher oder Kreuze in Schulen: Das Bundesverfassungsgericht hat wiederholt herausgestellt, dass es den Landesgesetzgebern obliegt, die verfassungsimmanenten Schranken der grundgesetzlichen Religionsfreiheit bei der Ausgestaltung der weltanschaulich-religiös neutralen öffentlichen Schule zu bestimmen (s. BVerfGE 41, 29 und 89; BVerfGE 108, 282 ff., gerade hiergegen wendet sich das Sondervotum, 336 ff.). Solche Landesgesetze bleiben an den Grundrechten des GG überprüfbar, aber unterschiedliche Lösungen in den Ländern sind vorgesehen: BVerwG, NJW 2009, 1289; zur föderalen Vielfalt, die hierdurch konkret zur Kopftuchfrage entstanden ist vgl. J. v. Blumenthal Das Kopftuch in der Landesgesetzgebung, 2009. Überlässt ein Landesgesetz die Entscheidung der einzelnen Schule oder Klasse, so ist eine solche Einzelentscheidung ihrerseits auf ihre Grundrechtskonformität hin überprüfbar: BVerwGE 109, 40.

124 Kritisch dagegen T. Langer: http://www.lto.de/recht/hintergruende/h/ bverwg-urteil-6c1212-krabat-zeugen-jehovas/?googlenews=1\&cHash= eeda2e0593868edac60f6fcb185a47f, Abruf 17.10.2013.

125 Hierzu mit ausführlichen grundsätzlichen Erwägungen BVerwG (Fn. 122), Rn. 21 ff. Entscheidend für den hier erörterten Zusammenhang ist, dass das BVerwG die Würdigung der Vorinstanz zur Frage, ob die Schule mit der Filmvorführung gegen das Neutralitäts- und Toleranzgebot verstoße, nicht mit durchgreifenden Verfahrensrügen angegriffen sieht (Rn. 22). Es sieht diese Wertung daher als im Revisionsverfahren bindend an. Das OVG Münster hat allerdings die Zulässigkeit der Unterrichtsgestaltung nur an den Vorgaben des Kultusministeriums - dem Lehrplan sowie Empfehlungen speziell zu diesem Film - gemessen. Wären diese Vorgaben bindend für die konkrete Unterrichtsgestaltung gewesen - etwa wie die Vorgabe eines koedukativen Sportunterrichts - so wäre dieser Prüfungsmaßstab ausreichend. Da jedoch der Lehrplan diese Themen- und Filmauswahl zwar ermöglicht, aber nicht bindend vorgibt, 
der Schüler muss die Grundrechtsbeeinträchtigung hinnehmen, die im verpflichtenden Filmbesuch liegt, oder die allgemeine Schulpflicht muss im Zuge einer Unterrichtsbefreiung zurückstehen. Der Konflikt würde aber gar nicht erst entstehen, wenn die Lehrkraft durch eine andere Gestaltung des Unterrichts zwischen den grundrechtlichen Bedürfnissen und schulischen Belangen ${ }^{126}$ hätte praktische Konkordanz herstellen können.

$\mathrm{Ob}$ sie hierfür die Möglichkeit hat, hängt vom Konkretisierungsgrad des Lehrplans ab. ${ }^{127}$ Wäre er so detailliert, dass er den Besuch des Filmes zwingend vorsähe, hätte die Lehrkraft keinen Gestaltungsspielraum. Ist der Lehrplan aber offen, trifft die Lehrkraft ${ }^{128}$ bei der Unterrichtsgestaltung die grundrechtliche Verantwortung.

\section{c. Revisibilität der Unterrichtsgestaltung}

Je nach Konkretisierungsgrad des Lehrplans ${ }^{129}$ ändert sich auch die gerichtliche Kontrolle.

hätte das OVG auch noch die Vereinbarkeit mit Grundrechten prüfen müssen. Es hätte fragen müssen, ob für den Lehrer bei der Unterrichtsplanung der drohende Konflikt vorhersehbar war und ob er die konfligierenden Grundrechte und Bildungsziele auf andere Weise hätte in praktische Konkordanz bringen können. Erst diese Wertung ist dann für das BVerwG bindend.

${ }^{126}$ Wie weit der staatliche Bildungs- und Erziehungsauftrag reicht, aus dem sich die konkreten schulischen Belange ergeben, ist Gegenstand einer umfangreichen Debatte. Für den Bereich religiöser Neutralität vgl. BVerwG (Fn. 122), Rn. 21 ff. mwN, allg. etwa M. Bothe und A. Dittmann Erziehungsauftrag und Erziehungsmaßstab der Schule im freiheitlichen Verfassungsstaat, VVDStRL 54 (1995), 8 und 48; M. Thiel Der Erziehungsauftrag des Staates in der Schule, 2000; aus der Kommentarliteratur etwa: F. Brosius-Gersdorf in: H. Dreier (Hrsg.) GG-Kommentar, Bd. I, 2. Aufl. 2004, Art. 7 Rn. 23 ff.; M. Jestaedt HStR VII (Fn. 19), § 156 Rn. 43 ff., 68 ff.

127 Der in der staatlichen Schulaufsicht iSd Art. 7 Abs. 1 GG wurzelnde Gestaltungsspielraum des Staates bei der Entscheidung über das schulische Bildungsangebot (vgl. nur Brosius-Gersdorf in: Dreier [Fn. 126], Art. 7 Rn. 36) kann nämlich auf unterschiedlichen Ebenen der Verwaltungsorganisation konkretisiert werden.

${ }^{128}$ Entsprechendes gilt bei einem Konkretisierungsrahmen der Schule etwa im Rahmen ihres Schulprogramms, s. hierzu H. Wißmann JöR n.F. 60 (2012), 225 (239 f.).

${ }^{129}$ Seine Rechtsnatur ist in den Bundesländern unterschiedlich: teils in Form der Rechtsverordnung (vgl. etwa $\S 4$ Abs. 5 S. 2 HessSchulG), teils in Form von Verwaltungsvorschriften (vgl. etwa Art. 45 Abs. 2 BayEUG). Für die Steuerungsintensität der Schulverwaltung ist diese Unterscheidung bedeutsam, da die Forderung, Lehrpläne als Rechtsverordnungen auszugestalten, mit einer Rücknahme der Schulverwaltung als Rechtsaufsicht verbunden war, die zu einer Stärkung der pädagogischen Freiheit der Lehrkräfte führen sollte, vgl. § 7 DJT-SchulGE der Kommission Schulrecht des Deutschen Juristentages (Hrsg.) Schule im Rechtsstaat, Bd. I, 1981, Entwurf für ein Landesschulgesetz, 318; zu dieser Debatte der 1970er Jahre s. etwa B.-O. Bryde DÖV 1982, 661 (671); nachzeichnend $H$. Wißmann Pädagogische Freiheit als Rechtsbegriff, 2002, 53 ff.; vgl. auch J. Rux Die Pädagogische Freiheit des Lehrers, 2002, 43 f. und 77 f. 
Bei konkreten Lehrplänen bleibt der Lehrkraft bzw. der Schulleitung nur die Entscheidung, ob im Einzelfall eine Befreiung gewährt werden muss. Das Bundesverwaltungsgericht als Revisionsinstanz prüft dementsprechend nur die bundesrechtliche und damit vor allem grundrechtliche Rechtmäßigkeit dieser Abwägungsentscheidung. ${ }^{130}$

Besteht hingegen ein Gestaltungsspielraum der Lehrkraft, so muss sie schon bei der Auswahl des Unterrichtsstoffes den Grundrechten Rechnung tragen. ${ }^{131}$ Etwaige Grundrechtsverstöße dieses Verwaltungshandelns sind dann gerichtlich bis in die Revisionsinstanz überprüfbar. ${ }^{132}$ Das Bundesverwaltungsgericht entscheidet dadurch auch über die Unterrichtsgestaltung. ${ }^{133}$

${ }^{130}$ Für die Zulässigkeit der Revision ist die Rechtsnatur des Lehrplans nicht entscheidend, denn es kommt nur darauf an, dass er die Verwaltung bindendes Landesrecht ist. Es ist daher nicht revisibel, vgl. F. O. Kopp/W.-R. Schenke (Hrsg.) VwGOKommentar, 18. Aufl. 2012, § 137 Rn. 9, 10, für Verwaltungsvorschriften allgemein Rn. 18; F. Schoch/J.-P. Schneider/W. Bier (Hrsg.) VwGO-Kommentar, 24. EL 2012, $\S 137 \mathrm{Rn} .80 \mathrm{ff}$.

${ }^{131}$ Dies wird bei der Betonung des staatlichen Gestaltungsspielraums unterschätzt oder jedenfalls nicht herausgearbeitet; ähnlich die rechtliche Steuerung ausblendend Dittmann Erziehungsauftrag (Fn. 126), 66. Hintergrund hierfür ist die dogmatische Unschärfe der Verwaltungsrechtswissenschaft, die durch die Fokussierung auf das Eingriffshandeln entsteht. Gestaltendes Verwaltungsrealhandeln wie der Unterricht entbehrt daher eines rechtsdogmatischen Zugriffs. Vgl. etwa bereits auf der Jahrestagung 1965 die Bemerkung von H. Ehmke Aussprache zu: Verwaltung und Schule, VVDStRL 23 (1965), 257 (258 f.): Der Referent sei „Opfer“ der Meinung geworden, „daß Verwaltung Gesetzesvollzug sei [...]. Das Problem ist aber doch, daß die Schulverwaltung, obgleich sie vielleicht am tiefsten von aller Verwaltung auf den Menschen einwirkt, mit den Vorstellungen der Eingriffsverwaltung nur sehr am Rande zu fassen ist, während die rechtsstaatlichen Sicherungen gerade gegenüber der Eingriffsverwaltung entwickelt worden sind." An diese dogmatische Lücke knüpft Wißmann Pädagogische Freiheit (Fn. 129), insb. 149 ff., 206 ff., an und folgert für das Gestaltungshandeln der Lehrkraft die gleiche Kontrolldichte wie beim Beurteilungsspielraum.

${ }_{132}$ Die These von Boysen Gleichheit (Fn. 12), 155 ff., dass ein verfassungsrechtliches Gebot der bundeseinheitlichen Anwendung von Bundesrecht - und damit Grundrechten - der föderalen Vielfalt auch bei richterlicher Anwendung und Auslegung des Bundesrechts nicht entgegenstehe, hat nicht die instanzgerichtlichen Entscheidungen im Blick, sondern die der Landesverfassungsgerichte. Bei diesen setzt das Prozessrecht föderalen Divergenzen nichts entgegen; Beispiel hierfür sächs. VerfGH vom 15.11.2013 - Vf. 25 II 12 -, der sich provokant vom Bundesrecht (insb. zu gerichtlich überprüfbaren ,prozeduralen“ Anforderungen an den Gesetzgeber entgegen BVerfGE 75, 40 [67], BVerfGE 90, 107 [117], BVerfGE 132, 134 [Rn. 70], BVerwG vom 21.12.2011 - 6 C 18/10 - juris, Rn. 14, 25) absetzt, sich allerdings zugleich auch von den rationalitätsund akzeptanzstiftenden Methoden und Argumentationsmustern deutscher Jurisprudenz weitgehend frei macht.

133 Die Konsequenz der Revisibilität der Unterrichtsgestaltung - im Unterschied zum individuellen Befreiungsanspruch - wird deutlicher, wenn man den konkreten Fall 
Zugespitzt könnte man sagen, dass mit den Grundrechten als Vorgaben zur Unterrichtsgestaltung bundeseinheitliche Lehrplangrundsätze bestehen. Je weniger die Lehrpläne der Landesschulverwaltung bestimmen, desto relevanter werden diese „Bundeslehrplangrundsätze“.

\section{Einbettung in steuerungswissenschaftliche Überlegungen}

Die geschilderte Beobachtung lässt sich auch mit steuerungswissenschaftlichen Überlegungen deuten. ${ }^{134}$

Neue Steuerungsformen, die Verwaltungseinheiten in ein Wettbewerbsverhältnis setzen und über Anreize zur effizienten Zielerreichung führen wollen, drängen die inhaltliche Steuerung der hierarchischen und parlamentarisch verantwortlichen Verwaltung zurück. Werden zudem die Inhalte als Expertenstandards definiert und für ihre Ermittlung externe Institutionen herangezogen, so nimmt auch bei der Normsetzung die demokratische Gestaltungsmöglichkeit ab. Es bleibt nur die gerichtliche Kontrolle am Maßstab der Grundrechte.

Dies findet im Bildungswesen statt, indem die KMK bundeseinheitliche Bildungsstandards durch externe Experten erarbeiten lässt. Die Landeskultusministerien übernehmen sie und greifen den Steuerungsmodus auf: Die Lehrpläne beschränken sich auf zunehmend abstraktere, kompetenzorientierte Zielvorgaben. Die weitere Ausgestaltung wird den Schulen und Lehrkräften überlassen. Die gerichtliche Kontrolle erfolgt nur an den Grundrechten und deshalb letztlich durch das Bundesverwaltungsgericht. ${ }^{135}$

Aus der Perspektive des Bildungsföderalismus lässt sich festhalten: Wettbewerbssteuerung im Bildungswesen erfolgt auf Kosten der Länderhoheit.

\footnotetext{
hypothetisch zu Ende denkt: Hätte das Bundesverwaltungsgericht nicht den Befreiungsanspruch, sondern die Unterrichtsgestaltung überprüft, und hätte es dabei entschieden, dass der Film Krabat nicht Unterrichtsgegenstand sein dürfe, dann würde in der ganzen Bundesrepublik dieser Film nicht mehr im Unterricht verwendet. Würden stattdessen Landeslehrpläne verbindlich die Filme vorgeben, die im Unterricht behandelt werden können, so könnte der Film Krabat etwa in Sachsen zum Unterrichtsgegenstand gehören, in Hessen hingegen nicht.

${ }^{134}$ S. etwa A. Voßkuhle in: W. Hoffmann-Riem/E. Schmidt-Aßmann/A. Voßkuhle (Hrsg.) Grundlagen des Verwaltungsrechts, 2012, § 1 Rn. 18 ff.; generell V. Mehde Neues Steuerungsmodell und Demokratieprinzip, 2000.

${ }^{135}$ Die Unitarisierung des Bildungsrechts durch die Grundrechte wurde häufig dargestellt, vgl. nur M. Jestaedt HStR VII (Fn. 19), § 156 Rn. 21; Wißmann Pädagogische Freiheit (Fn. 129), 31 ff., 40 ff.; Rux Pädagogische Freiheit (Fn. 129), 29, 32 f.
} 


\section{Bildungsföderalismus als Verfassungsvergleichung}

Bisher wurde festgestellt, dass Bildungsföderalismus weder als Wettbewerbsföderalismus funktioniert (oben unter II.) noch durch Bildungswettbewerb gefördert wird (oben unter III.). Interessanterweise lenkt aber die Wettbewerbsorientierung im Schulwesen den Blick auch auf eine verfassungsrechtliche Dimension, die deutlich macht, dass Bildungsföderalismus nur als Verfassungsvergleichung ${ }^{136}$ praktisch werden kann.

\section{Kernfrage: Schule und Staat}

Wird der Staat als Bildungsträger bzw. als „Dachorganisation“ kommunaler Bildungsträger in ein wettbewerbliches Steuerungssystem gestellt, wirft das die Frage auf, warum überhaupt der Staat und nicht andere Institutionen Träger des Bildungssystems ist. ${ }^{137}$ Für die Bildungswissenschaften ist diese Frage viel interessanter als die, welcher Staat Bund oder Land - diese Rolle einnimmt. ${ }^{138}$

\section{Verhältnis von öffentlicher und privater Schule \\ a. Grundgesetz: zwei Systeme}

Damit ist die Stellung der Privatschulen angesprochen. Sie ist Gegenstand des Verfassungsrechts, das eine klare Dichotomie vorgibt:139 Auf der einen Seite weist das Grundgesetz in Art. 7 Abs. 1 die Schulaufsicht

${ }^{136}$ In der Aussprache zum Beratungsgegenstand Wettbewerb von Rechtsordnungen, VVDStRL 69 (2010), 106 ff., wurde in zahlreichen Beiträgen deutlich, dass die Verfassungsvergleichung und daraus folgende Verfassungsberatung als „Wettbewerb“ um die Rechtsordnung oder bestimmte Rechtsinstitute durch die reformwilligen Staaten reformuliert werden kann.

137 Vgl. etwa den Argumentationsgang bei G.-B. Oschatz in: D. Merten (Hrsg.) Die Zukunft des Föderalismus in Deutschland und Europa, 2007, 69, der zunächst das Dilemma zwischen föderaler Struktur und unitarischer Politikerwartung (dazu oben bei Fn. 16) beschreibt, deshalb die Schwerfälligkeit der bestehenden Strukturen kritisiert und daraus dann einen Rückzug des Staates überhaupt aus dem Bildungssektor fordert.

138 Vgl. H.-P. FüssellP. M. Roeder ZfPäd Beiheft 47 (2003), 8 (9); vgl. H.-E. Tenorth VBE aktuell 2009, 11 (12).

139 Da grundgesetzlich eine Dichotomie von staatlicher und privater Schule vorgegeben ist, zählen im Folgenden auch die kirchlichen Schulen zu den Privatschulen, vgl. G. Robbers in: v. Mangoldt/Klein/Starck (Fn. 34), Art. 7 Rn. 179; dessen ungeachtet wurde zumindest bis in die 1960er Jahre ein kirchlicher Bildungs- und Erziehungsauftrag auch in Art. 4 GG verankert, mit der Konsequenz der Forderung nach öffentlichen Bekenntnisschulen, vgl. A. Hollerbach Kirchen unter dem Grundgesetz, VVDStRL 26 (1968), 57 (90). 
im umfassenden Sinne ${ }^{140}$ dem Staat zu. ${ }^{141}$ Auf der anderen Seite garantiert Art. 7 Abs. 4 GG ein Grundrecht auf Gründung und Betrieb von Privatschulen. In verwaltungswissenschaftlicher Perspektive entstanden dadurch zwei getrennte Steuerungsregime: die öffentliche Schule als Teil unmittelbarer Staatsverwaltung und die „freien“ Schulen als private Veranstaltungen, die zwar Genehmigungs- bzw. Anerkennungsvoraussetzungen unterliegen, aber grundsätzlich nicht in staatliche Steuerung eingebunden sind. ${ }^{142} \mathrm{Ihr}$ Verhältnis zueinander wird in jüngerer Zeit in Frage gestellt.

\section{b. Aktuelle Debatte: Wettbewerb zwischen öffentlichen und privaten Schulen?}

In den letzten Jahren haben einige Bundesländer die Finanzierung privater Schulen beschränkt. Der auch gerichtlich ausgetragene Protest der freien Schulträger ${ }^{143}$ lenkt den Blick auf das Arrangement öffentlicher und privater Schulen. ${ }^{144}$

Die demografische Entwicklung, konkret die Überalterung des ländlichen Raumes, führt vor allem in Kombination mit den bereits angesprochenen Sparzwängen im Bildungswesen dazu, dass das öffentliche Schulsystem in manchen Regionen empfindlich ausgedünnt wird. ${ }^{145}$ Immer

${ }^{140}$ Vgl. nur M. Jestaedt HStR VII (Fn. 19), $§ 156$ Rn. 38 ff. oder Füssel in: Avenarius/Füssel (Fn. 21), 180 f. mwN.

${ }^{141}$ Alle Landesverfassungen, soweit sie überhaupt das Schulwesen regeln, greifen dies auf: Art. 11 LVerf. BaWü; Art. 130 Abs. 1 und Art. 133 Abs. 1 Bay. Verf.; Art. 30 Abs. 2 Verf. Brandenburg; Art. 27 Abs. 2 und Art. 28 Brem. Verf.; Art. 56 Abs. 1 S. 2 Hess. Verf.; Art. 15 Abs. 1 und 2 Verf. Meck-Vorpomm.; Art. 4 Abs. 2 Verf. Nieders.; Art. 8 Abs. 1 S. 2 und Abs. 3 Verf. NRW; Art. 27 Abs. 2 und Abs. 3 Verf. Rheinl.-Pfalz; Art. 27 Abs. 2 Verf. Saarl.; Art. 102 Abs. 1 Sächs. Verf.; Art. 26 Abs. 1 Verf. Sachs.-Anh; Art. 8 Abs. 3 Verf. Schlesw.-Holst.; Art. 21 Abs. 2 und Art. 24 Abs. 1 Thür. Verf.

${ }_{142} \mathrm{Zu}$ den rechtlichen Rahmenbedingungen s. den Überblick bei Avenarius in: Avenarius/Füssel (Fn. 21), 295 ff. mwN; F. Brosius-Gersdorf Die Verwaltung 45 (2012), 389.

${ }^{143}$ Vgl. Sächs. VerfGH vom 15.11.2013, Vf. 25-II-12; weitere Verfahren in anderen Bundesländern sind anhängig.

144 Auch im Schrifttum wird dies kontrovers diskutiert, s. insb. H. Avenarius/ B. Pieroth/T. Barczak Die Herausforderung des öffentlichen Schulwesens durch private Schulen - eine Kontroverse, 2012.

${ }^{145}$ Besonders stellt sich dieses Problem aktuell in den ostdeutschen Bundesländern, aber nicht nur dort, vgl. Autorengruppe Bildungsberichterstattung (Hrsg.) Bildung in Deutschland 2010, 17 ff. Ebenso wird ein Schulsterben in NRW und Hessen beschrieben: K. Frigelj Das große Sterben der Grundschulen im Westen, die Welt vom 16.10.2011 (http://www.welt.de/dieweltbewegen/article13663781/Das-grosse-Sterben-derGrundschulen-im-Westen.html, Abruf 17.10.2013); dazu das neue Grundschulkonzept NRW unter http://www.nrw.de/landesregierung/neues-grundschul-konzept/, Abruf 17.10. 2013; für Hessen P. Wettlaufer-Pohl Rechnungshof rät zu Zwergschulen-Schließung, 
häufiger werden Schulen geschlossen. In solche Regionen stoßen Privatschulen vor - nicht selten in Übernahme der geschlossenen Schule. ${ }^{146}$

Immer wieder findet sich die Vorstellung, dass so öffentliche und private Schulen in ein Wettbewerbsverhältnis um die knappe Schülerschaft treten. Daraus wird sodann die Forderung nach gleichen Wettbewerbsbedingungen abgeleitet. Private Schulträger meinen damit gleiches Geld ${ }^{147}$ - öffentliche Schulträger, oft die betroffenen Kommunen, gleiche Bedingungen. ${ }^{148}$ Die Vorstellungen von dem gebotenen Wettbewerbsrahmen sind also sehr unterschiedlich. Wie problematisch ein Nachfragewettbewerb zwischen Anbietern ist, die zwei ganz unterschiedlichen Systemen angehören, zumal wenn der entsprechende „Markt“ verfassungsrechtliche Gewährleistungsaufträge erfüllen und sozial gestaltet sein soll, kann hier mit einem Verweis auf das Nebeneinander gesetzlicher und privater Krankenversicherung nur angedeutet werden. ${ }^{149}$

\section{c. Vielfalt durch unterschiedliche Bildungsgewährleistungsverpflichtungen in den Landesverfassungen}

Für den Bildungsföderalismus ist von Bedeutung, dass die Ausgestaltung des Verhältnisses von privaten und öffentlichen Schulen entscheidende Weichenstellungen in den jeweiligen Landesverfassungen findet. Denn sie bestimmen, wer die Bildungsgewährleistung zu erfüllen hat. ${ }^{150}$ Manche Landesverfassungen stellen Staat und freie Träger gemeinsam in diese

HNA vom 24.5.2012 (http://www.hna.de/nachrichten/hessen/sparvorschlaege-empoeren2332031.html, Abruf 17.10.2013); zu den Vorschlägen der Parteien nach den Schließungsforderungen des Rechnungshofs siehe: http://leb-hessen.de/fuer-eltern/wahlpruefsteine/ wps-2013/14/, Abruf 17.10.2013).

${ }^{146}$ Sog. „Anstattschulen“: VerfGH Sachsen vom 15.11.2013 - Vf. 25-II-12 - juris, Rn. 170.

147 Etwa der Verband Deutscher Privatschulenverbände e.V.: http://www. privatschulen.de/images/stories/PDF/Pressemitteilungen/2013/20131022_ _VDP_Forderungskatalog.pdf B. Eisinger in www.wiwo.de/finanzen/vorsorge/berndeisinger-im-interview-bis-an-die-schmerzgrenze/ 5373108.html.

148 Vgl. in diese Richtung K.-D. Hanßen RdJB 2009, 334 (345 f.).

149 Vgl. A. Wallrabenstein in: A. Schmehl/A. Wallrabenstein (Hrsg.) Steuerungsinstrumente im Recht des Gesundheitswesens, Bd. III, 2007, 67; A. Wallrabenstein Versicherung im Sozialstaat, 2009, $121 \mathrm{ff}$., $173 \mathrm{ff}$.

${ }^{150}$ Deshalb bleibt F. Brosius-Gersdorf Die Verwaltung 45 (2012), 389 (395), mit der Aussage, dass der Staat seine Pflicht aus Art. 7 Abs. 1 GG, für ein leistungsfähiges Schulwesen zu sorgen, sowohl durch Errichtung und Lenkung öffentlicher Schulen als auch durch Beaufsichtigung privater Schulen erfüllen könne, zu oberflächlich auf der Bundesebene. 
Pflicht, ${ }^{151}$ andere verpflichten ausdrücklich nur das öffentliche Schulsystem. ${ }^{152}$

Deshalb kann ein Land etwa Privatschulen in die Schulplanung einbeziehen und für diese Schulen besondere Regelungen aufstellen, so dass es zu einer Binnendifferenzierung zwischen ,,beplanten“ und „freien“ Privatschulen kommt. ${ }^{153}$ Andere Länder können diesen Weg aufgrund ihrer verfassungsrechtlichen Gewährleistungsverpflichtung nicht wählen. Sie können gezwungen sein, beschränkende Maßnahmen zur Aufrechterhaltung des öffentlichen Schulsystems zu treffen. ${ }^{154}$

\section{Hausunterricht statt Schulpflicht?}

Der verfassungsrechtliche Spielraum der Länder ist noch weiter, als in der bisherigen Bildungspraxis wahrgenommen.

Wenn das skizzierte Problem eines ausgedünnten Schulnetzes weiter gedacht wird, stößt man auf die Frage, ob Unterricht überhaupt nur in einer Schule oder nicht auch ganz privat möglich sein sollte. Im sächsischen Seifhennersdorf existiert bereits heute ein Beispiel: ${ }^{155}$ Da die Schü-

\footnotetext{
151 Art. 28 Verf. Rheinl.-Pfalz; Art. 27 Abs. 1 Verf. Saarl. und Art. 102 Abs. 2 Sächs. Verf.

${ }_{152}$ Art. 133 Abs. 1 Bay. Verf.; Art. 27 Abs. 2 Brem. Verf.; Art. 56 Abs. 1 S. 2 Hess. Verf.; Art. 15 Abs. 2 Verf. Meck.-Vorpomm.; Art. 8 Abs. 3 Verf. NRW; Art. 26 Abs. 1 Verf. Sachs.-Anh.; Art. 24 Abs. 1 Thür. Verf.

${ }^{153}$ M. Rothkopf SächsVBl. 2011, 149 (155); anders hält offenbar der VerfGH Sachsen vom 15.11.2013 - Vf. 25-II-12 - juris, Rn. 163 ff., eine Differenzierung zwischen Privatschulen nicht für zulässig und verweist das Land darauf, den Bildungsauftrag im Zusammenwirken mit Ersatzschulen zu erfüllen, die freiwillig dazu bereit sind. Ein anderes Beispiel ist die Vorgabe von Einzugsgebieten für private Förderschulen in Bayern, die sich bei der Finanzierung auswirken (s. VG Bayreuth, Urteil v. 19.10.2009 - B 3 K 07.1131 - juris): Für den finanzierenden Staat ist hiermit eine Reduktion der Kosten verbunden, da er die Schülerfahrtkosten der Förderschüler übernimmt. Die Lenkungswirkung der privaten Förderschulen - sie können weiterhin alle Schüler aufnehmen, erhalten aber für Schüler außerhalb des Einzugsgebietes keine Fahrtkosten - beruht darauf, dass die bayerische Finanzierung der privaten Förderschulen an ein öffentliches Bedürfnis anknüpft.

${ }^{154}$ Welche Rahmenbedingungen in welchem Bundesland zulässig sind, beschäftigt bereits: Avenarius/Pieroth/Barczak Eine Kontroverse (Fn. 144).

${ }_{155}$ Dresden Fernsehen vom 22.8.2013, http://www.dresden-fernsehen.de/Aktuelles/ Artikel/1322180/Keine-Kl, Abruf 17.10.2013; MDR vom 28.08.2013, http://www.mdr. $\mathrm{de} / \mathrm{sachsen} /$ bautzen/seifhennersdorf140.html, Abruf 17.10.2013. Die Gemeinde hat eine Verfassungsbeschwerde gegen das sächsische Schulgesetz angestrengt, um eine stärkere Beteiligung bei der Schulnetzplanung zu erreichen: Sächsische Zeitung online vom 28.2.2013, http://www.sz-online.de/sachsen/seifhennersdorfer-schulstreit-geht-ansbundesverfassungsgericht-2519744.html, Abruf 17.10.2013. Politisch führt nicht zuletzt
} 
lerzahl für eine Fortführung der Mittelschule nicht ausreichte, wurde sie geschlossen. Trotzdem setzen (Groß-)Eltern und verrentete Lehrerinnen und Lehrer mit Unterstützung der Gemeinde den Unterricht für aktuell noch ein Dutzend Kinder ehrenamtlich fort. Schulrechtlich ist dies ein Verstoß gegen die allgemeine Schulpflicht.

Auch über dieses Beispiel hinaus wird in den letzten Jahren vermehrt diskutiert, ob nicht eine „rein“ private Unterrichtung in der Familie oder durch Hauslehrer erlaubt werden sollte, ${ }^{156}$ wie dies etwa in Österreich möglich ist. ${ }^{157}$

In der Bundesrepublik besteht in dieser Frage keinerlei Varianz. Das Bundesverfassungsgericht begründet die allgemeine und ausnahmslose Schulpflicht als Teil der im Grundgesetz vorgesehenen Staatsaufsicht über das Schulwesen. ${ }^{158}$ Auch in Rechtswissenschaft und Bildungspolitik wird die Debatte bisher nur auf der Ebene des Grundgesetzes geführt. ${ }^{159}$ Dabei ist sie Gegenstand föderaler Bildungskompetenz. ${ }^{160}$

\section{Schluss}

Föderale Vielfalt ist bei der Kernfrage nach der Staatlichkeit des Schulwesens in den Landesverfassungen angelegt. $\mathrm{Ob}$ sie gelebt wird, hängt

dieser Fall zu einer Debatte, um neue - und flexiblere - Instrumente der Schulgestaltung: MDR vom 20.9.2013, http://www.mdr.de/sachsen/konzept-fuer-landschulensachsen100.html, Abruf 17.10.2013.

156 Weitere Beispiele: Religiös motivierte Schulverweigerer in Südhessen: http://www. faz.net/aktuell/rhein-main/darmstadt-schulverweigerer-kinder-von-eltern-getrennt12558035.html, Abruf 17.10.2013; den fließenden Übergang der Homeschooling-Frage zum Privatschulwesen verdeutlicht auch der schon seit Jahren schwelende Konflikt in Bayern, der jüngst zur Verbringung der Kinder aus der Gemeinschaft der Zwölf Stämme in Klosterzimmern bei Deiningen in Heime und Pflegefamilien geführt hat: http://www.tagesspiegel.de/weltspiegel/misshandlungsvorwuerfe-polizei-holt-40-kinderaus-sekte-in-bayern/8748488.html, Abruf 17.10.2013. Zur rechtswissenschaftlichen Debatte s. insb. F. Reimer (Hrsg.) Homeschooling, 2012; F. Hanschmann FS Bryde, 2013, 381.

157 K. Stöger in: Reimer (Fn. 156), 109.

158 BVerfGK 1, 14; BVerfGK 8, 151; BVerfG, NJW 2009, 3151.

159 Etwa Brosius-Gersdorf in: Dreier (Fn. 126), Art. 7 Rn. 72, dies. Die Verwaltung 45 (2012), 389 (400 ff.): Da sie dem Staat primär nur einen Bildungsauftrag zuschreibt und der Erziehungsauftrag hierzu nur akzessorisch sei, folgert Brosius-Gersdorf einen grundrechtlichen Anspruch auf Homeschooling. Da sich ihrer Auffassung nach dieser beschränkt verstandene Bildungsauftrag aus Art. 7 Abs. 1 GG ergibt, bleibt offen, wie sich die landesverfassungsrechtlichen Erziehungsziele und in ihrer Folge die landesrechtliche Schulpflicht gegen das Bundesrecht behaupten können.

${ }^{160}$ Vgl. A. Wallrabenstein in: Reimer (Fn. 156), 67, 78, $80 \mathrm{f}$. 
nicht davon ab, ob sich die Länder in einem Wettbewerb miteinander sehen. Vielmehr werden sie als Bildungsakteure zurückgedrängt, wenn Bildung nach Wettbewerbsgesichtspunkten gesteuert werden soll. Wegen ihres Wettbewerbsleitbildes fördert die Föderalismusreform diesen Trend und schadet damit der föderalen Bildungsvielfalt eher, als dass sie ihr nützt. 
Leitsätze der 2. Referentin über:

\section{Der Bildungsföderalismus auf dem Prüfstand}

\section{Föderalismusreform und Bildungsföderalismus}

1. Reföderalisierung der Bildungspolitik?

a. Föderalismus und ,Unitarismus"

(1) Föderalismus und Vielfalt einerseits und Zentralismus und Einheit andererseits hängen nicht zwingend zusammen. Das Leitbild des deutschen Föderalismus ist der unitarische Bundesstaat. Auch für den Bildungssektor fällt die staatsrechtliche föderale Struktur und die allgemeine Erwartung einer bundesweit einheitlichen Bildungslandschaft auseinander.

\section{b. Gemeinsam gegen den Bund}

(2) Die Änderungen der Bildungskompetenzen bei der Föderalismusreform 2006 hatten nicht die Stärkung von Vielfalt unter den Ländern zum Ziel, sondern die Beschränkung der Gestaltungsmöglichkeiten des Bundes. Diese Politikentflechtung durch klare Kompetenzverteilung und Transparenz hat die Reform aber nicht erreicht. Denn den politischen Akteuren genügt für Finanzhilfen des Bundes bereits, dass die Worte Bund und Bildung irgendwie zusammen in einem Verfassungssatz vorkommen.

\section{Erklärungsangebote}

a. Föderale Unitarisierungsinstitutionen

(3) Bei der Föderalismusreform setzten sich letztlich die Fachinteressen gegenüber der Generallinie der Politikentflechtung durch. In der Bildungspolitik konnte sich dadurch auch die Kultusministerkonferenz gestärkt etablieren. Mit ihr setzte sich auch ihr Verständnis einer föderal organisierten, aber inhaltlich unitarischen Bildungspolitik fort.

b. Gemeinsame Diagnose - unterschiedliche Therapieansätze

(4) Auch wenn in den letzten Jahren das bestehende System des kooperativen Föderalismus praktisch einhellig kritisiert wurde, besteht alles andere 
als Einigkeit über eine bessere Alternative. Es verwundert daher nicht, dass die Föderalismusreform 2006 letztlich so unterschiedliche Ziele vereint, dass vom Ursprungsanliegen - der Beseitigung der Politikverflechtung - nur wenig übrig blieb.

II. Gemeinsamer Nenner: Wettbewerb

1. Bildungswettbewerbsföderalismus

(5) Föderalismusreform und bildungspolitischer Wandel des letzten Jahrzehnts haben einen gemeinsamen Nenner, nämlich Wettbewerb als neues Leitbild.

a. Wettbewerb im Bildungswesen

(6) Im Bildungswesen wird ein Paradigmenwechsel konstatiert: Es etabliere sich eine neue Governance-Philosophie, die auf wettbewerbliche Steuerung der Bildungsakteure setze.

\section{b. Wettbewerbsföderalismus}

(7) In der staatsrechtlichen Diskussion etabliert sich die Vorstellung eines Wettbewerbsföderalismus. Ihr Ausgangspunkt ist die politikwissenschaftliche Kritik der Politikverflechtung, die Demokratie als Parteienwettbewerb versteht, der durch die Verflechtung im föderalen System behindert werde. In der politischen Arena haben Geberländer im Finanzausgleich die Vorstellung entwickelt, im Bundesstaat stünden die Länder ähnlich wie Unternehmen am Markt zueinander im Wettbewerb. Diese Ansätze wurden in der Rechtswissenschaft aufgegriffen und Wettbewerbsföderalismus so beschrieben, dass die Länder zueinander in Wettbewerb um die beste Form der Aufgabenverwirklichung treten.

\section{Funktionsbedingungen}

(8) Bildungsföderalismus kann aber als Wettbewerb der Länder um die beste Bildungspolitik nicht gelingen, denn:

a. Praktische Voraussetzungen eines Nachfragewettbewerbs

(9) In Bezug auf Bildung gibt es keinen praktischen Nachfragewettbewerb zwischen den Bundesländern. 
b. Inkompatibilität mit demokratischer Entscheidungsfindung

(10) Der politische Entscheidungsprozess folgt nicht ökonomischen Rationalitätskriterien. Aus demokratischer Sicht ist dies gut so.

(11) Wettbewerbsföderalismus ist vielmehr ein Konzept, das Exekutivföderalismus voraussetzt. Im Bereich der Bildung konkurrieren nach diesem Modell nicht nur die Exekutiven um die effektivste Aufgabenerledigung, zudem regulieren die Länderexekutiven diesen Wettbewerb auch selbst, indem sie kooperativ seine Rahmenbedingungen setzen.

\section{c. Finanzökonomische Rationalitäten}

(12) Unterstellt, die Länder hätten ausreichende Finanzmittel, um Bildungsinvestitionen zu tätigen, so sprächen doch die Gründe ökonomischer Rationalität dagegen. Denn Bildungsgewinne werden erst mit großer zeitlicher Verzögerung und nicht nur im eigenen Land, sondern ebenso extern in anderen Ländern erzielt.

\section{d. Wettbewerb und Parteiendemokratie}

(13) Nicht nur die föderale Kompetenzverflechtung behindert Parteienwettbewerb, wie es die Kritik der Politikverflechtung herausgearbeitet hat. Auch umgekehrt behindert die Parteiendemokratie einen föderalen Ideenwettbewerb. Daher kann Bildungswettbewerbsföderalismus letztlich in Deutschland nicht gelingen.

\section{Bildungswettbewerb und Unitarisierung}

(14) Das neue Governance-Konzept im Bildungswesen, das auf Wettbewerb der Schulen setzt, wird durch die Vorstellung gestärkt, das Bildungswesen sei auch auf verfassungsrechtlicher Ebene als Wettbewerb, nämlich als Wettbewerbsföderalismus konzipiert.

(15) Ein solcher Wettbewerb der Schulträger bringt allerdings keine Vielfalt im Sinne föderaler Unterschiede hervor. Vielmehr führt die Gestaltung seiner rechtlichen Rahmenbedingungen zur Unitarisierung des Bildungsrechts.

\section{Grundrechte als „Bundeslehrplangrundsätze“}

(16) Für die Unterrichtsgestaltung entsteht durch die inhaltliche Rücknahme der Landeslehrpläne ein Gestaltungsraum der Schulen und Lehrkräfte. In ihm erzeugen nur noch Grundrechte gewissermaßen als „Bundeslehrplangrundsätze" rechtliche Bindung, die letztlich bundesgerichtliche Kontrolle nach sich zieht. 
2. Einbettung in steuerungswissenschaftliche Überlegungen

(17) Wettbewerbssteuerung im Bildungswesen erfolgt also letztlich auf Kosten der Länderhoheit.

IV. Bildungsföderalismus als Verfassungsvergleichung

(18) Bildungsföderalismus kann daher nicht als Wettbewerb, sondern nur als Verfassungsvergleichung praktisch werden.

1. Kernfrage: Schule und Staat

(19) Wird der Staat als Bildungsträger bzw. als „Dachorganisation“ kommunaler Bildungsträger in ein wettbewerbliches Steuerungssystem gestellt, wirft das die Frage auf, warum überhaupt der Staat Träger des Bildungssystems ist und nicht andere.

2. Verhältnis von öffentlicher und privater Schule

(20) Die Ausgestaltung des Verhältnisses von privaten und öffentlichen Schulen steht angesichts insbesondere demografischer Veränderungen vor neuen Herausforderungen. Zentrale Weichenstellung ist, ob das öffentliche Schulwesen allein oder gemeinsam mit privaten Schulträgern den Bildungsgewährleistungsauftrag erfüllen muss. Die Landesverfassungen treffen diese Entscheidung unterschiedlich.

\section{Hausunterricht statt Schulpflicht?}

(21) Demgegenüber besteht in Deutschland keine Varianz bei der Frage der allgemeinen Schulpflicht. Die Debatte um eine Zulassung von privatem Hausunterricht wird auch nur auf der Ebene des Grundgesetzes geführt. Dabei wäre sie ebenfalls Gegenstand föderaler Bildungskompetenz.

\section{Schluss}

(22) Föderale Vielfalt ist bei der Kernfrage nach der Staatlichkeit des Schulwesens in den Landesverfassungen angelegt.

(23) Ob sie gelebt wird, hängt nicht davon ab, ob sich die Länder in einem Wettbewerb miteinander sehen.

(24) Vielmehr werden sie als Bildungsakteure zurückgedrängt, wenn Bildung nach Wettbewerbsgesichtspunkten gesteuert werden soll. 
(25) Wegen ihres Wettbewerbsleitbildes fördert die Föderalismusreform diesen Trend und schadet damit der föderalen Bildungsvielfalt eher, als dass sie ihr nützt. 


\section{Aussprache und Schlussworte}

\section{Der Bildungsföderalismus auf dem Prüfstand}

Biaggini: Liebe Kolleginnen, liebe Kollegen, ich möchte Sie zum zweiten Teil des heutigen Vormittags herzlich begrüßen. Dieser ist der Diskussion zum ersten Tagungsthema „Der Bildungsföderalismus auf dem Prüfstand" gewidmet. Es sind etwa zehn Wortmeldungen eingegangen. Es würde daher durchaus noch Raum bestehen für die eine oder andere spontane Meldung.

Engel: Es ist mir eine ehrliche Freude, dass ich mich in unser aller Namen für zwei sehr schöne Referate bedanken darf. Wenn unsere Tagungen gut funktionieren, dann erfüllen sie eine ganze Menge Funktionen gleichzeitig. Ich fand, dass das heute Morgen besonders gut gelungen ist. Die Referate waren ausgesprochen informativ; wir haben über verschiedene Rechtsordnungen und Rechtskulturen erfahren, dass das Tagungsthema sehr unterschiedlich behandelt werden kann. Und wir sind, wie wir es erwartet haben, zum Thema sehr nachdenklich gemacht worden.

$\mathrm{Zu}$ einem der Punkte, der mich persönlich ganz besonders nachdenklich gemacht hat, möchte ich nun auch in der Sache etwas sagen. Ich fühle mich ein bisschen hin- und hergerissen, weil ich die Grundthese eigentlich vollkommen richtig finde und auch immer wieder selber vertreten habe nämlich dass der Wettbewerbsföderalismus eine ziemlich komplizierte Angelegenheit ist. Ich habe mich deshalb sehr über Ihre präzise Auseinandersetzung mit dem Wettbewerbsföderalismus gefreut, Frau Wallrabenstein. Nur, wie die Wissenschaftler mit ihrem Widerstandsgeist so sind, zu jedem Ihrer Argumente ist mir dann auch ein Gegenargument eingefallen. Die wollte ich Ihnen einmal nennen.

Sie meinen ja, dass Wettbewerbsföderalismus eigentlich schon aus theoretischen, aus konzeptionellen Gründen gar nicht funktionieren kann. Diese These ist vielleicht doch etwas zu steil. Ihr erstes Argument lautet: Es gibt keinen Nachfragedruck. Das haben Sie klug begründet, aber er könnte ja aus etwas anderem herrühren, zum Beispiel aus der Unternehmensansiedlung; dass ich in ein Land Unternehmen herein holen kann, weil ich glaubwürdig versprechen kann: bei uns lernen Ihre Kinder etwas. Ihr zweites Argument war: Wettbewerbsföderalismus zwingt zu Exekutivföderalismus; das ist etwas, was wir entweder nicht 
haben oder nicht wollen. Doch auch beim Wettbewerb von Firmen besteht die erste Näherung immer darin, die Firma als unitarischen Akteur zu deuten. Aber jeder Gesellschaftsrechtler weiß natürlich, dass das Unfug ist und sieht sich die Effekte von Wettbewerb auf Corporate Governance an. In gleicher Weise könnte man auch beim Wettbewerbsföderalismus sagen: das könnte Effekte auf die Corporate Governance der Länder haben, also auf die Verfassungspolitik, aber das muss ja nicht von vornherein schlecht sein. Dann hatten Sie das Externalitäten-Argument gebracht. Da fiel mir ein, dass ich sogar ein Experiment zu der Frage gemacht habe, wie gut Wettbewerb funktionieren kann, wenn die Verfügungsrechte am Wettbewerbsgegenstand nicht vollständig gesichert sind. In unseren Daten finden wir, dass der eigentlich ziemlich gut funktioniert, so lange nicht vollständige Aneignung möglich ist. Aber so weit wird es ja wohl kaum gehen. Das letzte Argument, das Sie hatten, war: Bei uns ist der Parteienwettbewerb so dominant, dass ein Länderwettbewerb allenfalls ein relativ irrelevanter Überbau wäre. Man könnte einwenden: Vielleicht sollten wir gerade über die umgekehrte Kausalität nachdenken. Könnte es nicht sein, dass Wettbewerbsföderalismus die ausschließliche Orientierung auf die Parteien als politische Akteure ein Stück aufbricht und wir konkurrierende, durch Landesinteressen bestimmte Akteure zurückbekommen?

Folgt daraus, dass wir mit fliegenden Fahnen zum Wettbewerbsföderalismus übergehen sollten? Das möchte ich nicht vorschlagen. Aber vielleicht geht es doch eher darum, dass in einer Gesamtschau der Effekte, die Sie aufgezählt haben, nicht genügend gewichtige Gründe für die Funktionsfähigkeit des Wettbewerbsföderalismus sprechen, und nicht so sehr, dass wir schon theoretisch sagen können: Wir wissen, dass er gar nicht funktionieren kann.

Leisner-Egensperger: Vielen Dank. Der Wettbewerbsföderalismus ist in ein zunehmend negatives Licht gerückt. Er breche die Solidargemeinschaft zwischen den Ländern auf, finanzschwache Länder würden finanziell immer stärker ausgetrocknet, im Hinblick auf ihre ja nachweisbare geringe Steuerkraft gehe ihre Wirtschaftskraft immer weiter zurück, sodass sie ihre Aufgaben nicht mehr effektiv erfüllen könnten. Besonders deutlich hat sich das herauskristallisiert im Antrag der Länder Bayern und Hessen vor dem Bundesverfassungsgericht, mit dem wir uns ja heute Nachmittag vertieft beschäftigen wollen, ich will insoweit auch gar nicht vorgreifen. Festzuhalten ist hier nur: Der Wettbewerbsföderalismus hat seine größten Zeiten gehabt, er muss jedenfalls deutliche Grenzen erfahren. Die Kompetition muss dort enden, wo die Akteure aus finanziellen Gründen nicht mehr in der Lage sind, ihre Aufgaben effektiv zu erfüllen, 
besonders was jetzt die Förderung der neuen Länder betrifft, die auch über 2020 hinausgehen muss. Gerade dieser Blick auf die notwendigen Grenzen des kompetitiven Föderalismus zeigt meines Erachtens aber auch die nach wie vor bestehenden Spielräume für Wettbewerb auf. Gerade im Bereich der Bildung, in dem eben nicht alles nur vom Geld abhängt und es vielleicht sogar ohne Geld teilweise besser geht, gibt es für Kompetition nach wie vor erheblichen Raum, und dieser sollte auch genutzt werden. Insoweit würde ich Ihnen, Frau Wallrabenstein, deutlich widersprechen wollen. Ich meine, dass es durchaus viele Eltern gibt, die gerade wegen der unterschiedlichen Schulsysteme die Bundesländer wechseln - das lässt sich auch empirisch nachweisen -, die täglich über Grenzen fahren, die vielleicht ihre Lebensplanung auch davon abhängig machen. Zweifellos führt es auch zu einer Effektivierung und Verbesserung des Schulsystems, wenn die kleinere Einheit zuständig ist, politische Verantwortlichkeiten entsprechend verteilt und ihre Wahrnehmung regelmäßig demokratisch kontrolliert wird. Vielen Dank.

Reimer, Franz: Ich möchte an die beiden Referenten die Frage richten, ob Sie Ihre Beurteilungskriterien noch explizieren oder konkretisierten könnten - verfassungspolitische, aber auch verfassungsrechtliche Kriterien. Ich will versuchen, deutlich zu machen, was ich damit meine. Frau Wallrabenstein hat für mich sehr überzeugend den Wettbewerbsföderalismus demontiert. Er hat eine homogenisierende Wirkung. Ich würde den Gedanken weiterführen und sagen, er setzt bereits Homogenität voraus, nämlich einheitliche Beurteilung von Kriterien: sei es Preis, seien es Qualitätskriterien. Meine Frage ist nun: Wenn wir solche Kriterien hinter uns lassen und sagen, es geht nicht nur um Effizienz (also einen Effizienzwettbewerb), sondern es geht auch um Vielfalt als Eigenwert: Was würde das dann bedeuten? Nicht zwingend eine Zuordnung der Bildungshoheit zu den Ländern. Sondern man könnte auch sagen: Gegenüber den globalen Playern, deren Bedeutung eben ja eindrucksvoll unter Beweis gestellt worden ist, könnte es auch für eine Hochzonung des Bildungssystem/der Bildungshoheit auf die Ebene des Bundes sprechen. Also, Vielfalt als Eigenwert, nicht nur als instrumentelle Kategorie im Rahmen eines Wettbewerbs. Zweites mögliches Kriterium: Demokratische Zurechenbarkeit. Auch sie ist angeklungen, aber hierzu die Rückfrage: Haben wir nicht in der Ausgestaltung der Bundesrepublik den besonderen Vorteil, dass Landtagswahlen tatsächlich zu Plebisziten über Bildungspolitik gemacht werden können? Und würde sich das nicht verlieren, wenn man Bildungshoheit hochzonen würde? Würde dann die Bildungspolitik nicht untergehen in der Zuständigkeitsfülle des Bundes? Das wäre ein verfassungspolitischer Aspekt. Der verfassungsrechtliche Aspekt wäre: Was bliebe von 
der Eigenstaatlichkeit der Länder, wenn man ihnen - ich spitze zu - auch noch die Bildungshoheit nähme? Und wäre das dann möglicherweise nicht auch problematisch sub specie Art. 79 Abs. 3 GG? Vielen Dank.

Wißmann: Ich möchte zu dem sehr thesenstarken Referat von Astrid Wallrabenstein eine Bemerkung machen und eine Frage stellen. Der Gang durch die Punkte 8 bis 17 war in meiner Beobachtung eine sehr anspruchsvolle Reise, die mit der Widerlegung des Wettbewerbsgedankens für die Bildungsbelange abgeschlossen wurde. Ich möchte die Pointe dieses Gedankengangs unterstreichen: Aus rechtsdogmatischer Sicht leuchtet mir vollkommen ein, dass die Rücknahme von staatlicher Binnensteuerung - also die Übertragung von Gestaltungsspielräumen auf die Ortsebene, auf die einzelne Schule - dazu führt, dass wir eine Verstärkung unitarischer Vorgaben qua Bundesverwaltungsgericht bekommen. Allerdings ist die Pointe natürlich ein bisschen zu stark, denn „Krabat“ wäre auch bei bestehender Schulaufsicht unter dem alten Modell so zu entscheiden gewesen. Das Bundesverwaltungsgericht und das Bundesverfassungsgericht haben ja seit den 1970er Jahren das Schulwesen laufend umgestaltet durch grundrechtsbezogene Rechtsprechung. Und diese Rolle der Bundesgerichte und der Verfassung ist eine wesensnotwendige Funktionsbedingung des Schulwesens und gehörte deswegen, glaube ich, eine Kategorie höher in der Thesenanordnung. Darin liegt eine wesentliche Tiefendimension des Themas: Schule ist keine öffentliche Einrichtung wie andere und schon gar keine Firma. Sie ist ein Ort, wo Grundrechte in die öffentliche Verwaltung unmittelbar einwirken und allen nutzenbezogenen Steuerungsfantasien verfassungsrechtliche Grenzen setzen. Also, kurz gesagt, alle Reformen, die wir hier seit Jahren erdulden und erleiden müssen, sind ja nur Reformen zweiter Ordnung. Die Grundverabredungen eines verfassungsstaatlichen Schulwesens können davon nicht berührt werden, denn sonst verlieren wir in der Tat die Voraussetzungen, mit denen so etwas wie Schulpflicht durchgesetzt werden kann. Es steht eben nicht zur Disposition von Reformern, ob man die Entfaltung der Persönlichkeit als Leitwert des öffentlichen Schulwesens begreift.

Meine Frage, die sich damit verbindet: Wie wäre diese verfassungsstaatliche Grundorientierung denn nun bei Hausunterricht und freien Privatschulen zu gewährleisten - oder ist sie dort, im gesellschaftlichen Freiraum, verzichtbar? Da blieb das Referat nach meinem Eindruck am Ende etwas offen. Wollen und können wir diese Formen stärken, oder bleiben sie ein Notbehelf? Danke.

Meyer, Hans: Ich möchte zunächst zu Finanzverfassungsreform I und Wettbewerb sprechen. Es ist nicht zu verkennen, dass anfänglich die 
Ministerpräsidenten der starken Länder von Wettbewerb gesprochen haben. Aber der Begriff des Wettbewerbs und die Sache haben in den Verhandlungen überhaupt keine Rolle gespielt. Wettbewerb im echten Sinne setzt einen freien Markt und Egoismus der beteiligten Marktteilnehmer voraus sowie die Hoffnung, dass, wenn alle nach ihren Egoismen handeln, etwas Gutes herauskommt. Die öffentliche Hand kann aber nicht egoistisch handeln, sondern sie ist rechtlich sehr vielfältig gebunden. Für den öffentlich-rechtlichen Bereich sollte man den Begriff Wettbewerb daher vergessen und vielleicht etwas anderes erfinden, ein Wettbewerb ist das jedenfalls nicht, was hier stattfindet. Der zweite Punkt ist: Die Föderalismusreform I stand natürlich unter dem Eindruck der Finanzen. Auch die nächste Reform wird unter diesem Eindruck der Finanzen stehen. Alles, was nicht unmittelbar finanzträchtig war, ließ sich einfacher reformieren, während die Finanzregeln fast überhaupt nicht zu reformieren waren. Die Reform ist ja erst gelungen, nachdem die Kommission erfolglos ihre Arbeit beendet hatte und dann durch Zufall die beiden Vorsitzenden der Kommission auch Mitglieder der Verhandlungskommission bei den Koalitionsvereinbarungen wurden und schlicht das Kommissionsergebnis übernommen haben. Auf diese Weise wurde die Debatte innerhalb der Koalition verhindert. Der dritte Punkt: Ich darf vielleicht daran erinnern, dass Hochschulgesetze eine ganz neue Erscheinung gewesen sind. Das Hochschulrahmengesetz von 1976 ist die Reaktion auf die 68er-Revolte. Weil die Bundesparteien - es gab damals eine unausgesprochene große Koalition zwischen der Union und der SPD - nicht wollten, dass einzelne Länder bei ihrer Hochschulgesetzgebung zu radikal vorgehen. Das wollte man einfangen. Damit hatte das Hochschulrahmengesetz seine Funktion erfüllt. Vorher gab es keine Landesgesetze, die Hochschulen haben vielmehr nach ihren Statuten gelebt, und das offensichtlich ganz ordentlich. Sie haben nur nicht verstanden, dass die 68er-Bewegung eine allgemeine Bewegung war, die in die Statuen aufzunehmen gewesen wäre, was aber damals die Ordinarien abgelehnt hatten. Deswegen kamen die Länder dazu, kam der politische Teil des Volkes dazu, nun das Hochschulrecht gesetzgeberisch zu lösen, und zwar zunächst durch ein Rahmengesetz, anschließend durch Landesgesetze. Wenn ich es richtig sehe, sind wir heute wieder zurück zu einer Art Selbstverwaltung der Hochschulen, indem man nämlich Stiftungsuniversitäten gründet, sie aus den Hochschulgesetzen der Länder herausnimmt und ihnen Stiftungsstatuten gibt. Wir hätten also nach 40 Jahren zurückgefunden in einen Zustand, der vorher immer bestanden hat.

Faber, Angela: Ich glaube, und das hat auch Herr Professor Ehrenzeller unter anderem erwähnt, dass in den letzten Jahren der größte Motor für 
Bildungsentwicklung die Bildungsberichterstattung bzw. das Bildungsmonitoring (OECD) waren und die Transparenz, die damit über schulische Leistungsdaten und über soziale Selektivität im Bildungswesen hergestellt wurde Frau Professor Wallrabenstein, was mir bei Ihrem Vortrag etwas unklar geblieben ist, ist Ihre Position zur künftigen Rolle des Bundes und zwar bezogen auf den Schulbereich (ich möchte das jetzt nur auf den Bereich der schulischen Bildung und nicht auf die Hochschulbildung beziehen). Das wird ja zurzeit überall diskutiert, ist also durchaus sehr populär, aber gleichwohl könnte man darüber ja nachdenken. Wenn ich von der Zuständigkeit her ausgehe, ist es so, dass nach Art. 91b GG der Bund ja nur noch zur Feststellung der Leistungsfähigkeit im Bildungswesen eine Zuständigkeit hat. Bei den Finanzzuweisungen nach Art. 104b GG kann er gar keine Finanzzuweisung mehr an die Länder und Kommunen im Bildungsbereich leisten; es sei denn, er hätte eine Gesetzgebungszuständigkeit oder es handle sich um einen außergewöhnlichen Notfall, was im Bildungswesen wohl nicht zu bejahen ist. Das heißt, dass das große Ganztagsschulprogramm des Bundes zur Finanzierung von Ganztagsinvestitionen in Höhe von 4 Milliarden Euro heute nicht mehr möglich wäre. Meine Frage ist jetzt: Wie sollen jetzt angesichts der von Ihnen geschilderten finanzverfassungsrechtlichen Situation der Länder und der Schuldenbremse in Zukunft erforderliche Investitionen im Bildungsbereich denn überhaupt getätigt werden? Dies angesichts der groBen Herausforderungen im schulischen Bereich, die wir ja haben: Die Ganztagsschulentwicklung ist nicht abgeschlossen, gerade nicht in qualitativer Hinsicht (Ganztag heißt ja nicht nur Unterbringung, sondern auch Förderung), und dann auch zum Beispiel die Umsetzung der Inklusion im Schulbereich. Das heißt, wir laufen Gefahr, dass wir nicht nur sehr vielfältige, sondern standortabhängige Bildungsverhältnisse bekommen werden. Eine Standortabhängigkeit von Bildungschancen als Lebenschancen ist aber schwer hinzunehmen. $\mathrm{Zu}$ den finanzökonomischen Erwägungen, These 12 bei Ihnen. Sie haben auf die großen zeitlichen Verzögerungen des Ankommens von Bildungsrenditen bei den Ländern hingewiesen. Ich möchte darauf hinweisen, dass es daneben natürlich auch so ist, dass die größten Bildungsrenditen (dazu hat sich auch der Vorsitzende dieser Vereinigung, Herr Prof. Wieland geäußert) bei den Sozialversicherungsträgern und beim Bund eintreten werden, und erst dann bei den Ländern. Würden diese finanzökonomischen Erwägungen nicht dafür sprechen, vielleicht dem Bund eine größere Möglichkeit von Finanzzuweisung, die es im Schulbereich gar nicht mehr gibt, einzuräumen? Dann noch an beide Referenten die Frage: Sie haben beide die Educational GovernancePhilosophie bemüht und zitiert. Da war mir die Rolle von Schulen und kommunalen Schulträgern ein bisschen $\mathrm{zu}$ wenig getrennt. Im Land 
Nordrhein-Westfalen zum Beispiel haben Schulen den Charakter von nichtrechtsfähigen Anstalten des öffentlichen Rechts. Die Schulleiter und -lehrer sind Landesbedienstete. Die kommunalen Schulträger sind verfassungsrechtlich abgesichert durch Art. 28 GG (kommunale Selbstverwaltung). Wie sieht nach Ihrer Auffassung die zukünftige Rolle der Kommunen, die ja im Bereich der frühkindlichen Bildung als wichtigste Bildungsstufe eine ganz große Rolle spielen, im Bereich der schulischen Bildung aus? Es gibt ja Bildungsexperten, die da für eine Stärkung plädieren. Und als letzte, eine an beide Berichterstatter gerichtete Frage: Wie sieht bei Educational Governance die Rolle der Zivilgesellschaft aus? Das ist ja auch nicht zu verachten. Die Zivilgesellschaft spielt eine große Rolle - ich nenne mal nur das Stichwort Bildungskonferenz in Nordrhein-Westfalen. Oder aber die Stiftungen, die aufgrund ihrer finanziellen Potenz eine immer wichtigere Rolle spielen. Danke schön.

Dörr, Oliver: Ich habe eine ganz banale Verständnisfrage, wie ich denke, an Herrn Ehrenzeller, und zwar zu Art. 62 Abs. 4 der Bundesverfassung. Die Frage beruht auf meiner Unkenntnis im schweizerischen Staatsrecht, für die ich um Nachsicht bitte. Sie haben uns sehr schön vorgeführt, dass hier die Bundeskompetenz gesperrt ist, wenn die Kantone eine Harmonisierung des Bildungswesens hinbekommen (in meinen Worten, natürlich). Wenn ich den Wortlaut der Norm aber richtig verstehe, ist eine Teilharmonisierung doch nicht ausreichend, sondern es muss eine, vielleicht nicht in der Tiefe vollständige, aber doch in der Breite umfassende Harmonisierung des Bildungswesens zustande gekommen sein. Dann ist der Bund weiterhin gesperrt. In Ihrer These 11 habe Sie uns aber sehr anschaulich gemacht, dass nur 15 der 26 Kantone sich an diesem Konkordat beteiligt haben. Wie kommt es, dass der Bund trotzdem gesperrt ist? Vielen Dank.

Kotzur: Beide Referate haben darauf hingewiesen, dass das Thema heute nicht mehr zu denken ist ohne die internationalrechtliche Einbettung und dass der Bildungsföderalismus nicht nur aus seinen Binnenstrukturen her zu begreifen ist, sondern das Völker- und das Europarecht auch eine Rolle spielen. Darauf zielt meine Frage ab. Sie haben angedeutet, welche rechtlichen Rahmungen es diesbezüglich gibt. Insbesondere das Europarecht finde ich hier sehr interessant und relevant. Es wird zwar in einem engeren Sinne kompetenzrechtlich nicht zum Thema, weil die Europäische Union auf dem Bildungssektor nur sehr zurückhaltend agieren kann. Es kann aber doch durch diese begrenzten Möglichkeiten und durch die relevanten Einbettungen unter Umständen die gesamte Grundtextur des Wettbewerbsföderalismus innerhalb eines Bundesstaates verändern. Diesbezüglich würden mich Ihre Beobachtungen und Ihre Analysen interessieren. 
Haben Sie festgestellt, dass international vorgedacht das Thema eventuell noch einmal eine deutliche Komplexitätssteigerung erfährt? Nur zwei Fragestellungen: Wenn wir sowohl die völkerrechtliche als auch die europarechtliche Rahmung anschauen, so spielt dabei, so glaube ich, zum einen die Chancengleichheit eine große Rolle, dass Bildung Gleichheit in den Lebenschancen vermitteln soll, und zum zweiten die Mobilität, dass Bildung so ausgestaltet sein soll, dass Mobilität innerhalb eines Bundesstaates, zwischen den Mitgliedstaaten der Europäischen Union und auch in der „global community“ möglich wird. Beide Aspekte könnten eine stark unitarisierende Wirkung haben und die unitarisierenden Momente, die Sie schon benannt haben, vielleicht noch verstärken. Darauf würde sich meine Frage beziehen, und ich wäre sehr dankbar, wenn Sie uns noch ein bisschen deutlicher machen könnten, ob diese internationale Einbettung die „wettbewerbsföderalistische Kampfzone“ noch ein wenig erweitert oder nicht. Vielen Dank.

Bryde: Ich habe auch eine Frage an Herrn Ehrenzeller, allerdings eigentlich keine kritische Frage. Ich fand die neuen Kompetenzbestimmungen in der Schweizer Bundesverfassung immer recht gut im Vergleich zu anderen Kompetenzaufteilungen in Bundesstaaten, weil ziemlich konkret geregelt ist, wer was macht, und man nicht mit allgemeinen Subsidiaritätsklauseln arbeitet. Aber hier haben wir sie jetzt doch in Art. 62 Abs. 4 BV. Ich finde die Regelung im Prinzip überzeugend. Für einen deutschen Verfassungsrechtler weiß man allerdings nicht genau, wie man in Deutschland damit arbeiten würde und was dabei herauskäme. Meine Frage ist: Kann man solche Vorschriften schaffen, weil man sicher ist, dass sie nicht in ein Gericht gehen? Kann man solche Vorschriften machen, weil man sicher ist, es wird kein Rechtsstreit darüber stattfinden, sondern man wird das konsensual regeln müssen?

Gröschner: Art. 61a der schweizerischen Bundesverfassung verwendet die Metapher des Bildungsraumes als Verfassungsbegriff. Obwohl es den Referenten gewiss gelungen ist, diesen Raum bildungsverfassungsrechtlich $\mathrm{zu}$ vermessen und föderalismustheoretisch auszuleuchten, erscheint er mir in vielen Hinsichten doch ziemlich dunkel. Ich möchte den Raum daher in Zimmer unterteilen, in denen Bildung stattfinden könnte und nach meiner Überzeugung von Verfassung wegen auch stattfinden sollte. Was zeigt sich dem Blick eines ehemaligen Kommentators des Art. 7 des Grundgesetzes? Im Kinderzimmer sieht er sogenannte Kids vor Spielkonsolen sitzen und schweigen. Im Esszimmer sieht er mittags kein einziges Mitglied der Familie und abends Teenager, die per SMS oder WhatsApp kommunizieren. In den Klassenzimmern von Grund-, Haupt- und Real- 
schulen sieht er die vergeblichen Bemühungen von tapferen Lehrerinnen und Lehrern, die Sprachlosigkeit ihrer Schüler zu kompensieren, die sich als zwingende Folge der verbreiteten Leseverweigerung ergeben hat. In den Klassenzimmern von Gymnasien sieht er viel zu wenige Abiturientinnen und Abiturienten, die sich für das Bildungsgut der alten Sprachen und für Geschichte interessieren, von Philosophie ganz zu schweigen. In den Hörsälen unserer Universitäten (ja, ich bin per Lehrauftrag immer noch in Jena tätig, und es hat sich nichts verbessert, sondern alles verschlechtert) sieht er in den ersten Reihen - niemanden. Unser Vorsitzender hat heute Morgen auf die chronisch leeren Sitze in den Vorderreihen angespielt. In den hinteren Reihen ahnt er nur Studierende, die berechtigte Angst davor haben, sich in präzisen Begriffen und prägnanten Bildern äußern zu müssen. Das düstere Bildungsgemälde mag Ausdruck des Kulturpessimismus eines soeben pensionierten Staatsrechtslehrers sein. Hätte er den Blick allerdings in die Beratungszimmer der KMK geworfen, wäre es noch dunkler geworden (Gelächter). Danke.

Winkler, Markus: Nach den düsteren Aussichten eines pensionierten Hochschullehrers nun der trockene Blick des Praktikers. Ich hatte mir eigentlich vorgenommen, mich nicht zu melden, nachdem ich schon einen Begleitaufsatz geschrieben habe und fast schon alles gesagt worden ist, insbesondere von Frau Faber, was ich auch hätte sagen können. Deswegen bleibt eigentlich nur eine kleine Detailfrage, die ich an Astrid Wallrabenstein richten möchte. Astrid, gegen Ende deines Referats hast du ja auch Beispiele, die mehr am Rande des Themas Bildungsföderalismus liegen, angesprochen, insbesondere die Problematik der Ausdünnung der öffentlichen Schullandschaft; dort, in ländlichen Regionen, wo die Gesellschaft überaltert, mit scheinbaren Lösungsansätzen wie Homeschooling durch pensionierte Lehrerinnen und Lehrern und Privatschulen. Das bringt mich spontan zu der Frage: Gibt es aus verfassungsrechtlicher Sicht nicht vielleicht auch Schranken für solche Entwicklungen? Schranken, die den Staat im weitesten Sinne zwingen könnten, ein öffentliches Schulwesen bis in den hintersten Winkel auch eines sehr dünn besiedelten Bundeslandes aufrechtzuerhalten? Spontan deswegen, weil mich dein Beispiel aus Seifhennersdorf an eine andere Entwicklung erinnert hat, die in Sachsen stattfindet, nämlich die Gründung von Privatschulen durch öffentliche Träger mit dem einzigen Zweck, die Kosten zu drücken, insbesondere die Lehrergehälter. Ist das zulässig? Danke.

Hufen: Ich hatte mich ursprünglich nicht gemeldet, weil ich glaubte, dass es in der Diskussion nicht nur um Wettbewerbsföderalismus, sondern um Bildungsföderalismus gehen würde und dieser seine Befürworter finden 
würde. Das scheint mir bis jetzt nicht der Fall zu sein, denn wir haben vorwiegend über Wettbewerbsföderalismus gesprochen. Da jetzt noch ein wenig Zeit bleibt, möchte ich versuchen, jetzt doch die eigentlichen Grundessenzen des Bildungsföderalismus noch einzubringen. Der Wettbewerbsföderalismus - rein ökonomisch verstanden -, ist zu Recht kritisiert worden. Aber wenn man Wettbewerb nicht rein ökonomisch, sondern kulturell oder auch sozial versteht und ihn schlicht und einfach mit Vielfalt übersetzt, dann ist die Kritik doch wahrscheinlich sehr viel geringer und dann wird das Bild insgesamt doch sehr viel positiver. Und in diesem Sinne möchte den Bildungsföderalismus und den Kulturföderalismus insgesamt als System, das Vielfalt ermöglicht, doch energisch verteidigen, wie ich dies mein ganzes wissenschaftliches Leben über getan habe. Ich glaube, Vielfalt ist das, was angesichts der Komplexität der Lebensverhältnisse, einschließlich der von Herrn Ehrenzeller ja sehr zu Recht angesprochenen horizontalen und vertikalen Verflechtungen, für Bildung und Kultur angemessen ist. Wir können doch gar nicht wissen, was richtige Bildung und richtige Kultur ist. Wir können es nur immer wieder mit möglichst vielen unterschiedlichen Ansätzen versuchen. Wir brauchen Föderalismus, um vielfältige Blumen blühen zu lassen, wie es mal so schön geheißen hat. Und die blühen nun mal besser, wenn sie dezentral, ortsnah, nah an den Menschen und nah an den unterschiedlichen Institution blühen. Zentralismus, das Beispiel Frankreich zeigt es ganz deutlich, taugt weder im kulturellen Bereich noch im Bildungsbereich, um die Probleme zu lösen. Es existieren natürlich Probleme, wenn wir Vielfalt in Verbindung bringen etwa mit Problemen der Mobilität. So werde ich auf bildungspolitischen Tagungen - und nicht nur dort - immer wieder angesprochen: Können wir nicht dafür sorgen, dass wir endlich ein einheitliches Abitur in ganz Deutschland haben? Bevor ich die Nachteile eines bundeseinheitlichen Zentralabiturs am Beispiel des auf nichts als das Abklopfen von Standardwissen und Drill ausgerichteten französischen Baccalauréats an die Wand male, versuche ich dann immer den Wert von Vielfalt, Kreativität und örtlicher Identität zu erklären. Auch versuche ich $\mathrm{zu}$ verdeutlichen: Vielfalt bedeutet nicht Mobilitätsverlust, jedenfalls dann nicht, wenn Bildungsföderalismus in der wechselseitigen Anerkennung von Vielfalt besteht. Da löst nicht der Zentralismus, sondern die wechselseitige Anerkennung die Probleme. Diese allerdings ist unabdingbar, und wenn jeder Bildungspolitiker meint, selbst das beste, wenn nicht das einzige Modell zu haben, dann gefährdet das in der Tat die Mobilität. Natürlich brauchen wir eine möglichst gleichwertige Bildung in allen Bundesländern. Aber es gilt eben im Bildungsföderalismus (wie auch im Verhältnis von öffentlichen Schulen zu den Privatschulen): Gleichwertigkeit bedeutet nicht Gleichartigkeit. Dies vorausgesetzt, sollten auch 
Unterschiede im Bildungswesen und ein richtig verstandener föderaler Wettbewerb nicht schrecken. Vielen Dank.

Classen: Zunächst möchte ich, im Anschluss an Herrn Hufen, auf folgendes hinweisen: Der Europäische Gerichtshof hat aus den Grundfreiheiten und den Freizügigkeitsrechten eine Verpflichtung abgeleitet, die Gleichwertigkeit von in einem anderen EU-Mitgliedstaat erworbenen Abschlüsse zu prüfen. Das Gleiche kann man auch mit Blick auf Art. 33 Abs. 1 GG diskutieren. Hier sind aus meiner Sicht noch manche Schätze zu heben. Vielleicht wird die entsprechende Bundeskompetenz da gar nicht benötigt. Ich habe mich aber eigentlich gemeldet, weil ich eine konkrete Frage zur Schweiz habe, und zwar zu den subsidiären Kompetenzen nach Art. 62 BV. Solche Subsidiärkompetenzen nach dem Motto „Wenn es die untere Ebene ein Problem nicht vernünftig löst, darf es die obere Ebene Bund richten" gibt es ja vor allem auch im Bereich der Umsetzung völkerrechtlicher und europarechtlicher Verpflichtungen. In Österreich oder Spanien darf, wenn insoweit an sich die Länder oder die Provinzen zuständig wären, diese aber die Verpflichtungen nicht korrekt umsetzen, der Zentralstaat eingreifen. Dazu hat Herr Öhlinger einmal bei einer Diskussion gesagt, dass das theoretisch alles wunderbar wäre, aber praktisch daran scheitert, dass es für diesen Bereich keine Verwaltungskompetenz auf Bundesebene gibt. Gesetzgebung ohne begleitende Administration (Ministerium usw.) ist eben doch nur schwer realisierbar. Dann steht das zwar schön in der Verfassung, kann aber aus faktischen Gründen praktisch nicht genutzt werden. Dementsprechend ist meine Frage, ob es in der Schweiz auf Bundesebene im Bildungsbereich entsprechende Ministerialstrukturen gibt, die im gegebenen Fall zur praktischen Wahrnehmung der genannten Kompetenzen auch tatsächlich beitragen könnten, soweit ein entsprechender Bedarf vorhanden wäre? Vielen Dank.

Gallwas: Ich möchte an den vorletzten Beitrag anknüpfen. Mein erster Punkt: Föderalismus hat etwas mit Vielfalt zu tun. Wir müssen neben der Überlegung, dass es einen Wettbewerbsföderalismus gibt, aufdröseln, um welche Vielfältigkeit es heute und vielleicht auch in früherer Zeit, als man sich für den Föderalismus entschieden hat, geht bzw. gegangen ist. Vor einigen Jahren wurde in Bayern eine Umfrage gemacht, ob die Schüler sich mehr als Bayern oder mehr als Deutsche fühlen. Und da hat ein Schüler gesagt: „Ich bin Bayer und mehr braucht's nicht“. Beim Föderalismus geht es so besehen auch um die Identität der Bevölkerung und um die Wahrung föderaler Institutionen. Das mag in Bayern etwas anders sein als etwa in Niedersachsen, aber ich glaube nicht, dass die Differenz in der Einstellung zum Föderalismus soweit reicht, dass man über die nie- 
dersächsische oder bayerische Identität, wie sie sich aus der bayerischen bzw. niedersächsischen Volkszugehörigkeit ergibt, völlig hinweggeht. Immer kommt selbstverständlich die andere Frage, nämlich die speziell bundesstaatliche hinzu. Da habe ich vermisst, dass eine Bestimmung des Grundgesetzes, im Zusammenhang des Themas so gar keine Rolle gespielt hat, nämlich dass jeder Deutsche in jedem Land dieselben Rechte und Pflichten hat. Art. 33 Abs. 1 GG hat insoweit so etwas wie eine dirigierende Wirkung. Sie verpflichtet die Länder auf bundesstaatliche Erfordernisse Rücksicht zu nehmen. Die Bildung der Kinder muss in jedem Land des Bundes so beschaffen sein, dass sie die Fähigkeit erwerben die ihnen zustehenden Rechte und Pflichten des anderen Land auch tatsächlich auszuüben. Eine zweite Überlegung: Da und soweit das Grundgesetz in Art. 7 Abs. 4 die Privatschulfreiheit regelt, kommt es nicht darauf an, wie die Länder in ihren Verfassungen die Privatschulfreiheit regeln. Ein Wettbewerb zwischen privaten Schulen und den öffentlichen Schulen ist daher bereits in Art. 7 Abs. 4 GG angelegt. Man darf ja nicht vergessen, dass die Garantie der Privatschulen nicht nur irgendeine verfassungsgeschichtliche Reminiszenz, sondern speziell grundrechtsbezogen ist, nämlich als Konkretisierung des Elternrechts, des Weltanschauungsrechts und überhaupt des Rechts aus Art. 2 Abs. 1 GG, einen anderen Weg zu gehen als jenen, den die Parteien uns jeweils vorschlagen.

Stettner: Vielen Dank. Ich habe mich spontan gemeldet, weil einige Dinge hier noch nicht im dem Sinne akzentuiert worden sind, wie ich es für richtig halte. Zunächst einmal zu Herrn Hufen. Ich bin auch sehr für Vielfalt, denn was man auch bedenken sollte: Wenn ein System schlecht ist und es wird bundesweit praktiziert, dann ist das sicherlich nicht so gut, wie wenn in Teilen des Bundes ein besseres System experimentell ausprobiert oder angewandt werden kann. Was mir aber eigentlich noch wichtiger ist, ist die Frage dieses Privatunterrichts. Es gibt in Bayern gerade den Fall - es wundert mich, dass das niemand gesagt hat - der „12 Stämme“. Das ist eine auf urchristlicher Basis operierende Sekte, der man offensichtlich den Privatunterricht in ihren Räumen (eine Art Kloster in der Nähe von Nördlingen) erlaubt hat, aus denen jetzt die Kinder (es waren über 40) herausgeholt wurden. Denn zu den Praktiken dieses Privatunterrichts gehörte auch massive Prügelei. Das darf natürlich nicht sein. Ich bin aber auch der Meinung, dass dieser Differenzierung des Schulwesens generell Grenzen gesetzt werden sollten. Ich bin nicht wie Herr Gallwas der Meinung, dass das überall so einfach stattfinden sollte. Früher herrschte das Prinzip, im Volksschulbereich prinzipiell keine Privatschulen zuzulassen. Das hatte einen egalisierenden Hintergrund; jedenfalls hier sollte der Sohn des Fabrikanten neben dem des Arbeiters auf der Schulbank sitzen. 
Im höheren Schulwesen konnte man den Wünschen der Eltern eher Raum geben. Das erstgenannte Prinzip ist heute ziemlich verloren gegangen. Es gibt heute fast flächendeckend Privatschulen im Primärbereich. Dort treffen die Schulkinder sicherlich kaum jemals auf einen Ausländer oder auf irgendwelche ärmeren Bevölkerungsschichten. Das halte ich für nachteilig. Ich glaube nicht, dass man so fortfahren sollte und schon gar nicht im Bereich des Primärunterrichts. Vielen Dank.

Meyn: Ich habe mich deshalb gemeldet, weil - bevor Herr Gallwas sprach - bisher noch nicht darauf hingewiesen worden war, dass Schulen in jedem Staat auch eine ganz besondere Aufgabe im Hinblick auf die nationale Identität haben. Wenn wir daran denken, dass wir inzwischen jedenfalls faktisch auch ein Einwanderungsland sind (das verfassungsrechtlich einzufangen wäre eine ganz andere Frage), dann müssen wir bedenken, dass in den Schulen zum Teil über 50 Prozent der Kinder in einer bestimmten Klasse Ausländer sind oder aber einen Migrationshintergrund haben. Nationale kulturelle Identität wird vor allem in den Schulen hergestellt. Unter diesem Gesichtspunkt kann ich den Lobpreis der Föderalismusvielfalt nicht ganz nachvollziehen. Ich denke, dass es auch eine soziale, eine politische Bewegung in Deutschland gibt, die dem Bund doch ein kleines Stückchen mehr Einfluss auch auf die Inhalte der verschiedenen Länderschulverwaltungen geben will. Es wäre in der Tat zu überlegen, ob nicht der Bund eine Art Rahmenkompetenz erhalten sollte, wie es einmal im Hochschulrahmengesetz für die Hochschulen gewesen ist - Herr Meyer hat darauf hingewiesen. Ich denke, dass dann auch leichter versucht werden könnte, die erhöhte Mobilität von ihren Problemen zu befreien, die für viele Eltern und ihre Kinder aus der föderalen Vielfalt folgen. Also ein reiner Lobpreis des Föderalismus ist in einer sich ja auch globalisierenden Welt heutzutage auch verfassungsrechtlich nicht recht angebracht.

Oebbecke: Ich glaube, dass es für die Debatte doch außerordentlich hilfreich ist, wenn man zwei Formen des Wettbewerbs unterscheidet: den marktlichen Wettbewerb und den föderalen Wettbewerb. Was marktlichen Wettbewerb anlangt, so gibt es den - um etwa Herrn Meyer sehr konkret zu widersprechen - natürlich auch im öffentlichen Bereich. Die Länder, die Hochschulen konkurrieren um Hochschullehrer - marktlich. Es gibt marktliche Konkurrenz, wie ich vor einigen Jahren zu zeigen versucht habe, im Bereich der Justiz. Was föderalen Wettbewerb anlangt, möchte ich Herrn Hufen widersprechen. Föderalismus führt gerade wegen des föderalen Wettbewerbs nicht notwendig zu Vielfalt. Frau Wallrabenstein hat wunderbar beschrieben wie der parteipolitische Wettbewerb das ein 
bisschen verdeckt. Die Übernahmen, die da stattfinden, muss man anders nennen. Föderaler Wettbewerb funktioniert in aller Regel so, dass die Länder bei unseren sehr ähnlichen Lebensverhältnissen ganz ähnliche Probleme haben. Und es gibt für die meisten Probleme nicht zwei optimale Lösungen. Es dauert dann mehr oder weniger lang bis alle dieselbe Lösung haben. Also gerade keine Vielfalt. Vielfalt im Bildungsbereich kann das einzelne Land herstellen, indem es beispielsweise unterschiedliche Schulformen zulässt, es kann die privaten Schulen stark fördern und und und ... Aber im Ländervergleich führt Föderalismus auf die Dauer gerade in den Bereichen, die nicht parteipolitisch so extrem im Fokus stehen, eher zur Einheit als zur Vielfalt. Danke schön.

Dietz: Ich möchte nur einen Gedanken aufgreifen: die Frage des Wettbewerbs. Was setzt Wettbewerb voraus? Theoretisch das freie Spiel von Angebot und Nachfrage. Wie sieht es auf dem Bildungs,,markt" denn aus? Wir haben auf der einen Seite den Staat, sprich die Länder, die in irgendeinem politischen Sinne Bildungskonzepte durchsetzen, die vielleicht von der jeweils regierenden Partei auch ideologisch überfrachtet sind. Auf der anderen Seite haben wir Familien mit Kindern, denen eines wesentlich fehlt, nämlich die entsprechende Mobilität. Wettbewerb setzt ja voraus, dass sowohl die Anbieter als auch die Nachfrager nach Bildung wechseln und reagieren können. Aber welches Elternpaar kann mit seinen Kindern einfach, wenn sie mit dem Schulsystem nicht einverstanden ist, das Bundesland wechseln? In grenznahen Bereichen ist dies vielleicht noch möglich, aber mitten in den Bundesländer wohl nicht mehr. Wozu führt das? Eventuell dazu, dass die Eltern dann auf Privatschulen ausweichen. Wenn sie beim öffentlichen Anbieter nicht mehr das Angebot erwarten können, das sie für ihre Kinder wünschen, dann gehen sie in Richtung Privatschulen. Es gibt einige Bundesländer, aus denen mir Eltern aus befreundeten Familien berichten: „Für uns kommt eine öffentliche weiterführende Schule gar nicht in Betracht, nur eine Privatschule. Denn wenn wir eines Tages beruflich, was absehbar ist, das Bundesland wechseln, verliert unser Kind den Anschluss, und das soll unser Kind nicht erleiden." Ich denke, genau dieser Punkt führt letztlich zur zentralen Frage: Ist der Bildungsföderalismus ein Eigenzweck, ein Selbstzweck, in dem sich Politiker, Parteien, Parteiprogramme und Länder verwirklichen dürfen? Oder ist es nicht eher ein Angebot des Staates an die Bürger, das er erfüllen muss? Kurz, ist der Staat hier für die Menschen da oder sind die Menschen für den Staat da? Vielen Dank.

Müller, Georg: Ich möchte mich zu diesem schon mehrfach angesprochenem Art. 62 Abs. 4 äußern, der im Rahmen der neuen Bildungsverfassung 
in die Verfassung aufgenommen worden ist. Ich tue das etwas überspitzt, damit Herr Ehrenzeller mich nachher in seinem Schlusswort korrigieren und allfällige Missverständnisse klären kann. Denn er ist, das wissen Sie sicher, unser Superexperte auf diesem Gebiet. Er hat wesentlich an der Redaktion der Bildungsverfassung und an deren Umsetzung mitgewirkt. Artikel 62 Abs. 4 BV, wage ich einmal zu behaupten, ist eigentlich eine Mogelpackung. Deswegen wurde er auch mit so großer Mehrheit angenommen von Volk und Ständen (Gelächter). Wir haben alle nicht so ganz genau gemerkt, was wir beschlossen haben. Die Fragen, die von anderen Votanten im Zusammenhang mit diesem Artikel gestellt worden sind, sind durchaus berechtigt. Es steht da zwar, dass der Bund nur und erst dann selber regeln kann, wenn die Kantone nicht auf dem Wege der interkantonalen Vereinbarung gewisse Dinge harmonisiert haben. Aber wenn Sie diesen Text lesen, dann sehen Sie, dass die Vereinheitlichung sehr weit gehen kann. Und jetzt geschieht Folgendes: Immer dann, wenn ein Kanton ausspuren will, etwas anderes machen will oder wenn sogar das Volk nicht ganz konkordatskonform abstimmen will, wird ihm mit einer Regelung des Bundes gedroht. Man braucht gar keine Bildungsbürokratie im Bund, man braucht auch den Bundesgesetzgeber nicht; die Drohung mit dem Bundesvogt genügt. Es ist interessant, den Mechanismus zu beobachten: In den Kantonen müssen auch die für die Bildung verantwortlichen Mitglieder der Regierungen, die durchaus nicht reformfreundlich oder zentralistisch sind, unter dem Druck der Vereinheitlichung und der Drohung mit einer Bundeslösung Dinge vertreten, die ihnen inhaltlich überhaupt nicht passen. Danke.

Meyer, Hans: Herr Meyn, ich möchte Ihnen nur sagen, dass Sie die Rahmengesetzgebung vergessen können. Seit dem Urteil zum Hochschulrahmengesetz ist das keine praktikable Lösung mehr. Was Sie machen könnten, wäre eine Gesetzgebung des Bundes mit Abweichungsrecht oder eben eine neue Grundsatzgesetzgebung. Ich glaube beides hätte politisch keine große Aussicht.

Fechner: Ich habe mich deswegen zu Wort gemeldet, weil mir ein Begriff in der Diskussion zu kurz gekommen ist, ein, denke ich, elementarer Begriff. Das ist der Begriff der Bildung. Was ist eigentlich Bildung? Was verstehen Sie unter Bildung? Ist das lediglich die Vermittlung von Fertigkeiten - so kommt es im Moment bei mir an - dass man also lesen, schreiben und rechnen kann? Die Vermittlung von Fertigkeiten ist sicher wichtig und elementar. Aber geht es nicht auch um die Vermittlung von Werten? Muss die Schule nicht auch Werte vermitteln? Und wenn das der Fall wäre, dann ist natürlich die nächste Frage: Welche Werte sind das, wo 
nehmen wir diese Werte her? Vielleicht können wir gewisse Werte noch aus dem Grundgesetz ableiten, vor allem Menschenwürde, Toleranz und Gewaltfreiheit. Genau diese Überlegungen führen vielleicht dazu, dass die Schule, die von allen besucht wird (wie Herr Stettner das ja auch gesagt hat), durchaus ihren Sinn hat, gerade auch im Hinblick auf Migranten, die integriert werden sollten. Was dann die weitere Ausgestaltung dieser Werte anbetrifft, ist die Frage, ob man sich da einigen kann. Früher hätten wir uns in diesem Kreis einigen können - und können es vielleicht auch heute noch -, aber gesamtgesellschaftlich ist es sicherlich schwierig, eine solche Einigung herbeizuführen. Insoweit muss der demokratisch legitimierte Gesetzgeber den Wertekanon festlegen. Das spricht doch eher wieder für den Föderalismus. Er ermöglicht, dass man in einem Bundesland einen bestimmten Weg ausprobiert, ohne dass dies gleich Auswirkungen auf das ganze Land hat. Im Gegenteil, können die anderen Bundesländer aus den Fehlern eines Landes lernen. Der föderale Wettbewerb wirkt gerade nicht in erster Linie - wie das hier anklang - indem Familien der besseren Bildungspolitik wegen, aus einem Bundesland in ein anderes ziehen. Sondern es zeigt sich ganz von selbst, ob eine Landesregierung eine gute Bildungspolitik macht oder nicht. Als Bürger kann ich vergleichen und sehe, ob mich die Bildungspolitik meiner Landesregierung stärker überzeugt als die eines anderen Bundeslandes und habe dann bei der nächsten Landtagswahl die Möglichkeit, meine Landesregierung zu unterstützen oder mich für deren Abwahl einzusetzen. Insofern ist der Bildungsföderalismus aus meiner Sicht eben doch sehr sinnvoll. Vielen Dank.

Waechter: Als ich die Referate gehört hatte, habe ich mich gefragt, ob wir im Bildungsbereich eigentlich reale Probleme haben oder eher nicht. Wenn ich das jetzt einmal auf die Unitarisierungsfrage zuspitzen darf: Der erste Punkt zur Unitarisierung - das ist jetzt mehrfach angesprochen worden - ist aus der Sicht der Bürger die Mobilitätschance. Deswegen die Frage: Sehen Sie eigentlich ein Verfassungsgut dahinter? Hinter dem Recht auf Mobilität, das verunmöglicht wird durch unterschiedliche Schulstrukturen? Soweit ich weiß, kursiert im Niedersächsischen Ministerium der Bildung zurzeit eine Metastudie zu Bildungsstudien, die sagt: Organisationsformen haben überhaupt keinen messbaren Einfluss auf den Bildungserfolg. Zweiter Punkt. Unitarisierung aus Finanzgründen. Das ist im Grunde kein bildungsspezifisches Problem und gehört zum Nachmittag. Dritter Punkt: Sie haben Wettbewerb und Pisa betont. Wo taucht eigentlich die entscheidende Wirkung von Pisa in den dogmatischen Konstruktionen bei Ihnen auf? Wenn ich den realen Wettbewerb sehe zwischen den Ländern, geht er auf die Erhöhung der Abiturquote. Ist das ein positiver Wettbewerb oder eine Spirale nach unten? Beinhaltet 
die Kompetenz des Bundes eine Verpflichtung oder ein Recht, Hochschulzulassung- und Schulabschlussbefähigung festzulegen? Was muss eigentlich die inhaltliche Kompetenz der Schulabgänger sein? Ich meine, die Situation ist doch so: Die Juristen können kein Deutsch, die Englischstudenten können kein Englisch und die Mathematiker können nicht rechnen (zum Teil); deswegen werden vielfach Vorkurse angeboten. Dann stellt sich doch die Frage: Ist der Bund möglicherweise nach der Wesentlichkeitstheorie verpflichtet, dafür Maßstäbe zu setzen oder inwieweit muss er das den Ländern überlassen? Danke.

Biaggini: Vielen Dank. Da sich niemand mehr gemeldet hat für ein spontanes Votum, schließe ich hiermit, wie ,angedroht“, die Rednerliste. Bevor ich Frau Wallrabenstein das Wort für ihr Schlussvotum gebe, möchte ich Ihnen danken, besonders auch jenen, die sich spontan gemeldet haben. Es waren jetzt mehr Spontanmeldungen als angemeldete Voten. Ich weiß nicht, ob das ein Novum ist, erfreulich ist es allemal.

Wallrabenstein: Vielen Dank. Auch durch die vielen spontanen Wortmeldungen habe ich den Eindruck, dass die Debatte so verflochten war, dass mein Versuch, sie zu entflechten, wahrscheinlich genauso scheitern wird wie jener der Föderalismuskommission bei den Gesetzgebungskompetenzen. Ich bitte, das im Voraus zu entschuldigen.

Ich will zunächst nicht einen wirklichen Vergleich anzustellen, aber doch meinen Eindruck schildern, dass man in der Schweiz und wahrscheinlich auch in Österreich - über das wir leider nichts gehört haben ein wenig entspannter mit zentralen Kompetenzen, also Kompetenzen auf der Bundesebene, im Bildungsbereich umgeht. So hat die Schweizer Reform Bundeskompetenzen - wenn auch als Reservekompetenzen - eingeführt. Das fand ich überraschend. Wir in Deutschland reagieren sehr empfindlich, wenn wir von Kompetenzen des Bundes im Schulrecht sprechen. In Wirklichkeit haben wir aber gar nicht so andere Realitäten. Das wäre meine erste Beobachtung.

Sie führt zu einem zentralen Punkt, der, so glaube ich, einige Anmerkungen aufgreift. Wir haben sehr viel über Wettbewerb und dazugehörige Fragen - ob man Wettbewerb für Vielfalt braucht, ob man Föderalismus für Vielfalt braucht - gesprochen. Ich wollte deutlich machen und möchte das noch einmal betonen, dass nach meinem Verständnis die Vielfalt im Schulbereich - wenn wir es einmal auf diesen Bereich beschränken - den Föderalismus nicht braucht und sie von Wettbewerb nicht gefördert wird. Das ist insofern wertfrei, als dass ich nicht für oder gegen die Vielfalt sprechen möchte, sondern sagen möchte, dass Vielfalt auch ohne föderale Struktur möglich ist. Dies zeigt sich etwa daran, dass man wegen der kul- 
turellen Differenzierung in Deutschland - auch infolge vieler Jahrzehnte Migration - über Dinge nachdenken müsste, die wir häufig in anderen Kontexten diskutieren, z.B. bei der Frage, was im Klassenzimmer hängt. Daran merken wir, dass diese Frage nichts mit föderalen Strukturen zu tun hat. Umgekehrt erfordert sie aber auch nicht Bundesrecht im Sinne von nationaler Identitätsbildung, sondern einen Umgang mit Differenz, d.h. die Antwort im konkreten Klassenzimmer auf die konkrete Vielfalt unter den Schülerinnen und Schülern.

Wettbewerb - das wurde mehrfach deutlich - wird hier sehr unterschiedlich gesehen und bewertet. Ich glaube (das wurde auch in vielen Anmerkungen von Ihnen angesprochen): Wenn man Wettbewerb organisiert - wir sind hier im öffentlichen Bereich; es ist daher eine Frage, ob wir diesen Bereich durch rechtliche Strukturen so organisieren wollen - wenn man also Wettbewerb organisiert, dann tut man das, weil man ein bestimmtes Ziel vor Augen hat und glaubt, dass dieses Ziel damit erreicht werden könnte. Herr Oebbecke sagte hierzu: „Wir haben ein Problem und suchen nach der optimalen Lösung und Wettbewerb ist das Entdeckungsverfahren. Mehrere Leute probieren aus, was die Lösung sein könnte. Schau'n wir, welche funktioniert!“ Wenn es aber eine Lösung geben sollte bzw. eine Idee davon besteht, dann kommen wir nicht bei der Vielfalt an, die ich vorhin angesprochen habe. Das war die Vielfalt, von der wir sagten, in ihr selbst liegt die richtige Lösung. Der Wettbewerb als Entdeckungsverfahren hat Vielfalt als Durchgangsstadium, er ist eine Frage des Experimentierens. Dies kann man anders besser lösen als mit föderalen Strukturen: indem man beispielsweise Schulexperimente macht, indem man sagt, wir wollen unterschiedliche Wege ausprobieren, um bestimmte Probleme anzugehen.

An einem konkreten Punkt möchte ich noch einmal deutlich machen, wo Wettbewerb im Bildungssektor besteht und was das konkret heißt, nämlich beim Wettbewerb um Universitätsprofessoren. Zwar sind wir auf das Bildungswesens insgesamt bezogen, glaube ich, immer noch eine Minderheit, sodass wir nicht ganz so marktrelevant sind. Aber wenn wir dieses Beispiel nehmen, dann merken wir sehr deutlich, dass der Wettbewerb, den Universitäten um Professorinnen und Professoren anstellen, nichts mit dem Landesrecht, insbesondere nichts mit dem Landesbesoldungsrecht aber auch nicht mit dem Landesschulrecht, zu tun hat. Wenn ich von Nordrhein-Westfalen nach Hessen wechsle (oder umgekehrt), werden heute selbstverständlich in meinen Berufungsverhandlungen die besoldungsrechtlichen Differenzen durch Ziel- und Leistungsvereinbarungen und entsprechende Besoldungsvereinbarungen ausgeglichen. Dadurch findet der Wettbewerb eben nicht mehr auf der Landesebene statt. Die Frage, wo meine Familie lebt und in welche Schule meine Kinder gehen, 
ist nach meiner persönlichen Wahrnehmung - die falsch sein kann, ich habe nur meinen eigenen Horizont - nicht davon abhängig, welches Landesschulsystem ich bevorzuge. Viel relevanter ist, welchen Beruf der Partner in welcher Stadt ausüben kann.

Es wurde mehrfach ein Ausweg angesprochen, den mobile Familien häufig suchen: die Privatschule. Dies leitet über zum nächsten Punkt. Wie findet der Wettbewerb statt, wenn wir die Ansiedlung von Unternehmen, jedenfalls von internationalen, ansehen? Nicht selten durch die Gründung von Privatschulen. Leider kann ich die vielen, zum Teil detaillierten Fragen, die sich hier anschließen, nicht einzeln aufgreifen. Ein zentraler Punkt scheint mir die Frage zu sein, ob und wie Privatschulen oder privates Engagement in unser Bildungssystem einzubinden sind. Es handelt sich um eine Sache, zu der die Landesverfassungen etwas sagen. Beispielsweise ist die Verfassungslage in Sachsen anders als in Thüringen. In Sachsen gehören private Bildungsträger neben dem öffentlichen Schulsystem zu denen, die von Verfassung wegen verpflichtet sind, den staatlichen Gewährleistungsauftrag für ein den Bildungsbedarf deckendes Schulsystem bereitzustellen. Dies hat Konsequenzen für den Gesetzgeber, der Probleme bei der Erfüllung dieser Gewährleistungsverantwortung lösen will. Diese Konsequenzen gelten in anderen Ländern, in denen die Verfassung nur das öffentliche Schulwesen zur Erfüllung des Bildungsauftrags heranzieht, nicht. Ob die eine oder andere Variante optimal oder besser ist, ist dann wieder eine andere Frage.

Schließlich zu den ebenfalls mehrfach angesprochenen allgemeinen Problemen: Es wurde gefragt, was wir im Bildungswesen überhaupt für Probleme haben. Ich glaube, wir haben welche, aber nach meinem Eindruck solche, die doch relativ wenig damit zu tun haben, ob man ihre Lösung auf der Landes- oder auf der Bundesebene rechtlich strukturiert. Die Frage ist, wie man die rechtliche Vorstrukturierung so herunterbricht, dass vor Ort - ich komme zurück zum Anfang - die einzelne Schule bzw. die einzelne Lehrkraft die realen sowie konkreten Probleme sinnvoll lösen kann. Vielen Dank.

Ehrenzeller: Danke vielmals für die Einladung zum Vortrag und für die angeregte Diskussion. Es fällt auf, dass in der Bildungsdiskussion in der Schweiz und in Deutschland - das haben auch die Wortmeldungen gezeigt - die politischen Parteien fast nicht vorkommen. Sie sind kurz erwähnt worden in einem Votum, aber die Parteipolitik spielt eine beschränkte Rolle, und dort wo sie zu spielen begonnen hat, hat sie eher zu unglücklichen Ergebnissen geführt. Das ideologische setting ist gewissermaßen ein anderes. Wir können heute die Diskussion über den Bildungsföderalismus nicht mehr gleich führen, wie wenn solche Fragen vor 20 Jahren gestellt 
worden wären. Die Veränderung der äußeren Rahmenbedingungen diese sichtbare Entgrenzung der Bildungspolitik sowie die Vorgaben im europäischen Raum insbesondere - führen im Wesentlichen zu gleichen Herausforderungen in beiden Staaten.

Ich glaube, wenn man genauer hinschaut, dann spürt man, welch grundlegenden Veränderungen bis in die Schulzimmer hinein zum Beispiel die PISA-Studien bewirkt haben. Das kann man gut oder schlecht finden. Es ist jedenfalls eine Tatsache, dass hier Grundlegendes verändert worden ist. Als Staats- bzw. Verfassungsrechtler müssten wir eher fragen: Wie können wir diesen Prozess überhaupt noch steuern und wer kann ihn einigermaßen gut steuern? Das ist, glaube ich, einmal die Ausgangsfrage, die wir stellen müssten. Vielleicht auch, was gesagt worden ist: Kann man Bildung überhaupt definieren? Natürlich nicht! Das ist wohl auch gut so. Aber wir können gewisse Ziele vorgeben. In den Sozialzielen unserer Bundesverfassung gibt es einige bildungspolitische Vorgaben: die Persönlichkeitsentwicklung, dieses Hinführen zum verantwortungsvollen Menschen und Bürger. Es gibt zahlreiche bildungsrelevante internationale Konvention, in denen Ziele oder Programme enthalten sind. Auf den europarechtlichen Rahmen ist hingewiesen worden. Die EU hat praktisch keine Kompetenzen und ist trotzdem ein zentraler Player im ganzen Gebiet. Nehmen wir das Beispiel des Bologna-Prozesses. Bologna ist bewusst außerhalb der EU entstanden, aber heute ist die EU maßgeblich mit der Weiterentwicklung von Bologna beschäftigt und ist mitverantwortlich. Auch die Schweiz ist voll dabei, wie wenn wir auch Mitglied der Union wären.

Ich finde es schön, dass auch die Werte angesprochen wurden. Welche Werte spielen eigentlich eine Rolle? Es ist interessant zu beobachten, dass heute die ganze Bildungsdebatte in hohem Masse von der Wertediskussion entkoppelt worden ist. Die Wertedebatte spielt dagegen bei der Diskussion von doch eher Randproblemerscheinungen eine Rolle. So diskutieren wir beispielsweise über das Kreuz im Schulzimmer, wir diskutieren über das Kopftuch in der Schule (in der Schweiz gerade aktuell geworden), wir diskutieren über den Sexualkundeunterricht. Über solche Fragen führen wir Wertedebatten. Aber Kernfragen der Bildungsvermittlung sind gewissermaßen eine technische Materie geworden. Das finde ich heikel. Hier müssten wir den richtigen Rahmen wieder finden - ich komme noch einmal darauf zurück.

Die Fragen des Bildungswettbewerbs sind von verschiedenen von Ihnen angeschnitten worden, eher bezogen auf den deutschen Rahmen. Aber natürlich spielt das auch in der Schweiz eine Rolle. Wir verwenden den Wettbewerbsbegriff vor allem im Fiskalbereich, mit unterschiedlicher Wertung. Die einen finden das sehr gut, die anderen weniger sinnvoll. So einfach auf den Bildungsbereich übertragbar ist der Wettbewerbsgrund- 
satz nicht. Jetzt könnte man sagen, und es wurde auch gesagt: Ja, verabschieden wir doch den Wettbewerbsgedanken ganz aus der Bildungsdebatte. Das kann man machen, man kann den Begriff anders umschreiben. Ich würde es schade finden, wenn wir den Bildungswettbewerb als Leitidee überhaupt nicht mehr hätten. Bildungsföderalismus heißt ja nicht, dass jeder Kanton machen kann, was er will. Das würde heute nicht mehr funktionieren. Sondern wir müssen uns damit abfinden, dass Transparenz gefordert ist und Konkurrenz eine Rolle spielt - auf allen Stufen. Von der Volksschule begonnen bis in die Hochschulen hinein. Es ist doch richtig, dass wir uns fragen: Was kostet ein Jurastudium in Zürich, in St. Gallen oder in Genf? Und wenn wir einmal annehmen, dass die Abschlüsse überall gleichwertig sind: Wie kann es sein, dass das juristische oder das ökonomische Studium an einer Universität ein Drittel teurer ist als an einem anderen Ort? Da muss niemand etwas regeln. Aber eine Institution, beispielsweise eine Universität, aber auch ein Gymnasium oder sogar eine geleitete Volksschule - die meisten Schulen sind ja heute geleitet - die werden sich Gedanken machen: Ja, warum gibt es bei uns diesen Unterschied und wollen wir diesen? Ist das so, weil wir etwas ganz Spezifisches anbieten, weil das zu unserer Profilbildung gehört? Oder hängt der Umstand, dass wir so viel teurer sind als andere, mit anderen Fragen zusammen? Die Frage kann natürlich auch umgekehrt lauten: Warum sind wir so viel billiger? Liefern wir schlechtere Qualität? Ich finde, im Schul- bzw. im Bildungsbereich ist dieser Selbstbewertungsprozess, diese Selbstkontrolle und Eigendynamik, von ganz hohem Wert. Insofern sollten wir durchaus zum Wettbewerb im Bildungsbereich stehen.

Das Argument der Mobilität ist verschiedentlich aufgegriffen worden. Georg Müller hat darauf hingewiesen, dass die schweizerische Bildungsverfassung im Jahre 2006 mit 86 Prozent Zustimmung des Schweizervolkes und aller Stände angenommen wurde. Dabei war natürlich eines der Argumente: Wir wollen vollständige Mobilität in der Schweiz. Deshalb Ja zur Harmonisierungspflicht bei der Volksschule. Man hat immer gewusst, dass die Mobilität an sich nicht wirklich ein zentrales Problem ist. Es wechseln relativ wenige Primarschülerinnen und -schüler die Kantone. Also von der Quantität her ist es nicht das Problem. Nur: wir haben heute doch eine andere Zeit, so dass die Leute in Altdorf im Kanton Uri nicht schlechtere Volksschulen haben wollen als jene in der Stadt Zürich und in der Stadt St. Gallen. Die Eltern wollen die gleiche Qualität der Schulbildung. Sie wollen ihren Kindern in dem Sinne eine spätere Mobilität tatsächlich ermöglichen. Aus diesem Gedanken heraus wächst das Bedürfnis nach einheitlichen Standards.

Die Frage ist: Was heißt einheitliche Standards? Da sind wir bei der Vielfalt angelangt. Man könnte vielleicht auch hier eher noch von Subsi- 
diarität sprechen. Das heißt, vielleicht braucht es abgestufte Regelungen in diesem Bereich. Beim von mir erwähnten HarmoS-Konkordat - also bei der Koordination im Bereich der obligatorischen Schule - ist diese Abstufung bewusst so vorgenommen worden. Es gibt gewisse Standards, die national eingehalten werden sollen - Schulstrukturen beispielsweise. Aber nehmen wir einmal an, es braucht, wenn man das will, zwei Fremdsprachen. Dies ist jetzt auf der Stufe Grundschulunterricht so vorgesehen. Aber was genau, welche Ziele und Kompetenzen dabei erreicht werden sollen, das soll sprachregional herausgearbeitet werden. Auch diese sprachregionalen Lehrpläne lassen wiederum den einzelnen Kantonen Raum zur Ergänzung und Anpassung.

Es ist der wunderbare Begriff des Schulzimmers als pädagogischer Raum erwähnt worden - auch dort muss noch Freiheit herrschen. Ich nehme an, dass die meisten von uns davon überzeugt sind, dass am Schluss zumindest auf den ersten Stufen (also Primar- und Sekundarschulstufe), vielleicht sogar noch auf der Hochschulstufe) die Persönlichkeit des Dozierenden und Lehrenden, die eine gewisse Freiheit braucht, ganz entscheidend ist; vielleicht noch viel mehr als früher, weil heute das Wissen selber sehr viel einfacher abholbar ist. Umso mehr bekommt die Art der Vermittlung des Wissens und die pädagogische Freiheit eine große Rolle.

$\mathrm{Zu}$ Art. 62 Abs. 4 BV: Zuerst zum Begriff der „Harmonisierungspflicht", die da verankert wurde. In der Tat ist es so, dass man im Moment, als dieser Artikel verabschiedet wurde (übrigens sind sämtliche Artikel der Bildungsverfassung dem Volk zusammen vorgelegt worden, weil dahinter ein einheitliches Konzept steht), natürlich gewusst hat, dass die Kantone bestrebt sind, tatsächlich zum Abschluss eines solchen HarmoS-Konkordates zu kommen. Anders wäre das schwer möglich gewesen. Im Anschluss an die Verabschiedung auf nationaler Ebene kam der Genehmigungsprozess in den Kantonen. Dort ist die Diskussion eigentlich erst losgegangen. Diese Frage ist möglicherweise eher noch für die Politologen von Interesse als für uns. Warum eigentlich ist die erste Phase, also die Bildungsverfassung inklusive Schaffung des HarmoS-Konkordats relativ leicht über die politische Bühne gegangen? (Übrigens verhielt es sich ebenso im Hochschulbereich mit dem Hochschulförderungsgesetz.) Warum finden erst in der späten Phase - in den einzelnen Kantonen - wirkliche politische Diskussionen statt, die dann effektiv bis in die Wertediskussion hineingehen? Das ist eine Frage, auf die ich Ihnen nicht unbedingt eine Antwort habe. Vielleicht hat es am Schluss dann doch etwas zu tun mit gewissen politischen Parteien, die ein Thema aufgreifen und die sich erst spät bewusst geworden sind, welche Folgen eine bestimmte Regelung hat. Aber - trotz aller Kontroversen - die Harmoni- 
sierungspflicht ist an sich unbestritten, und die Meinung war immer, dass das - in Bezug auf die in der Verfassung erwähnten Bereiche - eine Vollharmonisierung unter den Kantonen sein soll. Es kann aber sein, dass die Kantone nur eine Teilharmonisierung erreichen. Dann müsste in dem Teil, in dem die Harmonisierung nicht erreicht worden ist, der Bundesgesetzgeber eine Regelung erlassen, sofern er sich auf eine solche Regelung einigen kann.

Wir haben zum Beispiel eine Regelung im Bereich der ersten Fremdsprache. Man würde denken, dass es in der Schweiz klar ist, dass die erste Fremdsprache Französisch ist und umgekehrt. So ist es nicht. Die meisten deutschsprachigen Kantone haben gesagt, dass die erste Fremdsprache Englisch ist. Das hat logischerweise zu politischen Diskussionen im Bundesparlament und anderswo geführt. Ist das jetzt ein Argument für eine zentrale Lösung? Warum denn eigentlich? Warum sollte sich die Bundesversammlung besser als die Kantone darüber verständigen können, welche Sprache die erste Fremdsprache ist? Die Tatsache, dass nur eine Teilharmonisierung stattgefunden hat - die Kantone der Romandie nehmen zuerst Deutsch, dann Englisch - ist ja nicht ohne Grund geschehen. Dieselbe Diskussion würde sich im Bundesparlament abspielen, falls diese Frage in einem Bundesgesetz geregelt werden müsste. Ich denke nicht, dass das Konkordat hier eine Mogelpackung ist. Ich war vor etwa zwei Jahren an einer Tagung in Berlin, an der unter anderem auch Fritz Scharpf anwesend war. Man würde ja von ihm erwarten, dass er sagt: Das ist unmöglich, eine solche Bildungsordnung wie sie nun in der Schweiz eingeführt worden ist; das, was ihr hier praktiziert, ist ja die Politikverflechtung par excellence. Er hat aber gesagt: Nein, die Regelung überzeuge ihn eigentlich, und zwar vor allem deswegen, weil aus seiner Sicht das Hauptproblem des Bildungsföderalismus die Überwindung der institutionellen Eigeninteressen der Länder und Kantone ist. Dazu brauche es eine nationale Koordinationspflicht. Der Konsensdruck bewirke, dass sich die Vertreter - die Kantonsvertreter oder Erziehungsdirektoren - letztlich einigen müssen, weil sie wissen, dass dann, wenn sie überhaupt nichts oder nur ein Minimum zustande bringen, der Bundesdruck zu einer zentralistischen Lösung führt.

Ich komme zum zweitletzten Punkt: Demokratische Legitimation. Hier sind wir besonders sensibel, das ist verschiedentlich angesprochen worden. Ist eine solche Bildungsverfassung, wie wir sie haben, eigentlich undemokratisch oder verunmöglicht sie demokratische Mitwirkung? Da wir in der Schweiz nicht nur das Referendum, sondern auch das Initiativrecht in Sachfragen haben, blüht diese Mitwirkung. Zum Beispiel haben wir jetzt eine schweizerische Volksinitiative über das Verbot des Sexualkundeunterrichts in den Schulen hängig. Ich bin nicht so sicher, ob das die rich- 
tige Form und Stufe demokratischer Mitwirkung ist, wenn wir in einer schweizerischen Volksabstimmung darüber befinden müssen, was im Bereich der Sexualität als biologisches Fortpflanzungswissen - und damit als zulässig und zumutbar - zu verstehen ist, und was darüber hinaus als Sexualkunde verboten sein soll. Ist das Volk hier wirklich das geeignete Entscheidungsorgan und Verfassung und Gesetz die angemessene Rechtsgrundlage? Also ich denke, dass man auch in der direkten Demokratie unterscheiden muss, was auf welcher Stufe und wie demokratisch legitimiert werden soll.

Ich komme zum Schluss. In der neuen Bundesverfassung gibt es viele schöne Bestimmungen. Eine ist aber besonders schön - nämlich Art. 43a BV (Sie merken, der Artikel ist erst nach der Totalrevision hinein gekommen). Art. 43a Abs. 1 lautet: „Der Bund übernimmt nur die Aufgaben, welche die Kraft der Kantone übersteigen oder einer einheitlichen Regelung durch den Bund bedürfen." Das ist natürlich eine sehr auslegungsbedürftige Bestimmung. Aber der Grundgedanke, um den es beim Thema „Bildungsföderalismus auf dem Prüfstand“ geht, ist, denke ich, an diesem Verfassungsgrundsatz zu messen. Übersteigen die Herausforderungen der Bildungspolitik die Kraft der Kantone? Wohl eben nicht nur finanziell verstanden - denn da müsste man zum Voraus eine negative Antwort geben. Nein, inhaltlich verstanden! Das wiederum hat sehr viel zu tun mit der Gewährleistung von Vielfalt und letztlich auch eines Bildungssystems, in dem alle Beteiligten laufend gegenseitig voneinander lernen können. Ich danke Ihnen. 